Aus der Abteilung Neurologie

(Prof. Dr. med. M. Bähr)

im Zentrum für Neurologische Medizin

der Medizinischen Fakultät der Universität Göttingen

\title{
Analyse der Proteinexpression zur Untersuchung der physiologischen Funktion des zellulären Prionproteins $\left(\operatorname{PrP}^{c}\right)$
}

\author{
INAUGURAL - DISSERTATION \\ zur Erlangung des Doktorgrades \\ der Medizinischen Fakultät \\ der Georg-August-Universität Göttingen
}

vorgelegt von

Eva Annabelle Weiß

aus

Hannover

Göttingen 2010 
Dekan: Prof. Dr. med. C. Frömmel

I. Berichterstatterin: Prof. Dr. med. I. Zerr

II. Berichterstatter: Prof. Dr. rer. Net. Bayer

III. Berichterstatter: Prof. Dr. Urlaub

IV. Promotor: Prof. Dr. med. Oppermann

Tag der mündlichen Prüfung: 10.01.2012 
Die Ergebnisse dieser Arbeit wurden veröffentlicht in der Zeitschrift Neuroscience (Weiss et. al. 2010). 


\section{Inhaltsverzeichnis}

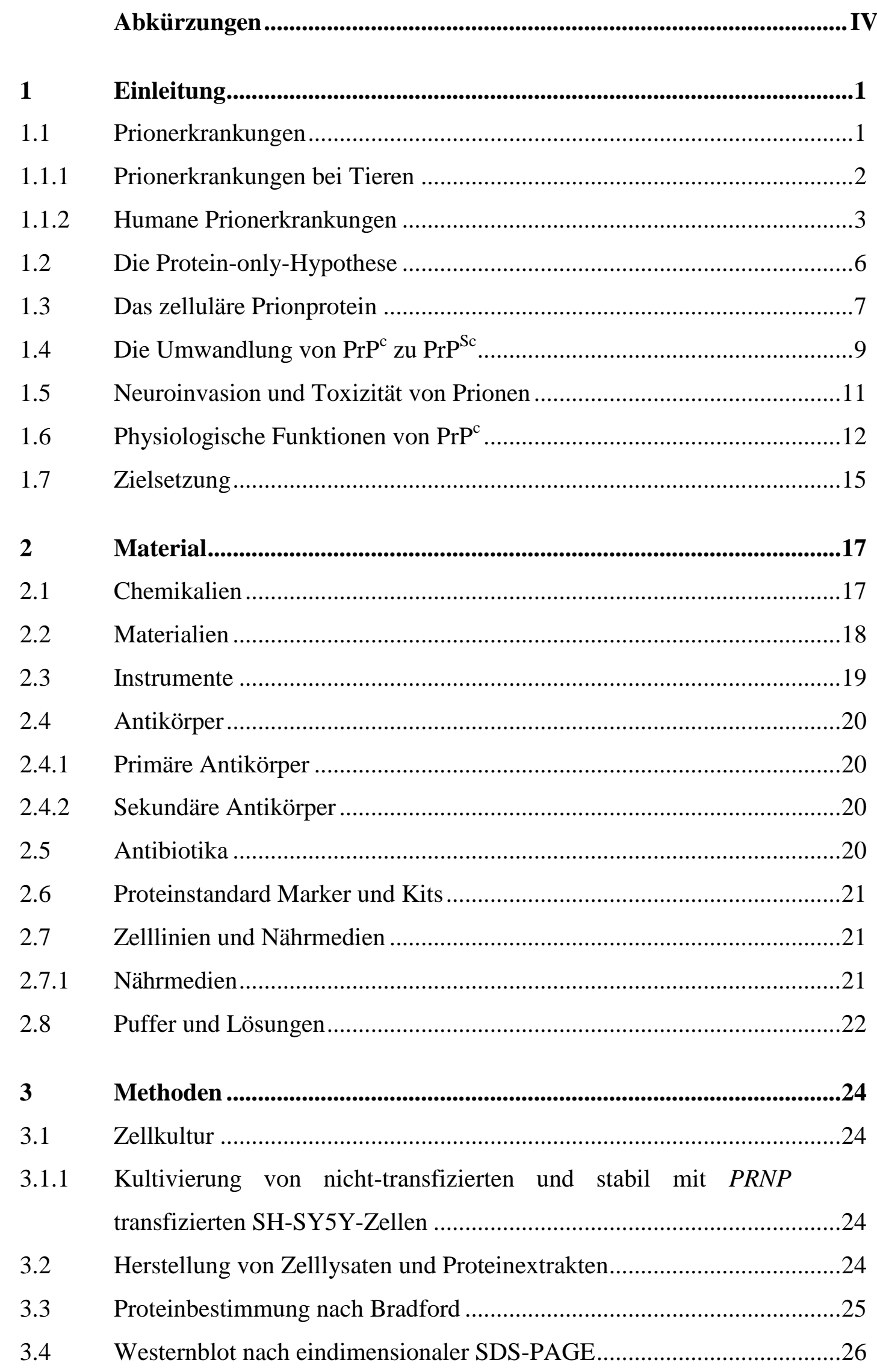


3.4.1 SDS-Polyacrylamidgelelektrophorese (SDS-PAGE) .............................26

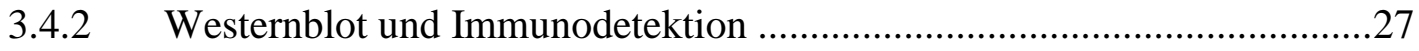

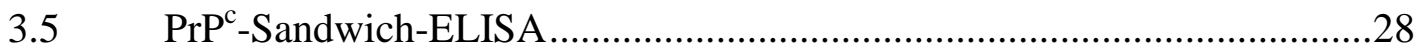

3.6 Zweidimensionale Gelelektrophorese....................................................28

3.6.1 Erste Dimension: Isoelektrische Fokussierung .......................................28

3.6.1.1 Probenvorbereitung und Rehydrierung................................................2.

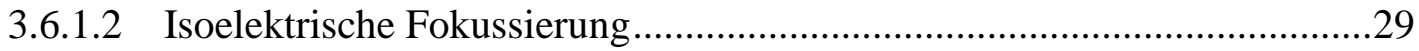

3.6.1.3 Äquilibrierung der Proteine für die zweite Dimension..............................29

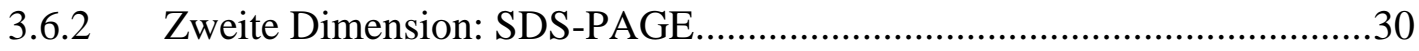

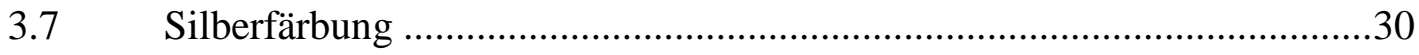

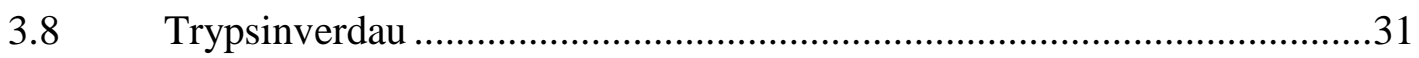

3.9 Massenspektrometrische Proteinidentifikation.........................................32

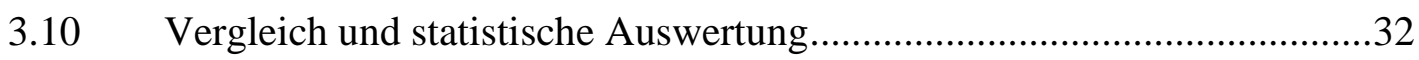

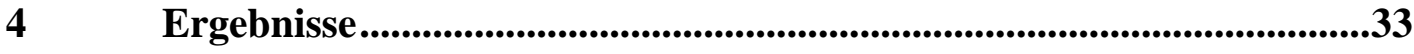

4.1 Morphologie transfizierter und nicht-transfizierter SH-SY5Y-

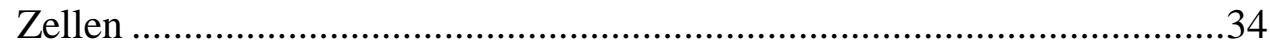

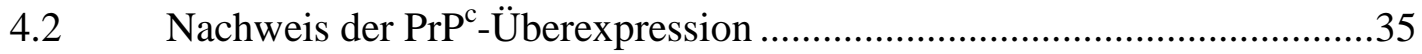

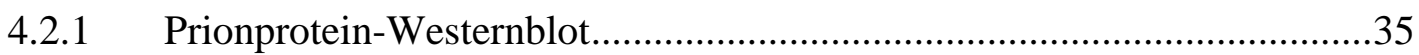

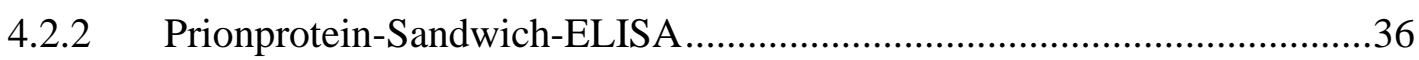

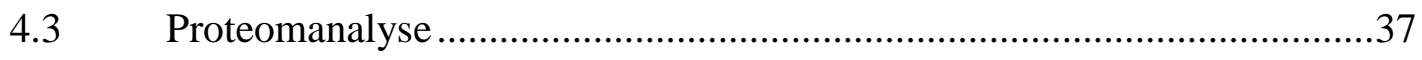

4.3.1 Proteine mit Einfluss auf Signalkaskaden ............................................40

4.3.2 Proteine mit Einfluss auf die Organisation des Zytoskeletts ....................42

4.3.3 Proteine mit Einfluss auf die Proteinfaltung ...........................................44

4.3.4 Weitere durch die $\operatorname{PrP}^{\mathrm{c}}$-Überexpression regulierte Proteine......................44

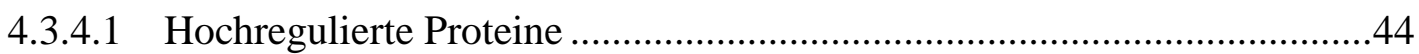

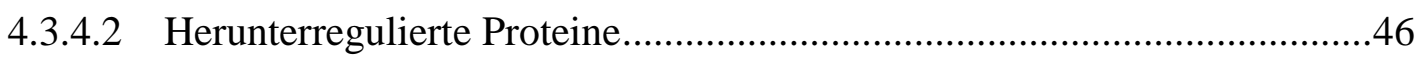

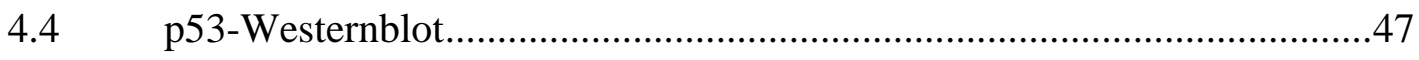

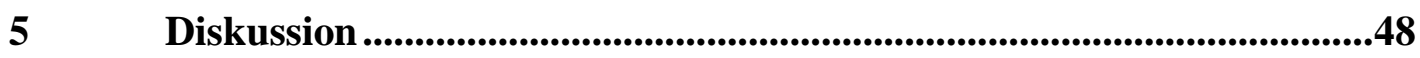

5.1 Proteine mit Einfluss auf Signalkaskaden ............................................49

5.2 Proteine mit Einfluss auf die Organisation des Zytoskeletts ....................51

5.3 Proteine mit Einfluss auf die Proteinfaltung ...........................................53

5.4 Weitere durch die $\mathrm{PrP}^{\mathrm{c}}$-Überexpression regulierte Proteine ......................55

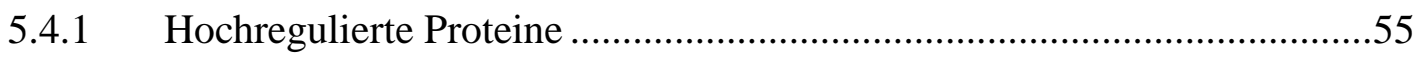




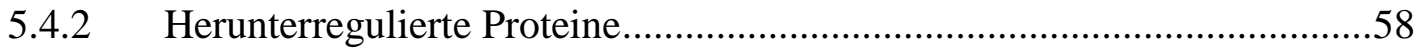

5.5 Zusammenhang: $\operatorname{PrP}^{\mathrm{c}}$-Überexpression und Apoptose ................................59

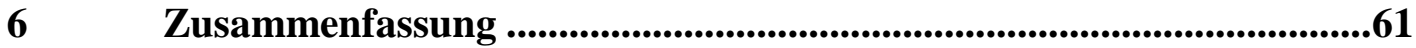

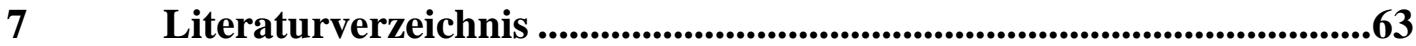

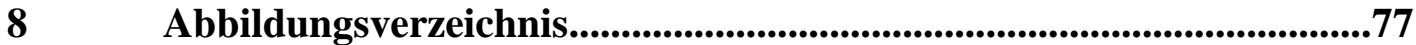




\section{Abkürzungen}

\begin{tabular}{|c|c|}
\hline Abb. & Abbildung \\
\hline $\mathrm{ACN}$ & Acetonitril \\
\hline ADHX & Alkoholdehydrogenase Klasse 3 \\
\hline $\mathrm{AgNO}_{3}$ & Silbernitrat \\
\hline ANXA5 & Annexin A5 \\
\hline APS & Ammoniumpersulfat \\
\hline Asn & Asparagin \\
\hline Bcl-2 & B-cell lymphoma 2 \\
\hline BSA & Bovines Serum Albumin \\
\hline BSE & Bovine Spongiforme Enzephalopathie \\
\hline${ }^{\circ} \mathrm{C}$ & Grad Celsius \\
\hline $\mathrm{Ca}^{2+}$ & Kalziumion \\
\hline $\mathrm{CaCl}_{2}$ & Kalziumchlorid \\
\hline cAMP & Zyklisches Adenosinmonophosphat \\
\hline CBBG & Coomassie-Brillant-Blau G-250 \\
\hline CHAPS & (3-(3-Cholamidopropyl)-Dimethylammonio)-1-Propansulfonsäure \\
\hline CJK & Creutzfeldt-Jakob-Krankheit \\
\hline $\mathrm{cm}$ & Zentimeter \\
\hline $\mathrm{CO}_{2}$ & Kohlendioxid \\
\hline CREB & cAMP response element binding protein \\
\hline $\mathrm{Cu}^{2+}$ & Kupferionen \\
\hline CV028 & UPF0027-Protein C22orf28 \\
\hline CWD & Chronic wasting disease \\
\hline Cys & Cystein \\
\hline $2 \mathrm{D}$ & zweidimensional \\
\hline $\mathrm{dd}_{2} \mathrm{H}_{2} \mathrm{O}$ & doppeltdestilliertes Wasser \\
\hline 2-DE & zweidimensionale Elektrophorese \\
\hline${ }_{\mathrm{d}} \mathrm{H}_{2} \mathrm{O}$ & destilliertes Wasser \\
\hline DNA & Desoxyribonukleinsäure \\
\hline DTT & Dithiothreitol \\
\hline ECL & Erhöhte Chemilumineszenz \\
\hline EDTA & Ethylendiamintetraessigsäure \\
\hline
\end{tabular}




\begin{tabular}{|c|c|}
\hline EEG & Elektroenzephalogramm \\
\hline ELISA & Enzyme-linked immunosorbent assay \\
\hline EPMS & Extrapyramidalmotorische Störungen \\
\hline ER & Endoplasmatisches Retikulum \\
\hline ERK & Extrazelluläre signalregulierte Kinase \\
\hline EtOH & Ethanol \\
\hline fCJK & Familiäre Creutzfeldt-Jakob-Krankheit \\
\hline FFI & Fatale Familiäre Insomnie \\
\hline FKBP4 & FK506-Bindungsprotein 4 \\
\hline FKBP52 & FK506-Bindungsprotein 52, entspricht FKBP4 \\
\hline FUMH & Fumarathydratase \\
\hline $\mathrm{g}$ & Gramm \\
\hline $1433 \mathrm{G}$ & 14-3-3 Protein gamma \\
\hline GPI & Glycosylphosphatidylinositol \\
\hline GRB2 & Wachstumsfaktor-Rezeptor-Bindungsprotein 2 \\
\hline GSS & Gerstmann-Sträussler-Scheinker-Syndrom \\
\hline GSTO1 & Glutathiontransferase omega-1 \\
\hline GTP & Guanosintriphosphat \\
\hline HEK 293 & Humane embryonale Nierenzelllinie \\
\hline $\mathrm{H}_{2} \mathrm{O}_{2}$ & Wasserstoffperoxid \\
\hline HRP & Horse Radish Peroxidase \\
\hline HSP & Hitzeschockprotein \\
\hline $\mathrm{iCJK}$ & Iatrogene Creutzfeldt-Jakob-Krankheit \\
\hline IEF & isoelektrische Fokussierung \\
\hline $\operatorname{IgG}$ & Immunglobulin Gamma \\
\hline IP & isoelektrischer Punkt \\
\hline IPG & Immobilisierter $\mathrm{pH}$-Gradient \\
\hline $\mathrm{J}$. & Jahr \\
\hline $\mathrm{K}^{+}$ & Kaliumion \\
\hline $\mathrm{kDa}$ & Kilodalton \\
\hline 1 & Liter \\
\hline $\mathrm{Lj}$. & Lebensjahr \\
\hline M & Molare Masse (mol/l) \\
\hline $\mathrm{mA}$ & Milliampère \\
\hline
\end{tabular}




\begin{tabular}{|c|c|}
\hline MAPK & Mitogen-aktivierte Proteinkinase \\
\hline $\mathrm{mg}$ & Milligramm \\
\hline$\mu \mathrm{g}$ & Mikrogramm \\
\hline Min. & Minuten \\
\hline $\mathrm{ml}$ & Milliliter \\
\hline$\mu 1$ & Mikroliter \\
\hline $\mathrm{mM}$ & millimolar \\
\hline $\mathrm{mm}$ & Millimeter \\
\hline$\mu \mathrm{M}$ & mikromolar \\
\hline MMP & Matrix-Metallo-Proteinase \\
\hline MoPrP & Maus-Prionprotein \\
\hline MRT & Magnetresonanztomographie \\
\hline MTDC & Methylentetrahydrofolat-Dehydrogenase/Cyclohydrolase \\
\hline Mte. & Monate \\
\hline $\mathrm{N} 2 \mathrm{a}$ & Murine Neuroblastomzellen N2a \\
\hline $\mathrm{Na}^{+}$ & Natriumion \\
\hline $\mathrm{Na}_{2} \mathrm{CO}_{3}$ & Natriumcarbonat \\
\hline $\mathrm{Na}_{2} \mathrm{~S}_{2} \mathrm{O}_{3}$ & Natriumthiosulfat \\
\hline $\mathrm{NaCl}$ & Natriumchlorid \\
\hline ng & Nanogramm \\
\hline $\mathrm{nm}$ & Nanometer \\
\hline NMR & Nuclear magnetic resonance, Kernspinresonanz \\
\hline NP & Neurotoxisches Peptid \\
\hline $\mathrm{Nr}$. & Nummer \\
\hline NSE & Neuronenspezifische Enolase \\
\hline PA1B3 & Acetylhydrolase IB Subunit gamma \\
\hline PAF & Platelet-activating-Factor \\
\hline PAF-AH & Platelet-activating-Factor-Acetylhydolasen \\
\hline PBS & Phosphat-gepufferte Salzlösung \\
\hline PBS-T & PBS + Tween-20 \\
\hline PC & Personal Computer \\
\hline PDIA1 & Proteindisulfidisomerase-Vorläuferprotein \\
\hline PI3K & Phosphatidylinositol-3-Kinase \\
\hline PMSF & Phenylmethylsulfonylfluorid \\
\hline
\end{tabular}




\begin{tabular}{|c|c|}
\hline PPI & Peptidylpropyl-Isomerasen \\
\hline PPID & 40kDa-Peptidylpropyl-cis/trans-Isomerase \\
\hline PQBP1 & Polyglutamin-bindende Protein 1 \\
\hline$P R N P$ & menschliches Prionproteingen \\
\hline Prnp & Prionproteingen der Maus \\
\hline $\operatorname{Prnp}^{0 / 0}$ & Prnp knockout \\
\hline $\operatorname{PrP}$ & Prionprotein \\
\hline $\operatorname{PrP}^{c}$ & zelluläres Prionprotein \\
\hline $\mathrm{PrP}^{\mathrm{Sc}}$ & abnormes Prionprotein, Scrapie Prionprotein \\
\hline PVDF & Polyvinylidenfluorid \\
\hline Q-TOF & Quadrupol-Time-of-Flight \\
\hline Ras & Rat sarcoma \\
\hline RD23B & UV-Exzisions-Reparaturprotein RAD23-Homolog-B \\
\hline RHG01 & Rho GTPase-Aktivierungsprotein \\
\hline $\mathrm{rpm}$ & Umdrehungen pro Minute \\
\hline $\mathrm{rPrP}$ & Rekombinantes humanes Prionprotein \\
\hline sCJK & Sporadische Creutzfeldt-Jakob-Krankheit \\
\hline$S C P 1$ & $\begin{array}{l}\text { Gen in Hefen, codierend für das Protein Scp1p, welches in } \\
\text { Säugetieren dem Protein Transgelin entspricht }\end{array}$ \\
\hline Scp1p & Protein in Hefen, in Säugetieren entspricht es Transgelin \\
\hline SDS & Natriumdodecylsulfat \\
\hline SDS-PAGE & SDS-Polyacrylamidgelelektrophorese \\
\hline Sek. & Sekunden \\
\hline SH-SY5Y & humane Neuroblastomzellen SH-SY5Y \\
\hline SOD & Superoxiddismutase \\
\hline SPSY & Sperminsynthase \\
\hline Std. & Stunden \\
\hline STI1 & Stressinduzierbares Protein-1 \\
\hline TAGL2 & Transgelin 2 \\
\hline ТСТP & Translationell kontrolliertes Tumorprotein \\
\hline TEMED & N,N,N',N'-Tetramethylethan-1,2-diamin \\
\hline TFA & Trifluoressigsäure \\
\hline TIMP & Tissue inhibitor of Metalloproteinases \\
\hline TLCK & Tosyl-Lysin Chloromethylketon \\
\hline
\end{tabular}




\begin{tabular}{l|l} 
TPCK & Tosyl-Phenylalanin Chloromethylketon \\
Tris & Tris(hydroxymethyl)-aminomethan \\
Tris-HCl & Tris Hydrochlorid \\
TSE & Transmissible spongiforme Enzephalopathien \\
Tween-20 & Polyoxyethylen(20)-sorbitan-monolaurat \\
UPF & Uncharakterisierte Proteinfamilie \\
UV & Ultraviolett \\
V & Volt \\
vCJK & Neue Variante der CJK \\
Vh & Voltstunden \\
w/v & weight/volume \\
$\mathrm{Zn}^{2+}$ & Zinkionen \\
ZNS & Zentralnervensystem
\end{tabular}




\section{$1 \quad$ Einleitung}

\subsection{Prionerkrankungen}

Unter Prionerkrankungen fasst man eine Gruppe neurodegenerativer Erkrankungen zusammen, die übertragen werden können, genetisch vererbbar sind oder sporadisch vorkommen und sich unter anderem durch schwammartige Veränderungen des Gehirns auszeichnen. Diese auch transmissible spongiforme Enzephalopathien (TSEs) genannten Erkrankungen treten sowohl bei Tieren als auch beim Menschen auf und verlaufen immer tödlich, da bisher keine kausalen Therapien gefunden worden sind (Zerr et al. 2003).

Die Ursache der TSEs liegt in den so genannten Prionen. Sie sind definiert als kleine proteinartige infektiöse Partikel, die gegenüber Nukleinsäure zerstörenden Maßnahmen resistent sind (Alper et al. 1967, Prusiner 1982). Prionen bestehen im Wesentlichen aus einer abnorm gefalteten Form des zellulären Prionproteins, dem Scrapie-Prionprotein $\left(\mathrm{PrP}^{\mathrm{Sc}}\right)$. Sie unterscheiden sich vom nicht-infektiösen zellulären Prionprotein $\left(\mathrm{PrP}^{\mathrm{c}}\right)$ beispielsweise durch ihre biochemischen Eigenschaften hinsichtlich ihrer Struktur durch den hohen $\beta$-Faltblattanteil (Pan et al. 1993).

Alle Prionerkrankungen, sowohl menschliche, als auch tierische, haben bestimmte histopathologische Kennzeichen gemeinsam. Dazu gehören Ablagerungen des abnormen Prionproteins in sogenannten Amyloidplaques, Nervenzellverlust, Astrozytose und schwammartige Veränderungen mit Bildung von Vakuolen in der grauen Substanz des Gehirns (Kretzschmar 1999).

Meistbekannt unter den tierischen Prionerkrankungen ist die bovine spongiforme Enzephalopathie (BSE), die ihren Ursprung in der bei Schafen und Ziegen natürlich vorkommenden Krankheit Scrapie findet. Des Weiteren gehören in diese Gruppe die übertragbare Enzephalopathie der Nerze (transmissible mink encephalopathy), die chronisch zehrende Erkrankung der Hirschartigen (chronic wasting disease, CWD) und andere spongiforme Enzephalopathien von Hauskatzen und Zootieren. $\mathrm{Zu}$ den humanen Prionerkrankungen werden die Creutzfeldt-Jakob-Krankheit (CJK), das Gerstmann-Sträussler-Scheinker-Syndrom (GSS), die letale familiäre Insomnie (FFI) und Kuru gezählt (Collinge 2005). 


\subsubsection{Prionerkrankungen bei Tieren}

Die älteste Prionerkrankung bei Tieren ist Scrapie. Die im deutschsprachigen Raum auch Traberkrankheit genannte ataxische Erkrankung von Schafen und Ziegen ist seit mehr als 250 Jahren bekannt. Ihren Namen verdankt sie dem starken Juckreiz, unter dem die befallenen Tiere leiden und sich daher an Bäumen o.ä. reiben (englisch scrape $=$ kratzen). 1936 konnten Cuillé und Chelle erstmals experimentell nachweisen, dass es sich bei Scrapie um eine infektiöse Erkrankung handelt (Cuillé und Chelle 1939).

Die CWD von Maultier und Elch ist eine Erkrankung, die v.a. im nordamerikanischen Raum vorkommt und als einzige TSE sowohl bei wildlebenden, als auch bei Haus- bzw. Nutztieren auftritt. Die CWD und Scrapie sind die einzigen spongiformen Enzephalopathien, die unter natürlichen Bedingungen von Tier zu Tier übertragen werden können. Hypothesen zu den möglichen Übertragungswegen sind zahlreich, Milben, Fliegenlarven oder andere Ektoparasiten werden beispielsweise als Überträger in Betracht gezogen (Wisniewski et al. 1996, Post et al. 1999, Lupi 2003). Man weiß, dass Scrapie in Regionen, in denen bereits erkrankte Schafe geweidet haben, häufiger auftritt und die Übertragung durch im Erdboden gebundenes Agens, welches über mehrere Jahre seine Infektiosität beibehält, stattfinden kann (Johnson et al. 2006, Seidel et al. 2007).

Der sogenannte Rinderwahnsinn, BSE, wurde 1987 in Großbritannien entdeckt und auf die Verwendung von Tiermehl mit Scrapie infizierter Schafe zurückgeführt, welches damals als Futterzusatz für Rinderkraftfutter verwendet wurde. Durch die Einführung von BSE-Schnelltests konnte die Erkrankung in zahlreichen anderen europäischen Ländern, Japan und Kanada nachgewiesen werden. Mit dem ersten Fall einer neuen Variante der CJK (vCJK) im Jahre 1996 in Großbritannien trat die Gefahr für den Menschen in den Mittelpunkt der Diskussionen. Ein hohes Risiko für die Übertragung von BSE auf den Menschen sah man unter anderem in kontaminierten Nahrungsmitteln, Medikamenten, Transplantaten oder Kosmetika (Ricketts 2004). Obwohl die Anzahl der vCJK-Fälle nur langsam ansteigt (siehe Kapitel 1.1.2) und die BSE-Epidemie durch die Einführung von Überwachungsrichtlinien unter Kontrolle ist, bleibt der weitere Verlauf der Zahlen an vCJK Erkrankten abzuwarten. 


\subsubsection{Humane Prionerkrankungen}

Die Prionerkrankungen des Menschen können in drei Gruppen eingeteilt werden: es gibt sporadische, genetische und übertragene Formen. Die weltweit häufigste Prionerkrankung ist mit einer Inzidenz von 1-1,5 pro einer Million Einwohner die sporadische CJK (sCJK) (Ladogana et al. 2005). Sie macht ca. 80-90\% aller menschlichen Prionerkrankungen aus. Bisher sind die Faktoren, die zum Ausbruch der Erkrankung führen, weitestgehend unbekannt, wobei der genetische Polymorphismus für Methionin oder Valin an Codon 129 eine Rolle spielt. Ein möglicher Risikofaktor für die Entstehung von Prionerkrankungen scheint die Homozygotie für Methionin an diesem Codon zu sein (Palmer et al. 1991, Lewis et al. 2006). Umgekehrt geht die Heterozygotie vermutlich mit einer Resistenz für die sCJK einher (Lewis et al. 2006).

Die Klinik der sCJK kennzeichnet zunächst eine rasch progrediente Demenz und Ataxie, später bilden sich Pyramidenbahnzeichen, Myoklonien und extrapyramidalmotorische Störungen, final zeigt sich ein akinetischer Mutismus. Diagnostisch stehen neben der klinischen Untersuchung das EEG, was bei der sCJK häufig periodische Sharp- and Slow-Wave-Komplexe aufweist, Liquordiagnostik mit Nachweis des 14-3-3 Proteins und die Kernspintomographie, die typischerweise Hyperintensitäten in den Basalganglien zeigt, zur Verfügung (Zerr et al. 2003).

Genetische Prionerkrankungen treten in ca. 10\% aller Fälle auf. Zu ihnen wird die sehr selten vorkommende FFI gezählt, die durch autonome Veränderungen des zirkadianen Schlafrhythmus geprägt wird. Des Weiteren gehört das GSS mit im Vordergrund stehenden zerebellären Symptomen (Gangataxie, Dysarthrie und Nystagmus) und die familiäre CJK (fCJK) in die Gruppe der genetischen spongiformen Enzephalopathien. Gemeinsam sind den drei Erkrankungen Mutationen im Prionproteingen (PRNP), die beim GSS und der fCJK einem dominanten Vererbungsmodus unterliegen (Poeck und Hacke 2001).

Die Kuru-Krankheit, die erstmals 1957 bei den Foren, einem Volksstamm im Hochland von Papua-Neuguinea, beschrieben wurde, zählt zu den übertragbaren Prionerkrankungen. Durch rituellen Kannibalismus wurde sie in diesem Volksstamm verbreitet. Andere Übertragungswege (diaplazentar oder postpartal von infizierten Müttern auf ihre Kinder) konnten nicht nachgewiesen werden (Poeck und Hacke 2001). Es war zu beobachten, dass vor allem Frauen und Kinder erkrankten, die bei den kannibalischen Ritualen Gehirn und Eingeweide der Verstorbenen verzehrten. 
Männer, die vorwiegend das Muskelfleisch zu sich nahmen, erkrankten weit seltener. Mit Aufgabe des Kannibalismus verschwand die Erkrankung (Hörnlimann 2001). Auch die CJK kann iatrogen (iCJK) übertragen werden. Beispielsweise bergen Duraund Corneatransplantate erkrankter Personen, Hormonpräparate aus infiziertem Hypophysenmaterial oder kontaminierte chirurgische Instrumente bei neurochirurgischen Eingriffen das Risiko einer Übertragung (Budka 2001a). So sieht man nicht zuletzt auch beim Auftreten der vCJK einen Zusammenhang zu BSE durch die orale Aufnahme infektiösen Materials. Nach ihrem Höhepunkt im Jahr 2001 bleibt die Anzahl der bis Februar 2009 aufgetretenen Fälle an vCJK mit 174 (NCJDSU Februar 2009) derzeit relativ stabil. Doch aufgrund der langen Inkubationszeit und nicht abschließend geklärter Übertragungswege ist die Gefahr für die öffentliche Gesundheit noch nicht vollkommen gebannt.

Trotz Fortschritten in der Prionforschung können die humanen Prionerkrankungen mit den heutigen Therapiemaßnahmen lediglich symptomatisch behandelt werden. Neuere Therapiestudien erbrachten mehrere Substanzen mit positivem Einfluss auf die Überlebenszeit. Wegen häufig toxischer Nebenwirkungen müssen jedoch weitere Studien abgewartet werden. Das Verständnis der Funktion des Prionproteins kann helfen, Strategien zu entwickeln, um gezielter in Stoffwechselprozesse und Pathomechanismen dieser Erkrankungen eingreifen zu können. 
Tabelle 1

\begin{tabular}{|c|c|c|c|}
\hline & $\begin{array}{l}\text { Typische Symptome und } \\
\text { diagnostische Kriterien }\end{array}$ & Auslösende Faktoren & Epidemiologie \\
\hline FFI & $\begin{array}{l}\text { - Schlafstörung } \\
\text { - Autonome Dysregulation }\end{array}$ & Mutation im $P R N P$ & $\begin{array}{l}7 \\
\text { - Seltene Erkrankung } \\
\text { - Dauer: } 9 \text { bzw. } 31 \text { Mte., schneller } \\
\text { Verlauf bei zusätzlich } \\
\text { Homozygotie für Methionin an } \\
\text { Codon } 129 \\
\text { - Erkrankungsalter: Mittel 51J. }\end{array}$ \\
\hline GSS & $\begin{array}{l}\text { - Langsam progrediente } \\
\text { Gangataxie } \\
\text { - Demenz erst im Verlauf }\end{array}$ & Mutationen im $P R N P$ & $\begin{array}{l}5 \text { - Äußerst seltene Erkrankung } \\
\text { - Dauer: Mittel 6,5 J. } \\
\text { - Erkrankungsalter: Mittel } 45 \text { J. }\end{array}$ \\
\hline fCJK & $\begin{array}{l}\text { - Rasch progrediente Demenz } \\
\text { - Progrediente Ataxie } \\
\text { - EPMS } \\
\text { - Myoklonien }\end{array}$ & $\begin{array}{l}\text { - Mutationen im PRNP } \\
\text { - Vererbungsmodus: } \\
\text { autosomal dominant, } \\
\text { - Penetranz: } \sim 100 \%\end{array}$ & $\begin{array}{l}\text { - Ca. } 10 \% \text { aller CJK } \\
\text { - Dauer: Mittel } 21 \text { Mte. }^{7} \\
\text { - Erkrankungsalter: Mittel } 50 . \mathrm{Lj} \text {. }\end{array}$ \\
\hline sCJK & $\begin{array}{l}\text { - Pyramidenbahnzeichen } \\
\text { - Endstadium: Rigor, Spastik, } \\
\text { akinetischer Mutismus } \\
\text { - EEG: zu 66\% PSWCs } \\
\text { - Proteine im Liquor erhöht: }\end{array}$ & $\begin{array}{l}\text { - Weitgehend unbekannt } \\
\text { - Risikofaktor: } \\
\text { Homozygotie für } \\
\text { Methionin an Codon } \\
129^{4}\end{array}$ & $\begin{array}{l}\text { - Ca. 80-90\% aller CJK } \\
\text { - Dauer: Mittel 4,5 Mte. } \\
\text { - Inzidenz weltweit } \\
\text { 1-1,5:1Million }{ }^{2} \\
\text { - Erkrankungsalter: Mittel 60. Lj. }\end{array}$ \\
\hline iCJK & $\begin{array}{l}\text { 14-3-3, Tau, S100, NSE } \\
\text { - MRT: Hyperintensitäten in } \\
\text { den Basalganglien } \\
\text { - Histologie: spongiforme } \\
\text { Veränderungen, Gliose, } \mathrm{PrP}^{\mathrm{Sc}} \text { - } \\
\text { Ablagerungen }\end{array}$ & $\begin{array}{l}\text { Kontakt mit infektiösem } \\
\text { Gewebe: } \\
\text { z.B. Dura- u. } \\
\text { Corneatransplantate, } \\
\text { Hormonpräparate aus } \\
\text { Hypohysenmaterial, } \\
\text { kontaminierte } \\
\text { chirurgische Instrumente }\end{array}$ & $\begin{array}{l}\text { - } 65 \text { Fälle } \\
\text { - Inkubationszeit abhängig von } \\
\text { Infektionsquelle } 15 \text { Mte. bis } 30 \\
\text { J. }^{8}\end{array}$ \\
\hline vCJK & $\begin{array}{l}\text { - Psychatrische Auffälligkeiten } \\
\text { - Schmerzhafte Dysästhesien } \\
\text { - Gangataxie } \\
\text { - Demenz erst spät im Verlauf } \\
\text { - EEG: nicht wegweisend } \\
\text { - MRT: Hyperintensitäten im } \\
\text { Thalamus, ,pulvinar sign“ } \\
\text { - Histologie: floride Plaques } \\
\text { - Nachweis von PrP }{ }^{\text {Sc }} \text { in } \\
\text { lymphatischem Gewebe } \\
\text { (Tonsillenbiopsie) }\end{array}$ & $\begin{array}{l}\text { Vermutlich } \\
\text { Zusammenhang mit BSE }\end{array}$ & $\begin{array}{l}\text { - } 174 \text { Fälle (bis Februar } 2009)^{6} \\
\text { - Dauer: Mittel } 14 \text { Mte. } \\
\text { - Erkrankungsalter: } 30 \mathrm{Lj} \text {. } \\
\text { - Inkubationszeit ca. } 10 \mathrm{~J}^{8}\end{array}$ \\
\hline Kuru $^{1}$ & $\begin{array}{l}\text { - Lokomotorische Ataxie } \\
\text { - Rhythmisches Zittern } \\
\text { - Gelächter, Euphorie } \\
\text { - Später schwere } \\
\text { Koordinationsstörungen } \\
\text { - Demenz selten, meist nur im } \\
\text { Endstadium } \\
\text { - Keine EEG-Veränderungen }\end{array}$ & $\begin{array}{l}\text { Übertragung durch } \\
\text { Kannibalismus }\end{array}$ & $\begin{array}{l}\text { - Entdeckung } 1957 \\
\text { - Höhepunkt der Epidemie 1957- } \\
1960 \\
\text { - östliches Hochland Papua- } \\
\text { Neuguinea } \\
\text { - } 2670 \text { Fälle insgesamt } \\
- \text { - }> \\
\text { - Krankheitsdauer: } 12 \text { Mte. } \\
\text { - } 1984 \text { Ende des Kannibalismus } \\
\end{array}$ \\
\hline
\end{tabular}

Übersicht über Prionerkrankungen beim Menschen: Alle Angaben stammen aus „Creutzfeldt-

Jakob-Krankheit“ in „Leitlinien für Diagnostik und Therapie in der Neurologie“ (Zerr et al. 2003), für Abweichendes siehe Kennzeichnung: ${ }^{1}$ (Hörnlimann 2001), ${ }^{2}$ (Ladogana et al. 2005), ${ }^{3}$ (Poeck und Hacke 2001), ${ }^{4}$ (Palmer et al. 1991), ${ }^{5}$ (Budka 2001b), ${ }^{6}$ (NCJDSU Februar 2009), ${ }^{7}$ (Sturzenegger 2001), ${ }^{8}$ (Budka 2001a), ${ }^{9}$ (NCJDSU Dezember 2007).

Farben: $\square$ genetische, $\square$ sporadische, $\square$ übertragene humane TSEs, $\square$ Symptomkomplex der CJK 


\subsection{Die Protein-only-Hypothese}

Wird heutzutage über den Erreger der TSEs gesprochen, so wird als infektiöses Agens meist das pathologische Prionprotein genannt. Diese Aussage stützt sich auf die Protein-only-Hypothese, die im Jahre 1967 von John Griffith begründet, durch Stanley Prusiner weiterentwickelt und im Laufe der Jahre durch zusätzliche wissenschaftliche Erkenntnisse gestützt wurde. Die Protein-only-Hypothese besagt, dass es sich bei den infektiösen Partikeln ausschließlich um Proteine handelt und Nukleinsäuren nicht beteiligt sind (Prusiner 1998). Stanley Prusiner führte 1982 die Bezeichnung „Prionen“ ein, um das infektiöse Agens von anderen möglichen Krankheitserregern zu unterscheiden (Prusiner 1982).

Die Liste an potentiellen Erregern war zunächst lang. Sie reichte von kleinen DNAViren über Zellmembranbestandteile hin zu Polysacchariden und letztlich wurden auch Proteine in Betracht gezogen (Prusiner 1998). Schon früh zeigten jedoch Versuche, dass das infektiöse Agens gegenüber Einflüssen wie ionisierender Strahlung oder UV-Licht, die DNA zerstören können, sehr resistent ist (Alper et al. 1966). Daraus schloss erstmals John Griffith 1967, dass der Erreger möglicherweise ohne Nukleinsäure repliziere und es sich dabei ausschließlich um Proteine handeln könnte (Griffith 1967). Schließlich gelang es Prionen aus infektiösem Hamstergehirn zu isolieren. Dabei wurde ein Protein gefunden, welches bei gesunden Tieren nicht nachweisbar war und als proteaseresistente Hauptkomponente des $\operatorname{PrP}^{\mathrm{Sc}}$ angesehen wurde (Bolton et al. 1982). Im Gegensatz dazu enthielten Proben gesunder Tiere die proteasesensitive Isoform $\operatorname{PrP}^{\mathrm{c}}$, ein Protein, das durch ein zelleigenes Gen kodiert wird (Oesch et al. 1985).

$\mathrm{Zu}$ den wichtigsten Argumenten, die die Prionhypothese stützen, gehören Versuche mit $\operatorname{PrP}^{\mathrm{c}}$ knockout-Mäusen. Durch Inokulation mit mausadaptiertem Erreger konnten bei diesen Mäusen keine Krankheitssymptome ausgelöst werden. Demnach sind Mäuse, die kein $\operatorname{PrP}^{\mathfrak{c}}$ bilden können, gegen die Erkrankung resistent. Somit ist für die Ausbildung und Ausbreitung einer Prionerkrankung das normale $\operatorname{PrP}^{\mathrm{c}}$ notwendig (Büeler et al. 1993, Brandner et al. 1996).

Wie in Kapitel 1.1.2 beschrieben, können verschiedene vererbbare Mutationen des Prionproteingens zur Entstehung einer TSE führen. Dabei untermauert die außerordentlich hohe Penetranz dieser Mutationen ebenfalls die zentrale Rolle des Prionproteins bei der Krankheitsentstehung (Hsiao et al. 1989, Medori et al. 1992). 
Ein weiterer Durchbruch gelang einer Arbeitsgruppe in San Francisco. Sie wandelten rekombinantes Maus-Prionprotein MoPrP (89-230) in infektöse Amyloidfibrillen um, die nach intracerebraler Inokulation bei Mäusen zum Ausbruch einer spongiformen Enzephalopathie führten (Legname et al. 2004). Auch entwickelten syrische Hamster nach Inokulation von in $\beta$-Faltblattform gebrachtem und durch längeres Erhitzen vorbereitetem rekombinantem Prionprotein $(\mathrm{rPrP})$ eine Prionerkrankung. Im Gehirn dieser Tiere waren daraufhin große Mengen $\mathrm{PrP}^{\mathrm{Sc}}$ nachweisbar (Makarava et al. 2009). Der endgültige Beweis der Prion-onlyHypothese, die Umwandlung von $\operatorname{PrP}^{\mathrm{c}}$ in $\operatorname{PrP}^{\mathrm{Sc}}$ in vitro, fehlt jedoch weiterhin. Zudem gibt es Befunde, die daran zweifeln lassen, ob der Erreger ausschließlich aus Prionprotein besteht. So wurden kürzlich Virionen in Neuroblastom-Zellen, die mit dem 22L-Strain infiziert waren, und in Hypothalamuszellen, die mit dem FU Creutzfeldt-Jakob-Krankeitsereger infiziert waren, nachgewiesen (Manuelidis et al. 2007). Ferner gelang die Infektion von Mäusen ohne abnormales protease-resistentes $\operatorname{PrP}^{\mathrm{Sc}}$ (Lasmezas et al. 1997). Alle diese Hinweise sprechen dafür, dass die TSEs möglicherweise nicht einzig durch $\mathrm{PrP}^{\mathrm{Sc}}$ ausgelöst werden. Ganz gleich, welche Kofaktoren für die Krankheitsentstehung zusätzlich vorliegen müssen, unumstritten wird hierfür $\operatorname{PrP}^{\mathrm{c}}$ benötigt.

\subsection{Das zelluläre Prionprotein}

$\operatorname{PrP}^{\mathrm{c}}$ ist ein im Verlauf der Evolution konserviertes Zellmembranprotein, welches durch das Prionproteingen kodiert wird. Beim Menschen ist das Prionproteingen auf dem kurzen Arm von Chromosom 20 lokalisiert, wo es sich über zwei Exons erstreckt (Puckett et al. 1991). Die Synthese von $\operatorname{PrP}^{\mathrm{c}}$ erfolgt, wie bei anderen membrangebundenen Proteinen auch, im rauhen endoplasmatischem Retikulum. Das Prionprotein wird anschließend im Golgi-Apparat prozessiert und von dort zur Zellmembran transportiert, wo es mittels GPI-Anker befestigt wird (Stahl et al. 1987). In höchsten Konzentrationen kommt $\operatorname{PrP}^{c}$ in Nervenzellen des Gehirns und Rückenmarks vor, wurde jedoch auch in zahlreichen anderen Zelltypen und Geweben gefunden (Bendheim et al. 1992). Das menschliche $\operatorname{PrP}^{\mathrm{c}}$ besteht vor der Prozessierung aus 253 Aminosäuren und kann in un-, mono- oder diglykosylierter Form vorliegen, wodurch das Molekulargewicht zwischen $27 \mathrm{kDa}$ und $36 \mathrm{kDa}$ variiert (Kretzschmar et al. 1986). 


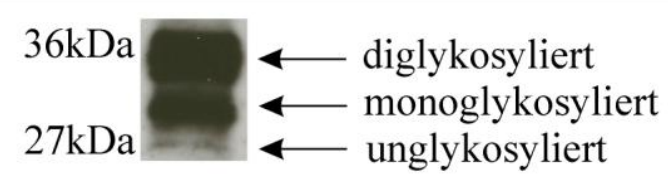

Abbildung 1 Glykosylierung des zellulären Prionproteins

NMR-Studien haben gezeigt, dass $\operatorname{PrP}^{c}$ aus einer variablen $\mathrm{N}$-terminalen und einer kugelförmigen C-terminalen Region besteht. Letztere enthält drei $\alpha$-Helices und zwei antiparallele $\beta$-Faltblätter (Riek et al. 1996). Wie auf Abbildung 2 ersichtlich, werden die Helices $\alpha_{2}$ und $\alpha_{3}$ durch eine Disulfidbrücke stabilisiert (Turk et al. 1988), die posttranslationell ausgebildet wird. Darüber hinaus finden sich im C-terminalen Segment Bindungsstellen für Oligosaccharidketten (Haraguchi et al. 1989). Das sogenannte neurotoxische Peptid (siehe Kapitel 1.6) liegt im zentralen Bereich des $\operatorname{PrP}^{\mathrm{c}}$ und eine Region mit fünf Octapeptid-Wiederholungen ist N-terminal lokalisiert. Diese Region ermöglicht die Bindung von Kupferionen (Hornshaw et al. 1995).

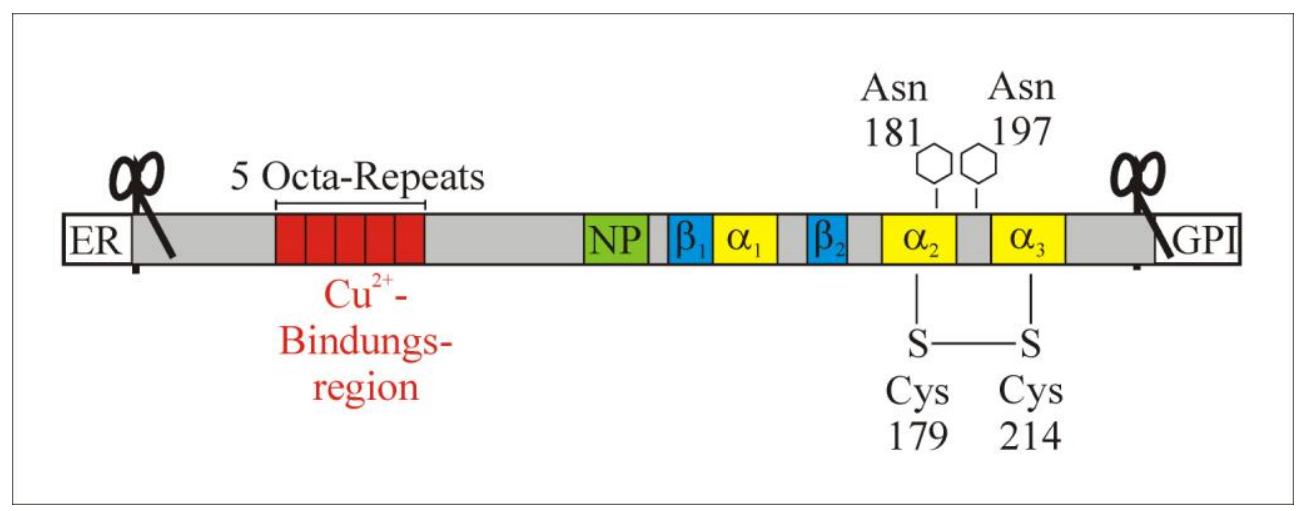

Abbildung 2 Schematische Darstellung des zellulären Prionproteins. ER: Endoplasmatisches Retikulum, NP: Neurotoxisches Peptid (Aminosäuren 106-126), $\alpha_{1-3}$ : drei $\alpha$-Helices, $\beta_{1+2}$ : zwei antiparallele $\beta$-Faltblätter, GPI: Glycosylphosphatidylinositol-Anker, $\bigcirc$ : Oligosaccharidketten, S - S: Disulfidbrücke, Cys: Cystein, Asn: Asparagin.

Auf der Zelloberfläche ist $\operatorname{PrP}^{\mathrm{c}}$ in sogenannten Lipid-Rafts, das sind sphingolipidund cholesterinreiche Mikrodomänen in Zellmembranen, angeordnet (Naslavsky et al. 1997). Genauer gesagt ist $\operatorname{PrP}^{c}$ in Caveolae lokalisiert, einer speziellen Sorte von Lipid-Rafts, die zahlreiche Funktionen wie Signaltransduktion oder Transzytose vermitteln (Gorodinsky und Harris 1995, Peters et al. 2003). Die fertigen $\operatorname{PrP}^{\mathrm{c}}$ Moleküle bewegen sich in einem kontinuierlichen Zyklus zwischen Zelloberfläche und Zellinnerem, die Transitzeit beträgt ungefähr eine Stunde. Während jeder 
Passage werden 1-5\% der Proteine proteolytisch gespalten und die $\mathrm{N}$ - und Cterminalen Spaltprodukte externalisiert. Ein Teil der membrangebundenen $\operatorname{PrP}^{\mathrm{c}}-$ Moleküle wird durch Spaltung innerhalb des GPI-Ankers in den Extrazellulärraum abgegeben (Shyng et al. 1993).

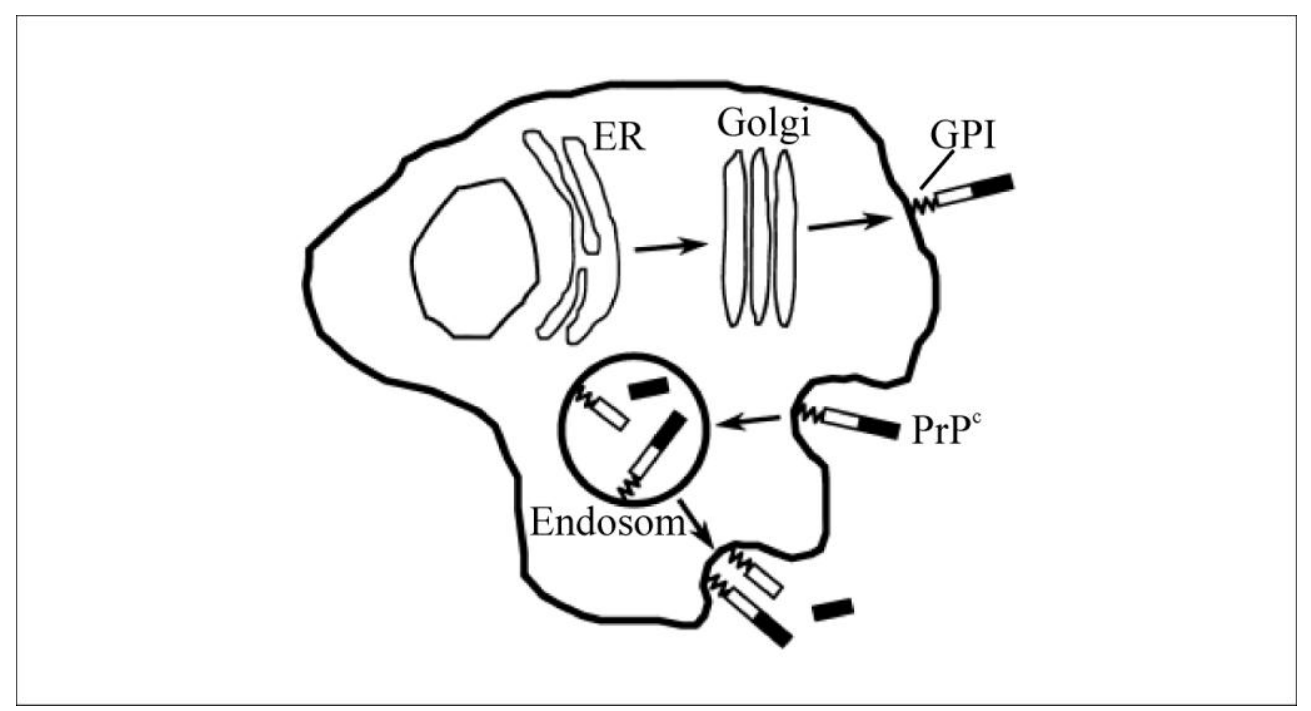

Abbildung 3 Trafficking und proteolytische Spaltung von $\operatorname{PrP}^{\mathbf{c}}$. $\operatorname{PrP}^{\mathrm{c}}$ bewegt sich in einem kontinuierlichen Zyklus zwischen Zelloberfläche und Zellinnerem. Wenige PrP ${ }^{c}$-Moleküle werden proteolytisch gespalten. Die Spaltprodukte werden an der Zellmembran präsentiert oder an den Extrazellulärraum abgegeben. Abbildung modifiziert aus Harris (2003, S. 73). ER: endoplasmatisches Retikulum, GPI: Glycosylphosphatidylinositol-Anker.

\subsection{Die Umwandlung von $\operatorname{PrP}^{\mathrm{c}} \mathrm{zu} \operatorname{PrP}^{\mathrm{Sc}}$}

Das physiologische $\operatorname{PrP}^{\mathrm{c}}$ und das pathologische $\operatorname{PrP}^{\mathrm{Sc}}$ unterscheiden sich hauptsächlich in ihrer Sekundär- und Tertiärstruktur (Stahl et al. 1993). Die Umwandlung von $\operatorname{PrP}^{\mathrm{c}}$ in $\operatorname{PrP}^{\mathrm{Sc}}$ ist ein posttranslationaler Prozess (Borchelt et al. 1990), dem eine Konformationsänderung zugrunde liegt, bei der der Anteil an $\alpha$-Helices von ursprünglich ungefähr $43 \%$ auf $30 \%$ reduziert wird und stattdessen der $\beta$-Faltblattanteil von ca. 3\% auf 43\% ansteigt (Pan et al. 1993). 


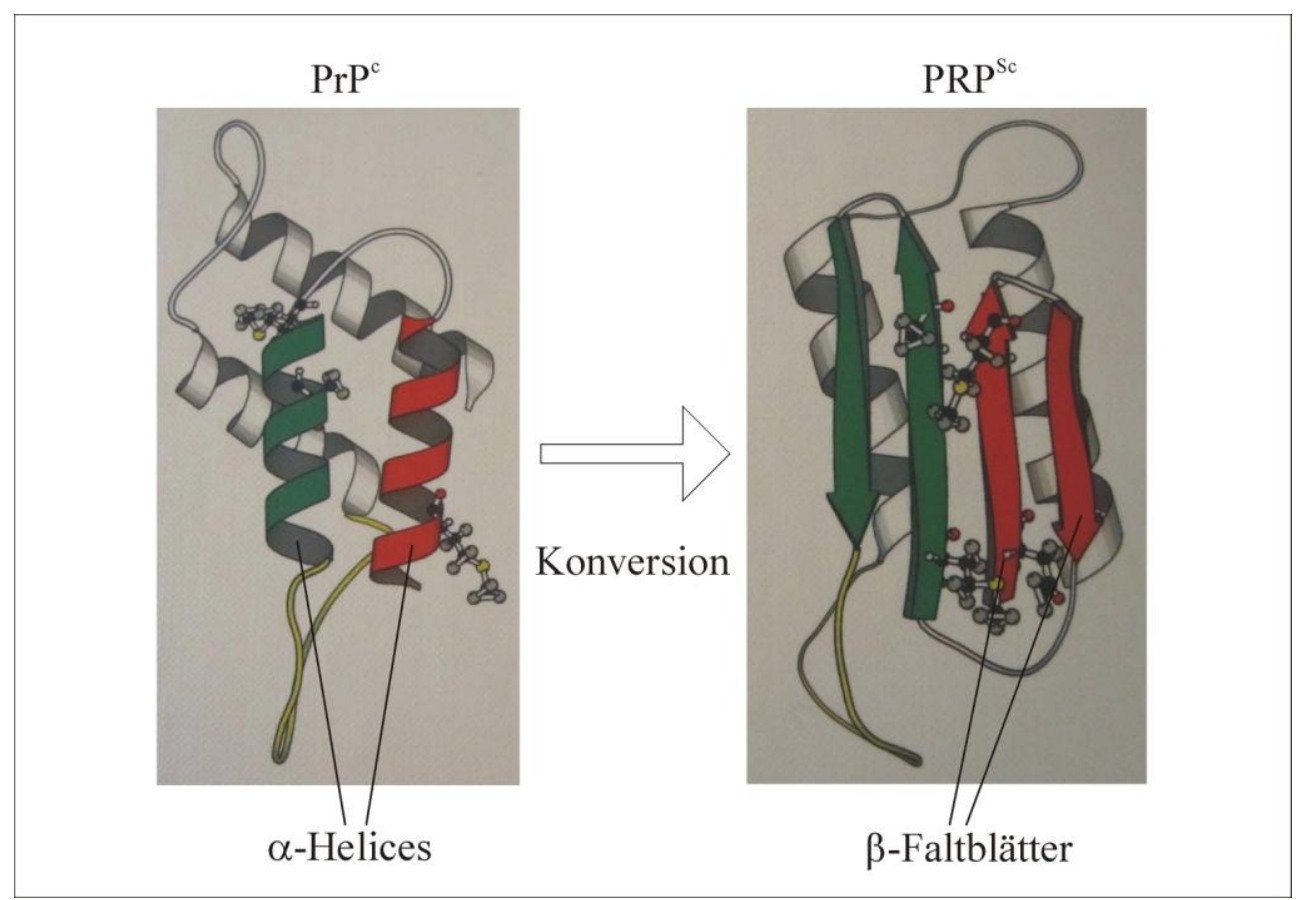

Abbildung 4 Schematische Darstellung von $\operatorname{PrP}^{\mathbf{c}}$ und $\operatorname{PrP}^{\mathrm{Sc}}$. $\operatorname{PrP}^{\mathrm{c}}$ hat im Vergleich zu $\operatorname{Pr} \mathrm{P}^{\mathrm{Sc}}$ einen höheren Anteil an $\alpha$-Helices, $\operatorname{PrP}^{\mathrm{Sc}}$ enthält mehr $\beta$-Faltblätter. Abbildung modifiziert nach Prusiner (1996, Einband).

Diese Konformationsänderung bedingt die unterschiedlichen biochemischen Eigenschaften von $\operatorname{PrP}^{\mathrm{c}}$ und $\operatorname{PrP}^{\mathrm{Sc}}$. So kann $\operatorname{PrP}^{\mathrm{c}}$ durch Proteasen gespalten oder in nicht-denaturierenden Mitteln gelöst werden, wohingegen $\operatorname{PrP}^{\mathrm{Sc}}$ teilweise proteaseresistent und unlöslich ist (Meyer et al. 1986, Cohen FE et al. 1994).

Um die Umfaltung von $\operatorname{PrP}^{\mathrm{c}} \mathrm{zu} \operatorname{PrP}^{\mathrm{Sc}}$ zu erklären, wurden zwei verschiedene Modelle entwickelt: das Nukleations- (a.) und das Umfaltungsmodell oder Heterodimermodell (b.) (siehe Abbildung 5). Das Nukleationsmodell besagt, dass zwischen $\operatorname{PrP}^{\mathrm{c}}$ und $\operatorname{PrP}^{\mathrm{Sc}}$ ein thermodynamisches Gleichgewicht besteht und die Umfaltung nur dann geschieht, wenn mehrere $\operatorname{PrP}^{\mathrm{Sc}}$-Moleküle mit $\operatorname{PrP}^{\mathrm{c}}$ verbunden werden (Come et al. 1993, Lansbury und Caughey 1995). Durch die Verbindung mit $\operatorname{PrP}^{\mathrm{c}}$ wird $\mathrm{PrP}^{\mathrm{Sc}}$ stabilisiert und kann sich in Amyloidfibrillen zusammenlagern. Teilen sich die $\mathrm{PrP}^{\mathrm{Sc}}$-Aggregate, die sogenannten Nuklei, die zur erneuten Anlagerung und Umwandlung des $\operatorname{PrP}^{\mathrm{c}}$ führen, kann dies in der exponentiellen Vermehrung der infektiösen Partikel resultieren. Im Heterodimermodell verhindert eine hohe Energiebarriere die spontane Umfaltung von $\operatorname{PrP}^{\mathrm{c}} \mathrm{zu}^{\mathrm{PrP}} \mathrm{P}^{\mathrm{Sc}}$ (Prusiner et al. 1990). Werden jedoch exogene $\mathrm{PrP}^{\mathrm{Sc}}$-Moleküle eingebracht, wird ein Prozess in Gang gesetzt, der dazu beiträgt die Energiebarriere zu überwinden. Möglicherweise 
ist an diesem Vorgang ein chaperonähnliches Protein (Protein X) beteiligt (Telling et al. 1995).

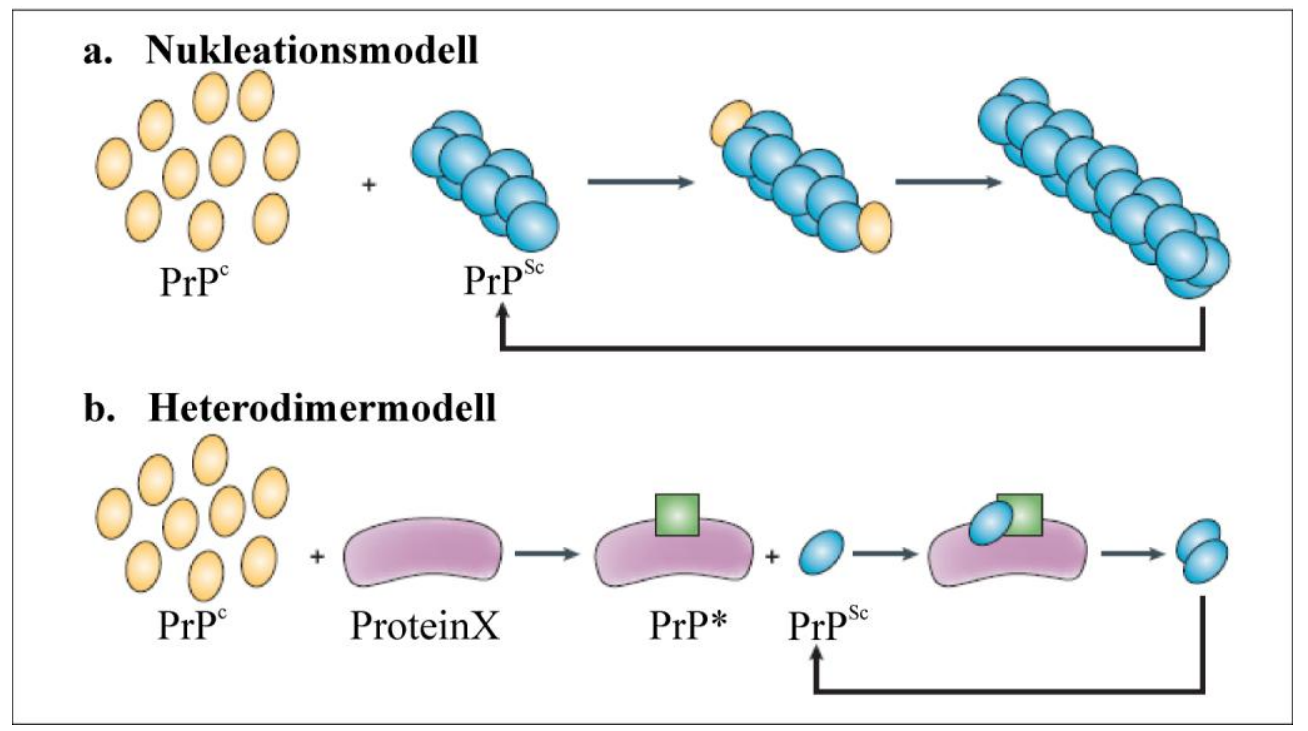

Abbildung 5 Modelle für die Konversion von $\operatorname{PrP}^{\mathbf{c}} \mathbf{z u} \operatorname{PrP}^{\mathrm{Sc}}$. Im Nukleationsmodell (a.) führt der Kontakt von $\mathrm{PrP}^{\mathrm{c}}$ mit einem $\mathrm{PrP}^{\mathrm{Sc}}$-Oligomer zur Umfaltung und Stabilisation des neugebildeten $\mathrm{PrP}^{\mathrm{Sc}}$. Das Heterodimermodell (b.) legt für die Umfaltung die Bildung eines an ein Chaperon (Protein X) gebundenes Zwischenprodukt (PrP*) zugrunde. Abbildung modifiziert aus Soto (2004, S. 811).

\subsection{Neuroinvasion und Toxizität von Prionen}

Der Eintritt von Prionen in den Körper erfolgt bei der Mehrzahl der Prionerkrankungen durch eine Infektion außerhalb des Nervensystems, je nach Erkrankung durch orale (BSE, Kuru, vCJK) oder parenterale (iCJK) Aufnahme von infektiösem Material. Zunächst wird das lymphoretikuläre System (bei oraler Aufnahme über die Peyerplaques) besiedelt. Anschließend breiten sich die Prionen retrograd entlang autonomer peripherer Nerven oder des Nervus vagus aus, bis sie schließlich das ZNS erreichen (Beekes et al. 1998, Aguzzi 2003). Bei der sporadischen CJK sind von der Infektion meistens keine lymphatischen Gewebe betroffen, sie bleibt auf das ZNS beschränkt (Hill et al. 1997).

Die Mechanismen der Neurotoxizität von Prionen sind weitgehend ungeklärt. Man weiß, dass das Vorhandensein von $\operatorname{PrP}^{\mathrm{Sc}}$ alleine nicht zur Entstehung einer TSE führen kann. Nur gemeinsam mit $\operatorname{PrP}^{c}$ bilden Prionen ihre neurotoxischen Eigenschaften aus. Wird die Umfaltung von $\mathrm{PrP}^{\mathrm{c}} \mathrm{zu} \mathrm{PrP}^{\mathrm{Sc}}$ verhindert, mindert dies auch das Fortschreiten der Erkrankung (Mallucci et al. 2003). 


\subsection{Physiologische Funktionen von $\operatorname{Pr} P^{c}$}

Das Verstehen der physiologischen Funktion von $\operatorname{PrP}^{\mathrm{c}}$ stellt eine Grundvoraussetzung dar, um neue Strategien für Therapie und Prävention von Prionerkrankungen entwickeln $\mathrm{zu}$ können. Mittlerweile sind zahlreiche Interaktionspartner und biologische Funktionen des $\operatorname{PrP}^{\mathrm{c}}$ bekannt, doch die genauen Zusammenhänge bleiben weiterhin unklar. Im Folgenden werden die wichtigsten bekannten physiologischen Funktionen und ihre mögliche Relevanz für die Krankheitsentstehung aufgezeigt (siehe Abbildung 6).

Neben Einflüssen auf Immunabwehr (Zomosa-Signoret et al. 2008) und Zelladhäsion (Schmitt-Ulms et al. 2001) und der Beteiligung an Energiestoffwechsel und Zellhomöostase (Ramljak et al. 2008) scheint die Hauptfunktion von $\operatorname{PrP}^{\mathrm{c}}$ innerhalb neuroprotektiver Prozesse zu liegen. Als ein in Rafts lokalisiertes GPI-verankertes Membranprotein liegt das Mitwirken von $\mathrm{PrP}^{\mathrm{c}}$ an Signalübertragungsketten nahe (Peters et al. 2003). Die bisher bekannten Übertragungswege fördern durch Stimulation von Neuritenwachstum, Synapsenbildung und Hemmung der Apoptose das neuronale Überleben. So ist $\operatorname{PrP}^{\mathrm{c}}$ durch die Aktivierung der Fyn Tyrosinkinase (Mouillet-Richard et al. 2000) oder der Interaktion mit dem Lamininrezeptor (Graner et al. 2000) am Wachstum von Neuriten und durch seine Interaktion mit Synapsin Ib an Synapsenbildung und Neurotransmitterregulation beteiligt. Außerdem hat $\operatorname{PrP}^{\mathrm{c}}$ über GRB2, einem Adapterprotein, das Signale von Wachstumsfaktoren vermittelt, wichtige Aufgaben für das Überleben von Nervenzellen (Spielhaupter und Schatzl 2001). Schließlich sind zytoprotektive Effekte von $\operatorname{PrP}^{c}$ über die Bindung an das stressinduzierbare Protein-1 (STI1) (Chiarini et al. 2002, Zanata et al. 2002) und über die Beziehung $\mathrm{zu}$ anderen neuroprotektiven Übertragungswegen, wie der Phosphatidylinositol-3-Kinase (PI3K) (Vassallo et al. 2005) und der mitogenaktivierten Proteinkinase/extrazellulärer signalregulierter Kinase (MAPK/ERK) (Chen S et al. 2003) möglich.

Die Ähnlichkeit zwischen der BH2-Domäne der Proteine der Bcl-2-Familie und der Oktarepeatregion des $\operatorname{PrP}^{c}$ führte zu der Annahme, dass $\operatorname{PrP}^{c}$ ähnliche Funktionen wie Proteine dieser Familie ausüben könnte (LeBlanc 1998). Die Bcl-2-Familie ist an der Regulation der Apoptose beteiligt. Nachgewiesen wurde die antiapoptotische Funktion von $\operatorname{PrP}^{\mathrm{c}}$ erstmals 1999 von Kuwahara und Kollegen, die zeigen konnten, dass der durch Serumentzug initiierte Zelltod in $\operatorname{Prnp}^{0 / 0}$-Zellen durch das Einbringen von $\operatorname{PrP}^{\mathrm{c}}$ oder Bcl-2 aufgehalten werden konnte (Kuwahara et al. 1999). Später 
wurde herausgefunden, dass das $\operatorname{PrP}^{\mathrm{c}}$ menschliche Neurone auch gegen den durch das BAX-Protein hervorgerufenen Zelltod schützt (Bounhar et al. 2001).

Eine weitere protektive Funktion der Oktarepeatregion des $\operatorname{PrP}^{\mathrm{c}}$ steht im Zusammenhang mit der Abwehr gegen oxidativen Stress. Durch ihre Fähigkeit, freie Kupferionen zu binden, die als Oxidans selbst toxisch wirken, reduziert $\operatorname{PrP}^{\mathrm{c}}$ den durch Kupfer ausgelösten oxidativen Stress (Vassallo und Herms 2003). Weitere molekulare Mechanismen, die die $\mathrm{PrP}^{\mathrm{c}}$-vermittelte Neuroprotektion bewirken könnten, liegen in antioxidativen Enzymen. Die Aktivität solcher Enzyme wie der kupfer- und zinkabhängigen Superoxiddismutase (SOD) oder der Glutathionreduktase scheint positiv mit $\mathrm{PrP}^{\mathrm{c}}$-Konzentrationen zu korrelieren (Brown und Besinger 1998, Rachidi et al. 2003). Weiterhin wird durch die Transfektion des Prnp-Gens in $P_{r n p}{ }^{0 / 0}$-Zellen die Aktivität der SOD hochreguliert, die Superoxidbildung vermindert und die Zellen vor Apoptose geschützt (Sakudo et al. 2003).

Nach traumatischen Gehirnverletzungen oder cerebraler Ischämie wird $\operatorname{PrP}^{\mathrm{c}}$ deutlich hochreguliert (Marciano et al. 2004, Weise et al. 2004). Besonders Prnp ${ }^{0 / 0}$ - und genetisch veränderte Mäuse, denen die Oktarepeatregion des $\operatorname{PrP}^{c}$ fehlt, zeigen wesentlich größere Infarktareale nach zerebraler Ischämie als Wildtyp-Mäuse (McLennan et al. 2004, Mitteregger et al. 2007, Weise et al. 2006). Dies unterstreicht ebenfalls die Wichtigkeit der Oktapeptidregion für die durch $\operatorname{PrP}^{\mathrm{c}}$ geförderte Neuroprotektion.

Einige $\operatorname{PrP}^{\mathrm{c}}$-knockout-Mäusestämme zeigten eine spät ausbrechende Ataxie, cerebelläre Neurodegeneration und Verlust von Purkinjezellen (Sakaguchi et al. 1996). Diese Veränderungen konnten nicht auf das Fehlen von $\operatorname{PrP}^{\mathrm{c}}$ selbst, sondern auf die Überexpression des $\operatorname{PrP}^{\mathfrak{c}}$-Paralogs Doppel zurückgeführt werden (Moore et al. 1999, Rossi et al. 2001). Durch Einbringen von $\operatorname{PrP}^{\mathrm{c}}$ in die Doppelüberexprimierenden Mäuse konnten sie vor den oben genannten Symptomen bewahrt werden (Nishida et al. 1999). Somit schützt $\operatorname{PrP}^{\mathrm{c}}$ vor der durch Doppel induzierten Neurodegeneration.

Alle bisher genannten Punkte machen die vermutlich wichtigsten Funktionen, die neuroprotektiven und das Zellüberleben fördernden Fähigkeiten, von $\operatorname{PrP}^{\mathrm{c}}$ deutlich. 


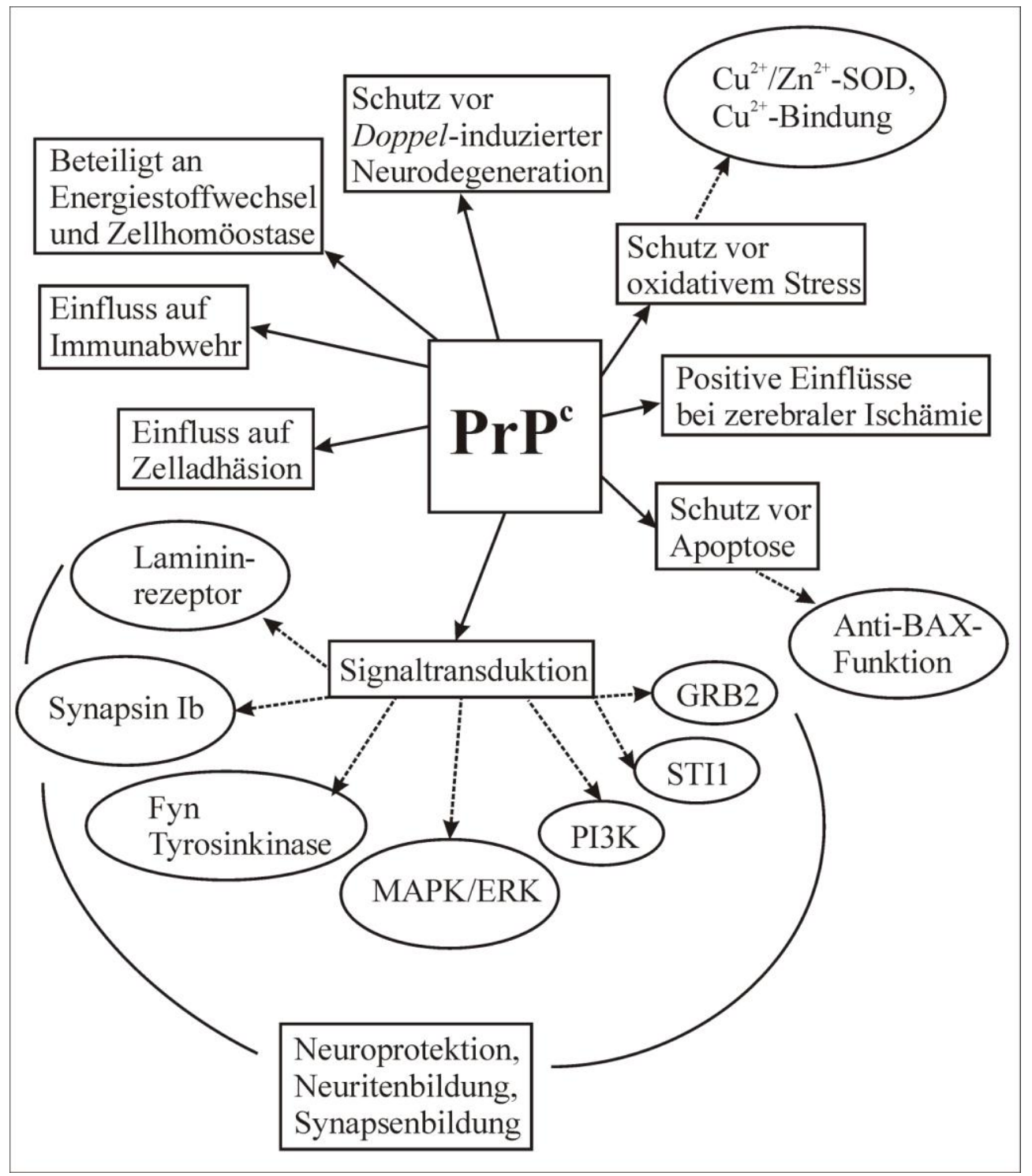

Abbildung 6 Physiologische Funktionen des PrP'. Übersicht über die im Text genannten Funktionen.

So eindrücklich die protektiven Aufgaben auch belegt sein mögen, geben andere Versuche $\mathrm{zu}$ Kontroversen Anlass. Beispielsweise konnte in vitro eine proapoptotische Aktivität unter Überexpression von $\operatorname{PrP}^{\mathrm{c}}$ nachgewiesen werden (Paitel et al. 2002, Paitel et al. 2003). In vivo zeigten sich unter $\operatorname{PrP}^{\mathrm{c}}$-Überexpression neurodegenerative Effekte (Westaway et al. 1994, Huang et al. 2007, Chiesa et al. 2008), die unter anderem im Zusammenhang mit der Akkumulation des C1Fragments gesehen werden. Das C1-Fragment entsteht durch Spaltung der Bindung zwischen Aminosäuren 110/111 und 112 und steigert p53-abhängig die Sensitivität für apoptotische Reize (Sunyach et al. 2007). Die Aminosäuren 110/111 und 112 liegen wiederum in der neurotoxisch wirkenden Domäne 106-126 (neurotoxisches 
Peptid) des menschlichen $\operatorname{PrP}^{c}$. Zwar kommt das Fragment 106-126 im natürlichen Stoffwechsel nicht vor, doch kann es Neurotoxizität induzieren (Forloni et al. 1993, Brown et al. 1996), indem es Eigenschaften des pathologischen $\operatorname{PrP}^{\mathrm{Sc}}$ ausbildet und sich zu Amyloidfibrillen zusammenlagert (Tagliavini et al. 1993, De Gioia et al. 1994). Weiterhin erscheint im Hinblick auf die neuroptotektive Funktion von $\operatorname{PrP}^{\mathrm{c}}$ widersprüchlich, dass $\operatorname{PrP}^{\mathrm{c}}$ für die Ausbildung und Vermehrung der neurotoxischen Prionen benötigt wird. So wird unter Bedingungen, an denen das Zellüberleben gefördert werden muss, mehr $\operatorname{PrP}^{\mathrm{c}}$ hergestellt. Dadurch steigt paradoxerweise auch die Chance auf Umfaltung von $\operatorname{PrP}^{\mathrm{c}}$ in das pathologische $\operatorname{PrP}^{\mathrm{Sc}}$, was die proapoptotische Funktion fördern dürfte. Alles in allem ist die normale Funktion des Prionproteins mehrdeutig und bedarf weiterer Aufklärung.

Abschließend möchte ich auf drei mögliche Hypothesen eingehen, die erklären, wie Veränderungen im $\operatorname{PrP}^{c}$ zur Krankheitsentstehung führen können (Westergard et al. 2007). Am häufigsten wird davon gesprochen, dass $\operatorname{PrP}^{c}$ einem toxischen Funktionszugewinn (,gain of function“) unterliegen könnte, so dass $\operatorname{PrP}^{\mathrm{Sc}}$ neue schädliche Eigenschaften bekommt, die nicht mit den normalen Aufgaben von $\operatorname{PrP}^{\mathrm{c}}$ in Verbindung gebracht werden können. Andererseits könnte $\operatorname{PrP}^{\mathrm{c}}$ durch die Umwandlung in $\operatorname{PrP}^{\mathrm{Sc}}$ auch schützende Funktionen verlieren (,loss of function“) und dadurch neurodegenerative Prozesse oder Zelltod in Gang setzen. Die dritte Alternative ist die Annahme, dass es durch Interaktion von $\operatorname{PrP}^{\mathrm{c}}$ mit $\mathrm{PrP}^{\mathrm{Sc}} \mathrm{zu}$ einer Umwandlung der neuroprotektiven Signale von $\operatorname{PrP}^{c}$ in neurotoxische Signale kommt.

\section{$1.7 \quad$ Zielsetzung}

Ziel dieser Arbeit ist, weitere Kenntnisse über die physiologische Funktion des $\operatorname{PrP}^{c}$ zu gewinnen. Bisher sind unter Überexpression des $\operatorname{PrP}^{\mathrm{c}}$ in verschiedenen Zelllinien widersprüchliche Funktionen des $\operatorname{PrP}^{c}$ zu Tage getreten. Wie in Kaptiel 1.6 beschrieben, weist es einerseits neuroprotektive und antiapoptotische Eigenschaften auf, andererseits kann es zellschädigend wirken und erhöht die Sensitivität für apoptotische Reize. Da in-vivo-Experimente zeigten, dass die Überexpression von wildtyp- $\operatorname{PrP}^{\mathrm{c}}$ in Mäusen zu Neurodegeneration (Westaway et al. 1994) und in der Muskulatur transgener Mäuse zur Ausbildung einer Myopathie führt (Huang et al. 2007), jedoch die postnatale Entfernung des endogenen $\operatorname{PrP}^{\mathrm{c}}$ keinerlei 
neurodegenerative Effekte nach sich zieht (Mallucci et al. 2002), stellt sich die Frage, welche Veränderungen die Überexpression von $\operatorname{PrP}^{c}$ in menschlichen Nervenzellen haben könnte. Um die Einflüsse des $\operatorname{PrP}^{\mathrm{c}}$ beurteilen zu können, ist es sinnvoll, die durch $\operatorname{PrP}^{c}$ regulierten Proteine zu kennen. Dafür steht einerseits wie schon mehrfach durchgeführt die Genomanalyse zur Verfügung (Satoh und Yamamura 2004, Martinez und Pascual 2007). Da jedoch die Transkription der DNA nicht zwangsläufig zur Ausbildung funktionstüchtiger Proteine führt, ist eine direkte Untersuchung der Einflüsse von $\operatorname{PrP}^{c}$ auf das Proteom notwendig (Strom et al. 2006, Ramljak et al. 2008). Nach dem Vorbild von Ramljak et al. (2008) wurde in dieser Arbeit das Proteom von nativen humanen Neuroblastomzellen SH-SY5Y mittels zweidimensionaler Gelelektrophorese mit dem Proteom von stabil mit PRNP transfizierten SH-SY5Y-Zellen verglichen. Die stabil transfizierten Zellen wiesen im Gegensatz zu den nativen Zellen eine Überexpression des $\operatorname{PrP}^{c}$ auf. Es wurde angenommen, dass durch die unterschiedliche $\operatorname{PrP}^{\mathrm{c}}$-Expression für das $\operatorname{PrP}^{\mathrm{c}}$ spezifische Proteine in ihrer Expression beeinflusst werden und somit Proteine gefunden werden, die Hinweise auf die Funktion des $\operatorname{PrP}^{\mathrm{c}}$ geben.

In der oben genannten Studie von Ramljak et al. wurde durch die transiente $\operatorname{PrP}^{\mathrm{c}}$ Überexpression in HEK293-Zellen die Expression von Proteinen reguliert, die an Energieproduktion und der Aufrechterhaltung der zellulären Homöostase beteiligt sind (Ramljak et al. 2008). Daher war ein weiteres Ziel der hier vorliegenden Arbeit $\mathrm{zu}$ untersuchen, ob ähnliche Phänomene auch in einer neuronalen Zelllinie (HEK293- vs. SH-SY5Y-Zellen) oder auch nach der Änderung der Transfektionsmethode (transiente vs. stabile Transfektion) reproduziert werden können. 


\subsection{Chemikalien}

\begin{tabular}{|c|c|}
\hline Bezeichnung & Hersteller \\
\hline Ammoniumperoxidsulfat & Roth (Karlsruhe, Deutschland) \\
\hline Ampholyte & Bio-Rad (Hercules, CA, USA) \\
\hline Bovines Serum Antigen & Roth (Karlsruhe, Deutschland) \\
\hline Bromophenolblau & Sigma-Aldrich (München, Deutschland) \\
\hline CHAPS & Bio-Rad (Hercules, CA, USA) \\
\hline Dithiothreitol & Merck (Darmstadt, Deutschland) \\
\hline Dulbecco's Modified Eagle Medium & Biochrom (Berlin, Deutschland) \\
\hline Essigsäure & Merck (Darmstadt, Deutschland) \\
\hline Ethanol & Merck (Darmstadt, Deutschland) \\
\hline Formaldehyd-Lösung & Sigma-Aldrich (München, Deutschland) \\
\hline Fötales Bovines Serum & Biochrom (Berlin, Deutschland) \\
\hline Glycerol & Sigma-Aldrich (München, Deutschland) \\
\hline Iodacetamid & Bio-Rad (Hercules, CA, USA) \\
\hline Isopropanol & Merck (Darmstadt, Deutschland) \\
\hline L-Glutamine & Invitrogen (Karlsruhe, Deutschland) \\
\hline Luminol & Sigma-Aldrich (München, Deutschland) \\
\hline Methanol & Merck (Darmstadt, Deutschland) \\
\hline Milchpulver & Roth (Karlsruhe, Deutschland) \\
\hline Mineralöl & Bio-Rad (Hercules, CA, USA) \\
\hline Natriumlaurylsulfat & Sigma-Aldrich (München, Deutschland) \\
\hline Natriumcarbonat & Roth (Karlsruhe, Deutschland) \\
\hline Natriumdodecylsulfat & Merck (Darmstadt, Deutschland) \\
\hline PBS Dulbecco & Biochrom (Berlin, Deutschland) \\
\hline p-Coumarsäure & Sigma-Aldrich (München, Deutschland) \\
\hline Roti®Load & Roth (Karlsruhe, Deutschland) \\
\hline Silbernitratlösung & Merck (Darmstadt, Deutschland) \\
\hline Tetramethylethylendiamin & Roth (Karlsruhe, Deutschland) \\
\hline
\end{tabular}




\begin{tabular}{|l|l|}
\hline Thiourea & Sigma-Aldrich (München, Deutschland) \\
\hline Tris & Roth (Karlsruhe, Deutschland) \\
\hline Tris Hydrochlorid & Roth (Karlsruhe, Deutschland) \\
\hline Tween-20 & Merck (Darmstadt, Deutschland) \\
\hline Urea & Roth (Karlsruhe, Deutschland) \\
\hline Kaliumferricyanid & Sigma-Aldrich (München, Deutschland) \\
\hline Natriumthiosulfat & Sigma-Aldrich (München, Deutschland) \\
\hline Acetonitril & Sigma-Aldrich (München, Deutschland) \\
\hline Ammoniumbicarbonat & Sigma-Aldrich (München, Deutschland) \\
\hline Trifluoressigsäure & Sigma-Aldrich (München, Deutschland) \\
\hline Trypsin & Promega (Madison, USA) \\
\hline Kalziumchlorid & Sigma-Aldrich (München, Deutschland) \\
\hline Natriumchlorid & $\begin{array}{l}\text { Mallinckrodt Baker B.V. (Deventer, } \\
\text { Niederlande) }\end{array}$ \\
\hline EDTA & Roth (Karlsruhe, Deutschland) \\
\hline Triton X 100 & Sigma-Aldrich (München, Deutschland) \\
\hline Rotiphorese® Gel 40 & Roth (Karlsruhe, Deutschland) \\
\hline
\end{tabular}

\subsection{Materialien}

\begin{tabular}{|l|l|l|}
\hline Bezeichnung & Spezifizierung & Hersteller \\
\hline $\begin{array}{l}\text { PVDF Transfer } \\
\text { Rembranen }\end{array}$ & Hybond-P & GE Healthcare (Freiburg, Deutschland) \\
\hline ReadyStrip IPG $17 \mathrm{~cm}$ & $\mathrm{pH} \mathrm{3-10} \mathrm{linear}$ & Bio-Rad (München, Deutschland) \\
\hline Zellkulturflaschen & $75 \mathrm{~cm}^{2}$ & Sarstedt (Nümbrecht, Deutschland) \\
\hline sterile Pipetten & $5 \mathrm{ml}, 10 \mathrm{ml}, 25 \mathrm{ml}$ & Sarstedt (Nümbrecht, Deutschland) \\
\hline Küvetten & $10 \times 4 \times 45 \mathrm{~mm}$ & Sarstedt (Nümbrecht, Deutschland) \\
\hline ECL-Hyperfilm & & $\begin{array}{l}\text { (Amersham Biosciences, } \\
\text { Buckinghamshire, England) }\end{array}$ \\
\hline Filterpapier (gefaltet) & $3 \mathrm{hw}$ & Sartorius (Göttingen, Deutschland) \\
\hline
\end{tabular}




\subsection{Instrumente}

\begin{tabular}{|c|c|c|}
\hline Anwendung & Modell & Hersteller \\
\hline Elektrophorese & PowerPac 3000 & Bio-Rad (München, Deutschland) \\
\hline ELISA & 1420 Victor & Wallac (Turku, Finnland) \\
\hline $\begin{array}{l}\text { Gelkammern und } \\
\text { Zubehör }\end{array}$ & $\begin{array}{l}\text { Mini Protean II }{ }^{\mathrm{TM}} \\
\text { Protean II xi }\end{array}$ & Bio-Rad (München, Deutschland) \\
\hline Horizontaler Shaker & HS 501 & $\begin{array}{l}\text { IKA Labortechnik (Straufen, } \\
\text { Deutschland) }\end{array}$ \\
\hline Inkubator & Cellstar & Nunc (Wiesbaden, Deutschland) \\
\hline Isofokussierung & Protean IEF Cell & Bio-Rad (München, Deutschland) \\
\hline Lichtmikroskop & $\mathrm{BH} 2$ & Olympus (Hamburg, Deutschland) \\
\hline Orbitaler Shaker & 3031 & GFL (Burgwedel, Deutschland) \\
\hline pH-Meter & MP-220 & Mettler-Toledo (Steinbach, Deutschland) \\
\hline Photometer & Bio Photmeter & Eppendorf (Hamburg, Deutschland) \\
\hline Magnetrührer & RCT & IKA-Combimag (Straufen, Deutschland) \\
\hline Scanner & CanoScan8400F & Canon (Krefeld, Deutschland) \\
\hline Vakuumtrockner & SVC 100 & Savant Instruments (Farmingdale, USA) \\
\hline Thermomixer & Comfort & Eppendorf (Hamburg, Deutschland) \\
\hline Ultraschallwasserbad & Transsonic $310 / \mathrm{H}$ & Elma ${ }^{\circledR}$ (Pforzheim, Deutschland) \\
\hline Wasserbad & & GFL (Burgwedel, Deutschland) \\
\hline Waagen & $\begin{array}{l}\text { BL } 150 \mathrm{~S} \\
\text { CP } 3202 \mathrm{P}\end{array}$ & Sartorius (Göttingen, Deutschland) \\
\hline Westernblot & $\begin{array}{l}\text { Trans-Blot DS } \\
\text { Semi-Dry } \\
\text { Transfer Cell }\end{array}$ & Bio-Rad (München, Deutschland) \\
\hline Zentrifugen & $\begin{array}{l}5810 \mathrm{R}, 5415 \\
5415 \mathrm{D}\end{array}$ & Eppendorf (Hamburg, Deutschland) \\
\hline Vortexer & REAX 200 & Heidolph (Schwabach, Deutschland) \\
\hline $\begin{array}{l}\text { Q-TOF } \\
\text { (Massenspektrometer) }\end{array}$ & $\begin{array}{l}\text { Ultima Global } \\
\text { coupled with } \\
\text { CapLC system }\end{array}$ & Micromass (Manchester, UK) \\
\hline
\end{tabular}




\subsection{Antikörper}

\subsubsection{Primäre Antikörper}

\begin{tabular}{|c|c|c|c|}
\hline Antikörper & Spezifizierung & Verdünnung & Hersteller/Referenz \\
\hline $\begin{array}{l}\text { Anti-PrP-12f10- } \\
\text { Antikörper }\end{array}$ & $\begin{array}{l}\text { Maus, } \\
\text { monoklonal }\end{array}$ & $1: 1000$ & (Krasemann et al. 1999) \\
\hline $\begin{array}{l}\text { Anti-14-3-3gamma- } \\
\text { Antikörper }\end{array}$ & $\begin{array}{l}\text { Rabbit, } \\
\text { polyklonal }\end{array}$ & $1: 4000$ & $\begin{array}{l}\text { SantaCruz Biotechnology } \\
\text { (Santa Cruz, USA) }\end{array}$ \\
\hline $\begin{array}{l}\text { Anti-Transgelin2- } \\
\text { Antikörper }\end{array}$ & $\begin{array}{l}\text { Maus, } \\
\text { monoklonal }\end{array}$ & $1: 625$ & $\begin{array}{l}\text { ProteinTech Group, Inc. } \\
\text { (Chicago, USA) }\end{array}$ \\
\hline $\begin{array}{l}\text { Anti-AnnexinV- } \\
\text { Antikörper }\end{array}$ & $\begin{array}{l}\text { Maus, } \\
\text { monoklonal }\end{array}$ & $1: 500$ & Abcam (Cambridge, UK) \\
\hline $\begin{array}{l}\text { Anti-human-p53- } \\
\text { Antikörper }\end{array}$ & $\begin{array}{l}\text { Maus, } \\
\text { monoklonal }\end{array}$ & $1: 250$ & $\begin{array}{l}\text { BD Biosciences (Franklin } \\
\text { Lakes, USA) }\end{array}$ \\
\hline $\begin{array}{l}\text { Anti- } \beta \text {-Actin- } \\
\text { Antikörper }\end{array}$ & $\begin{array}{l}\text { Maus, } \\
\text { monoklonal }\end{array}$ & $1: 10000$ & Abcam (Cambridge, UK) \\
\hline
\end{tabular}

\subsubsection{Sekundäre Antikörper}

\begin{tabular}{|l|l|l|l|}
\hline Antikörper & Spezifizierung & Verdünnung & Hersteller \\
\hline $\begin{array}{l}\text { Anti-Rabbit-IgG- } \\
\text { Antikörper }\end{array}$ & Ziege & $1: 5000$ & $\begin{array}{l}\text { Jackson ImmunoResearch } \\
\text { Laboratories, Inc. } \\
\text { (Newmarket, UK) }\end{array}$ \\
\hline Anti-Maus-IgG- & Ziege & $1: 5000$ & $\begin{array}{l}\text { Jackson ImmunoResearch } \\
\text { Laboratories, Inc. } \\
\text { Antikörper }\end{array}$ \\
& $1: 2000$ & (Newmarket, UK) \\
\hline
\end{tabular}

\subsection{Antibiotika}

\begin{tabular}{|l|l|l|}
\hline Antibiotika & Spezifizierung & Hersteller \\
\hline Penicillin/Streptomycin & $10000 \mu \mathrm{g} / \mathrm{ml}$ & Biochrom (Berlin, Deutschland) \\
\hline Geneticin & $50 \mathrm{mg} / \mathrm{ml}$ & Invitrogen (Karlsruhe, Deutschland) \\
\hline
\end{tabular}




\subsection{Proteinstandard Marker und Kits}

\begin{tabular}{|l|l|}
\hline Proteinstandard Marker und Kits & Hersteller \\
\hline Kaleidoscope Prestained standard & Bio-Rad (München, Deutschland) \\
\hline Precision Plus Protein Standards (dual color) & Bio-Rad (München, Deutschland) \\
\hline Cruz Marker Molecular weight standards & $\begin{array}{l}\text { Santa Cruz Biotechnology (Santa } \\
\text { Cruz, USA) }\end{array}$ \\
\hline BetaPrion® BSE EIA Test Kit & $\begin{array}{l}\text { AJ Roboscreen (Leipzig, } \\
\text { Deutschland) }\end{array}$ \\
\hline Biorad Protein Assay (Farbstoff-Konzentrat) & Bio-Rad (München, Deutschland) \\
\hline
\end{tabular}

\subsection{Zelllinien und Nährmedien}

Es wurden stabil transfizierte humane Neuroblastomzellen (SH-SY5Y) verwendet, die das humane Prionprotein Gen überexprimieren. Als Kontrollzellen dienten native (nicht-transfizierte) SH-SY5Y-Zellen.

Beide Zelllinien wurden mir freundlicherweise von C. Behrens, Insitut für Neuropathologie, Universitätsmedizin Göttingen, zur Verfügung gestellt.

\subsubsection{Nährmedien}

\section{Medium für nicht-transfizierte SH-SY5Y-Zellen:}

Dulbecco's modified Eagle's Medium

10\% Fötales Bovines Serum

$1 \%$ Penicillin/Streptomycin

$1 \%$ L-Glutamine

\section{Medium für stabil transfizierte SH-SY5Y-Zellen:}

Dulbecco's modified Eagle's medium

$10 \%$ Fötales Bovines Serum

$1 \%$ Penicillin/Streptomycin

$1 \%$ L-Glutamine

$0,4 \%$ Geneticin 


\subsection{Puffer und Lösungen}

Äquilibrationspuffer I: 6M Urea, 2\% SDS, 30\% Glycerin, 150mM Tris pH=8,8, $2 \%(\mathrm{w} / \mathrm{v})$ DTT in ${ }_{\mathrm{dd}} \mathrm{H}_{2} \mathrm{O}$

Äquilibrationspuffer II: 6M Urea, 2\% SDS, 30\% Glycerin, 150mM Tris pH=8,8, 2,5\% (w/v) Iodacetamid, Bromophenolblau für eine leicht blaue Lösung in ${ }_{\mathrm{dd}} \mathrm{H}_{2} \mathrm{O}$

Blockierungspuffer für Westernblot: 5\% Milchpulver in PBS-T

ECL-Lösung 1: 2,5mM Luminol, 0,4mM p-Coumarsäure, 0,1M Tris- $\mathrm{HCl}$ pH=8,5 in ${ }_{d} \mathrm{H}_{2} \mathrm{O}$

ECL-Lösung 2: $0,018 \% \mathrm{H}_{2} \mathrm{O}_{2}, 0,1 \mathrm{M}$ Tris $\mathrm{pH}=8,5$ in ${ }_{\mathrm{d}} \mathrm{H}_{2} \mathrm{O}$

Entwicklungslösung für Silberfärbung: $6 \% \quad \mathrm{Na}_{2} \mathrm{CO}_{3}, 0,0185 \%$ Formaldehyd, $16 \mu \mathrm{M} \mathrm{Na}_{2} \mathrm{~S}_{2} \mathrm{O}_{3}$ in ${ }_{d d} \mathrm{H}_{2} \mathrm{O}$

Fixierungslösung für Silberfärbung: $50 \%$ Methanol, $12 \%$ Essigsäure in ${ }_{\mathrm{dd}} \mathrm{H}_{2} \mathrm{O}$

Lysepuffer: 7M Urea, 2M Thiourea, 4\% CHAPS, 2\% Ampholyte, 1\% DTT, $1 \%$ Proteaseinhibitor in ${ }_{\mathrm{dd}} \mathrm{H}_{2} \mathrm{O}$

PBS: 9,55 g PBS-Pulver in $11_{\mathrm{dd}} \mathrm{H}_{2} \mathrm{O}$

PBS-T: 0,1\% Tween-20 in PBS

Proteaseinhibitor: $0,1 \mathrm{mM}$ PMSF, $10 \mu \mathrm{M}$ TPCK, $10 \mu \mathrm{M}$ TLCK in trockenem Methanol

SDS-Laufpuffer (Elektrophoresepuffer): $192 \mathrm{mM}$ Glycin, 0,1\% SDS, 25mM Tris

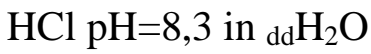

SDS-Sammelgel für 1D-Elektrophorese: $0,49 \mathrm{M}$ Tris $\mathrm{HCl} \mathrm{pH}=6,8,0,1 \%$ SDS, 7,4\% Acrylamid, 0,1\% APS, 0,11\% TEMED in ${ }_{d} \mathrm{H}_{2} \mathrm{O}$

SDS-Trenngel für 1D-Elektrophorese: $0,37 \mathrm{M}$ Tris $\mathrm{HCl} \mathrm{pH}=8,8,0,1 \%$ SDS, $12 \%$ Acrylamid, 0,1\% APS, 0,04\% TEMED in ${ }_{d} \mathrm{H}_{2} \mathrm{O}$

SDS-Gel für 2D-Elektrophorese: $0,367 \mathrm{M}$ Tris $\mathrm{HCl} \mathrm{pH}=8,8,0,1 \%$ SDS, $12,5 \%$ Acrylamid, $0,05 \%$ APS, $0,026 \%$ TEMED in ${ }_{d d} \mathrm{H}_{2} \mathrm{O}$

Sensitivierungslösung für Silberfärbung: $0,8 \mathrm{mM} \mathrm{Na}_{2} \mathrm{~S}_{2} \mathrm{O}_{3}$ in ${ }_{\mathrm{dd}} \mathrm{H}_{2} \mathrm{O}$

Silbernitratlösung für Silberfärbung: $\mathrm{AgNO}_{3} 0,2 \%, 0,026 \%$ Formaldehyd in ${ }_{\mathrm{dd}} \mathrm{H}_{2} \mathrm{O}$ Transferpuffer für Westernblot: $192 \mathrm{mM}$ Glycin, 20\% Methanol, 25mM Tris-HCl $\mathrm{pH}=8,3$ in ${ }_{\mathrm{d}} \mathrm{H}_{2} \mathrm{O}$

OKANO: $0,1 \mathrm{M}$ Tris Base $\mathrm{pH}=8,0,0,2 \mathrm{M} \mathrm{NaCl}, 0,5 \%$ Triton $\mathrm{X}$ 100, 0,1mM EDTA, $0,002 \%$ SDS, $0,1 \%$ BSA in ${ }_{d} \mathrm{H}_{2} \mathrm{O}$

Rehydrierungspuffer: $8 \mathrm{M}$ Urea, 2,5M Thiourea, 4\% CHAPS, 66mM DTT, 0,5\% Ampholyte, Bromophenolblau für eine leicht hellblaue Lösung in ${ }_{d d} \mathrm{H}_{2} \mathrm{O}$ 
Verdaupuffer ohne Trypsin: $0,5 \% 1 \mathrm{M} \mathrm{CaCl}_{2}, 2,5 \% \quad 1 \mathrm{M}$ Ammoniumbikarbonat in ${ }_{\mathrm{dd}} \mathrm{H}_{2} \mathrm{O}$

Verdaupuffer mit Trypsin: $1,25 \%$ Trypsin, $\quad 0,5 \% \quad 1 \mathrm{M} \quad \mathrm{CaCl}_{2}, \quad 2,5 \% \quad 1 \mathrm{M}$ Ammoniumbikarbonat in ${ }_{\mathrm{dd}} \mathrm{H}_{2} \mathrm{O}$ 


\section{$3 \quad$ Methoden}

\subsection{Zellkultur}

Die Zellkulturexperimente wurden grundsätzlich unter sterilen Bedingungen durchgeführt.

\subsubsection{Kultivierung von nicht-transfizierten und stabil mit PRNP transfizierten SH-SY5Y-Zellen}

In dieser Arbeit wurden nicht-transfizierte humane Neuroblastomzellen SH-SY5Y und stabil mit dem Prionproteingen (PRNP) transfizierte SH-SY5Y-Zellen in Kultur gehalten. Die stabile Transfektion bewirkt die Überexpression des zellulären Prionproteins $\left(\mathrm{PrP}^{\mathrm{c}}\right) . \mathrm{Um}$ den Prionprotein-Vektor nicht zu verlieren, benötigten die transfizierten Zellen zusätzlich das Antibiotikum Geniticin in ihrem Nährmedium. Auf dem Prionprotein-kodierenden Vektor liegt ein Bereich, der eine Resistenz gegen dieses Antibiotikum verursacht. Nicht-transfizierte Zellen besitzen diese Resistenz nicht und werden durch Zugabe dieses Antibiotikums abgetötet. Falls die transfizierten Zellen im Laufe ihres Teilungszyklus den Vektor verlieren, verlieren sie ihre Geneticinresistenz und sterben unter Geniticinzugabe ab. Somit ergibt sich durch den Zusatz von 0,4\% Geneticin zum Nährmedium der transfizierten Zellen eine Kultur, die ausschließlich aus $\operatorname{PrP}^{\mathrm{c}}$-überexprimierenden Zellen besteht.

Die Zellen wurden in $75-\mathrm{cm}^{2}$-Zellkulturflaschen mit je $10 \mathrm{ml}$ Zellkulturmedium bei $37^{\circ} \mathrm{C}$ unter $5 \% \mathrm{CO}_{2}$ und $95 \%$ Luftfeuchtigkeit kultiviert. Bei einer Zelldichte von ungefähr 70\% wurden die Zellen auf neue Kulturflaschen aufgeteilt (1:5, alle 3-5 Tage). Die Zellen wachsen adhärent am Boden der Zellkulturflasche, ließen sich jedoch durch vorsichtiges Spülen mit frischem Nährmedium ablösen.

\subsection{Herstellung von Zelllysaten und Proteinextrakten}

Die Herstellung der Lysate erfolgte nach ca. 20 Passagen der Zellen. Es wurde dabei darauf geachtet, dass die Anzahl der Passagen bei $\operatorname{PrP}^{\mathrm{c}}$-überexprimierenden Zellen und Kontrollzellen jeweils übereinstimmte. Um Zelllysate für 2D-Elektrophorese (2DE) oder Westernblots herzustellen, wurde zunächst das Nährmedium aus den 
Zellkulturflaschen abpipettiert und restliches Medium durch zweimaliges spülen mit gekühltem PBS von den Zellen entfernt. Anschließend wurden die Zellen mit einem Gummizellschaber vom Flaschenboden abgekratzt und in kaltem PBS gesammelt, danach zentrifugiert bei $+4^{\circ} \mathrm{C}, 4000$ x g für $20 \mathrm{Min}$. Der Überstand wurde verworfen und das Pellet erneut in kaltem PBS gelöst und in einer Mikrozentrifuge bei $+4^{\circ} \mathrm{C}$, 13200rpm für 10 Min. abzentrifugiert. Der Überstand wurde wiederum verworfen und der Bodensatz in $200 \mu 1$ Lysepuffer gelöst. Nach erneutem Zentrifugieren $\left(+4^{\circ} \mathrm{C}\right.$, 13200rpm, 10 Min.) wird der Überstand, in dem sich nun die Proteine befinden, vorsichtig abpipettiert und gesammelt. Der Vorgang wird mit 100 $\mu 1$ Lysepuffer wiederholt. Die Lysate wurden zu jeder Zeit auf Eis gelegt, anschließend bei $-20^{\circ} \mathrm{C}$ eingefroren.

\subsection{Proteinbestimmung nach Bradford}

Die Proteinkonzentration der Zelllysate wurde mit der Methode nach Bradford bestimmt (Bradford 1976). Diese photometrische Messmethode beruht darauf, dass sich das Absorptionsmaximum des ungebundenen Farbstoffes Coomassie-BrillantBlau G-250 (CBBG) in saurer Lösung bei 465nm befindet, sich jedoch durch Bindung an Proteine auf 595nm verschiebt. Die Zunahme der Absorption durch die Komplexbildung ist ein Maß für die Proteinkonzentration. Die Reaktionslösung mit dem CBBG-Farbstoff wurde hergestellt, indem das Farbstoff-Konzentrat (Biorad Protein Assay) mit ${ }_{d d} \mathrm{H}_{2} \mathrm{O}$ im Verhältnis 1:4 verdünnt und anschließend durch ein gefaltetes Filterpapier filtriert wurde. Aus der BSA-Proteinstandardlösung wurde ebenfalls in ${ }_{{ }_{d d}} \mathrm{H}_{2} \mathrm{O}$ eine Verdünnungsreihe mit Proteinkonzentrationen von 50 bis $1000 \mu \mathrm{g} / \mu 1$ hergestellt. Die Zelllysate wurden 1:40 oder 1:20 verdünnt. Jeweils $20 \mu 1$ der Proteinstandards oder verdünnten Proben wurden mit $980 \mu 1$ der Farbstoffverdünnung gemischt. Nach einer Inkubationszeit von 15 Minuten wurde die Absorption der Proben bei einer Wellenlänge von 595nm im Photometer gemessen. Für die Berechnung der Proteinkonzentrationen wurde die Microsoft Office 2003 Excel Software benutzt. 


\subsection{Westernblot nach eindimensionaler SDS-PAGE}

Zum Nachweis bestimmter Proteine in den Lysaten der SH-SY5Y-Zellen wurden nach eindimensionaler Gelelektrophorese Westernblots durchgeführt.

\subsubsection{SDS-Polyacrylamidgelelektrophorese (SDS-PAGE)}

Die SDS-Polyacrylamidgelelektrophorese (SDS-PAGE) ist eine Technik, die dazu dient, Proteine nach ihrem Molekulargewicht aufzutrennen. Dabei wird durch Anlage einer elektrischen Spannung eine Bewegung der entsprechend vorbehandelten, negativ geladenen Proteinproben durch das Gel bewirkt. Kleine Proteine wandern schneller und weiter als größere. Das Gel besteht aus einer kontinuierlich quervernetzten Polymermatrix (Polyacrylamid/Bisacrylamid). Die Quervernetzung wird durch freie Radikale verursacht, die durch die Zugabe von APS und TEMED entstehen. Zweiphasige Gele wurden verwendet, um die Proteine zunächst zu sammeln und anschließend anhand ihres Molekulargewichts $\mathrm{zu}$ trennen (7\% Sammelgel, $12 \%$ Trenngel). Die kleinen SDS-Gele $(8 \times 10 \mathrm{~cm})$ mit einer Dicke von $1,5 \mathrm{~mm}$ wurden im Mini Protean $\mathrm{II}^{\mathrm{TM}}$ System (Bio-Rad) hergestellt. Zunächst wurde 12\%iges Trenngel gegossen und gegen Verdunstung mit Isopropanol überschichtet. Nach einer Stunde waren die Gele polymerisiert, so dass Isopropanol abgegossen und das Sammelgel auf das Trenngel gegossen werden konnte. Das Trenngel musste mindestens 30 Min. polymerisieren.

Pro Geltasche wurden gleiche Proteinmengen verwendet und im Verhältnis 1:4 mit dem Probenpuffer Roti®Load gemischt. Um Sekundär- und Tertiärstrukturen der Proteine aufzuheben wurden die Proben für $5 \mathrm{Min}$. bei $95^{\circ} \mathrm{C}$ im Thermomixer erhitzt und dadurch denaturiert. Als Positivkontrolle wurden bei Bedarf 2ng rekombinantes Prionprotein (AJ Roboscreen, Leipzig, Deutschland) eingesetzt, welches wie die anderen Proben ebenfalls mit dem Probenpuffer Roti®Load und Hitze vorbehandelt wurde. Anschließend wurden die Proben auf die SDS-Gele aufgetragen. Um die Banden später im Westernblot ihrem Molekulargewicht zuordnen zu können, lief gleichzeitig ein Molekulargewichtsmarker mit. Die Elektrophorese lief unter konstanter Voltzahl bei 120V für etwa zwei Stunden in SDS-Laufpuffer ab, bis die Bromophenolblaufront der Roti®Load-Lösung den unteren Rand des Trenngels erreichte. 


\subsubsection{Westernblot und Immunodetektion}

Der oben beschriebenen Auftrennung der Proteine durch die SDS-PAGE folgte der Westernblot, wobei die Proteine auf Polyvinyliden Difluorid Membranen (PVDFMembranen) übertragen wurden. Vor Beginn des Blots wurden die Membranen einige Sekunden in Methanol inkubiert und anschließend in Transferpuffer gelegt. Der Blot lief bei Raumtemperatur für eine Stunde mit konstanter Ampèrezahl, 1mA pro $\mathrm{cm}^{2}$ Membran. Danach wurden die Membranen bei Raumtemperatur für eine Stunde unter leichtem Schütteln in Blockierungspuffer fixiert und anschließend mit PBS-T und OKANO gewaschen (1 x 5 Min. PBS-T, 1 x 15 Min. OKANO, 1 x 5 Min. OKANO, 1 x 5 Min. PBS-T).

Zur Immunodetektion wurden die Membranen danach über Nacht bei $4^{\circ} \mathrm{C}$ mit dem ersten Antikörper inkubiert (für Antikörper siehe Kapitel 2.4). Am nächsten Tag wurden die Membranen wiederum gründlich mit PBS-T gewaschen (3 x 5 Minuten PBS-T, 1 x 15 Minuten PBS-T). Anschließend wurde der dazugehörige zweite Antikörper (siehe Kapitel 2.4) aufgetragen und unter Schwenken für eine Stunde bei Raumtemperatur inkubiert. Die Verdünnungen für primäre Antikörper wurden immer in 5\% Milchpulver in PBS-T hergestellt, die für sekundäre Antikörper in 1\% Milchpulver in PBS-T. Die zweiten Antikörper sind mit dem Enzym Peroxidase konjugiert, so dass nach Eintauchen der Membranen in ECL-Entwicklungslösung auf ECL-Hyperfilm eine Immunreaktion nachgewiesen werden kann. Kurz vor Verwendung wird die Entwicklungslösung durch Mischung von ECL-Lösung 1 und 2 im Verhältnis 1:1 hergestellt (siehe Kapitel 2.8). 


\subsection{PrP ${ }^{\mathrm{c}}$-Sandwich-ELISA}

Der ELISA wurde zur Auswertung der $\operatorname{PrP}^{\mathrm{c}}$-Konzentrationen in den Lysaten nativer und $\operatorname{PrP}^{\mathrm{c}}$-überexprimierender SH-SY5Y-Zellen durchgeführt. Es wurde der BetaPrion ${ }^{\circledR}$ BSE EIA Test Kit (AJ Roboscreen, Leipzig, Deutschland) verwendet.

Dabei wurden jeweils gleiche Proteinmengen $(50 \mu \mathrm{g})$ der Zelllysate auf die Mikrotiterplatte aufgetragen und für 60 Minuten bei $37^{\circ} \mathrm{C}$ inkubiert. Rekombinantes $\operatorname{PrP}^{c}$ wurde als Standard verwendet. Die ELISA-Platte ist mit einem monoklonalen PrP-Antikörper, „Capture-Antibody“, beschichtet, so dass das in den Lysaten enthaltene PrP während der Inkubationszeit an die Antikörper binden kann. Anschließend wurde die Platte dreimalig gewaschen und ein monoklonaler Antikörper hinzugegeben und für 60 Minuten bei $4^{\circ} \mathrm{C}$ inkubiert. Dieser Antikörper ist HRP-gekoppelt, ein Enzym, welches bei Zugabe eines entsprechenden Substrates zu einem Farbreaktion führt. Nach der Inkubation wird überschüssiger Antikörper in fünf weiteren Waschschritten entfernt und es wird die Wasserstoffperoxid- und Tetramethylbenzidin-haltige Entwicklungslösung auf die Mikrotiterplatte aufgetragen. Nachdem die Reaktion gestoppt wurde konnte der Farbumschlag bei 450/620nm gemessen und die $\operatorname{PrP}^{\mathrm{c}}$-Konzentration in $\mathrm{ng} / \mathrm{ml}$ bestimmt werden.

\subsection{Zweidimensionale Gelelektrophorese}

Bei der zweidimensionalen Gelelektrophorese werden Proteine zunächst mittels isoelektrischer Fokussierung (IEF) nach ihrem isoelektrischen Punkt (IP) (erste Dimension, horizontal) aufgetrennt und anschließend mittels SDS-PAGE Gelelektrophorese (zweite Dimension, vertikal) nach ihrem Molekulargewicht. Dadurch entsteht ein zweidimensionales Bild.

\subsubsection{Erste Dimension: Isoelektrische Fokussierung}

Der isoelektrische Punkt ist derjenige $\mathrm{pH}-$ Wert, an dem ein Protein in einem elektrischen Feld nicht mehr wandert, und ist abhängig von den geladenen Gruppen des Proteins. Aufgrund der amphoterischen Eigenschaften von Aminosäuren sind Proteine bei $\mathrm{pH}-$ Werten unterhalb ihres IPs positiv und bei $\mathrm{pH}-$ Werten oberhalb ihres IPs negativ geladen. Unter dem Einfluss eines elektrischen Feldes wird das $\mathrm{pH}-$ Gefälle durch die Trägerampholyte verursacht und die Proteine wandern zu ihren IPs. 


\subsubsection{Probenvorbereitung und Rehydrierung}

Für die isoelektrische Fokussierung wurden $17 \mathrm{~cm}$ lange Gelstreifen (ReadyStrip IPG) mit linearem pH-Bereich von 3-10 verwendet, die zunächst 12-16 Stunden rehydriert wurden. Die eingesetzte Proteinmenge für die Gele die später mit Silberfärbung angefärbt werden sollen, betrug $130 \mu \mathrm{g}$ Protein pro Gel. Für die passive Rehydrierung der IPG-Streifen, d.h. ohne Anlage eines elektrischen Feldes, wurde auf jede Spur der Isofokussierungskassette 335 $\mu$ l Gesamtvolumen aufgetragen, welches sich aus Rehydrierungspuffer und derjenigen Menge Zelllysat zusammensetzte, welche $130 \mu \mathrm{g}$ Protein enthielt. Anschließend wurde die Schutzfolie von den Gelstreifen entfernt, ohne dabei die Gelseite zu berühren und die Streifen luftblasenfrei mit der Gelseite nach unten in die mit Rehydrierungspuffer und Protein befüllten Spuren gelegt. Es folgte eine Inkubationszeit von einer Stunde bei Raumtemperatur. Danach wurden die IPG-Streifen mit Mineralöl überschichtet, um eine Verdunstung der Probe während der Rehydratationszeit zu verhindern.

\subsubsection{Isoelektrische Fokussierung}

Die isoelektrische Fokussierung lief nach folgendem Schema ab:

1. Schritt: $500 \mathrm{~V}$ für $1 \mathrm{Std}$.

2. Schritt: 1000 V für 1 Std.

3. Schritt: 8000 V bis 32000 Voltstunden erreicht waren.

4. Schritt: 500V für 10 Std. als Reserve.

Nach Erreichen der 32000 Voltstunden wurden die IPG-Streifen für die SDS-PAGE äquilibriert.

\subsubsection{3 Äquilibrierung der Proteine für die zweite Dimension}

Für die zweite Dimension der Gelelektrophorese muss eine Umpufferung (Äquilibrierung) der durch die IEF aufgetrennten Proteine durchgeführt werden. Dieser Vorgang wird benötigt, um die Proteine aus dem IPG-Streifen auf das SDSGel übertragen zu können. Disulfidbrücken müssen reduziert und die entstehenden Sulfhydrylgruppen der Cysteinreste alkyliert werden, die Eigenladungen der Proteine werden dabei überdeckt.

Die Äquilibrierung verlief in zwei Schritten: zunächst wurden die Gelstreifen unter Schwenken 20 Min. in Äquilibrationspuffer I, anschließend ebenfalls für 20 Min. in Äquilibrationspuffer II inkubiert (für Puffer siehe Kapitel 2.8). 


\subsubsection{Zweite Dimension: SDS-PAGE}

Für die Gelelektrophorese wurden $17 \mathrm{~cm}$ große $12 \%$ SDS Gele im Protean II xi System (Bio-Rad) gegossen. Die äquilibrierten IPG-Streifen wurden vorsichtig und möglichst ohne Luftblasen auf die polymerisierten Gele aufgelegt. Außerdem wurde zum Nachweis des Molekulargewichts auf jedes Gel am linken Rand ein Proteinmarker aufgetragen, der auf schmalen Filterpapierstreifen aufgetragen wurde. Über Nacht lief die Elektrophorese bei konstanter Voltzahl von $110 \mathrm{~V}$ in SDSLaufpuffer unter Wasserkühlung. Direkt an die Gelelektrophorese schloss sich die Silberfärbung an.

\subsection{Silberfärbung}

Um die Proteinspots sichtbar zu machen, wurde die Silberfärbung nach dem Protokoll von Blum (Blum et al. 1987) durchgeführt. Die Silberfärbung ist eine sehr sensitive Färbemethode, die auch Proteinspots mit 0,5-1,2ng Proteinkonzentration detektierbar macht.

Nach der SDS-PAGE wurden die Gele für ein bis maximal zwei Stunden in Fixierungslösung gelegt. Der gesamte Färbevorgang findet bis zum letzten Schritt unter gleichmäßigem horizontalem Schwenken der Gele statt. Nach der Fixierung wurden sie zunächst $2 \times 20$ Min. in 50\%igem Ethanol, dann für 1 x 20 Min. in 30\%igem Ethanol gewaschen. Anschließend fand die Sensitivierung statt, wobei die Gele für genau 60 Sekunden in 0,02\%igem Natriumthiosulfat geschwenkt wurden, um die Empfindlichkeit der Proteine für die nachfolgende Behandlung zu steigern. Reste der Sensitivierungslösung wurden danach mit ${ }_{\mathrm{dd}} \mathrm{H}_{2} \mathrm{O}$ mit Waschschritten von 3 x 20 Sekunden entfernt. Dann wurden die Gele für 20 Min. in Silbernitratlösung gefärbt. Nachfolgend wurden die Gele erneut mit ${ }_{d d} \mathrm{H}_{2} \mathrm{O}$ für 3 x 20 Sekunden gewaschen und dann für 2 bis 10 Min. mit Entwicklungslösung inkubiert (nach visuellem Eindruck) bis alle Spots sichtbar waren. Die Entwicklung wurde durch Schwenken in Fixierungslösung für 5 Min. gestoppt. Gelagert wurden die gefärbten Gele in 5\% Essigsäure (für alle Lösungen siehe Kapitel 2.8). Für eine längerfristige Aufbewahrung wurden die Gele für $1 \frac{1}{2} 2$ Stunden bei $80^{\circ} \mathrm{C}$ getrocknet. 


\begin{tabular}{|l|l|l|}
\hline 1. Fixierung & $\begin{array}{l}\text { max. 2 Std. } \\
\text { (damit kompatibel mit MALDI) }\end{array}$ & Fixierungslösung \\
\hline 2. Waschen & $\begin{array}{l}2 \times 20 \mathrm{Min} . \\
1 \times 20 \mathrm{Min} .\end{array}$ & $\begin{array}{l}50 \% \mathrm{EtOH} \\
30 \% \mathrm{EtOH}\end{array}$ \\
\hline 3. Sensitivierung & genau 60 Sek. & Sensitivierungslösung \\
\hline 4. Waschen & $3 \times 20$ Sek. & $\mathrm{dd}_{2} \mathrm{O}$ \\
\hline 5. Silberfärbung & 20 Min. & Silbernitratlösung \\
\hline 6. Waschen & $3 \times 20$ Sek. & $\mathrm{dd}_{2} \mathrm{O}$ \\
\hline 7. Entwicklung & $2-10$ Min. & Entwicklungslösung \\
\hline 8. Stoppen & ca. 10 Min. & Fixierungslösung \\
\hline 9. Lagerung & einige Tage & $5 \%$ Essigsäure \\
\hline
\end{tabular}

\subsection{Trypsinverdau}

Um die massenspektrometrische Bestimmung der relevanten Proteine durchführen zu können, mussten diese zunächst aus den silbergefärbten Gelen ausgeschnitten und mit Trypsin vorbehandelt werden. Trypsin schneidet direkt unterhalb der Aminosäuren Lysin und Arginin, so dass durch den Verdau zahlreiche Peptide entstehen. Jedes Protein weist dabei ein charakteristisches Muster an unterschiedlichen Peptiden auf und kann darüber mittels Q-TOF eindeutig identifiziert werden. Der Trypsinverdau wurde nach dem abgewandelten Protokoll von Shevchchenko et al. (Shevchenko et al. 1996) durchgeführt.

Die relevanten Spots wurden mit einem sterilen Skalpell aus den silbergefärbten Gelen ausgeschnitten und jeweils in ein sauberes 0,5ml Eppendorf Cup gegeben. Die dabei entstandenen $1-2 \mathrm{~mm}^{2}$ großen Gelstücke wurden für 15 Min. in ${ }_{\mathrm{dd}} \mathrm{H}_{2} \mathrm{O}$ gewaschen. Danach wurden die silbergefärbten Gelstücke mittels $15 \mathrm{mM}$ Kaliumferricyanid/50mM Natriumthiosulfat inkubiert bis sie vollständig farblos waren und anschließend mit ${ }_{d d} \mathrm{H}_{2} \mathrm{O}$ gewaschen. Die Gelstücke wurden nun für 15 Min. in 50\% ACN inkubiert, anschließend in $100 \%$ ACN. Danach wurden sie für 5 Min. in 100mM Ammoniumbikarbonat äquilibriert, dann für 15 Min. in einer Lösung aus 50mM Ammoniumbikarbonat/50\% ACN inkubiert und anschließend für ca. 15 Min. mit dem Vakuumtrockner getrocknet. Nach dem Trocknen wurden die Gelstücke auf Eis mit dem trypsinhaltigen Verdaupuffer rehydriert und für 45 Min. auf Eis inkubiert. Hinterher folgte über Nacht die Inkubation mit dem Verdaupuffer 
ohne Trypsin bei $37^{\circ} \mathrm{C}$. Der Überstand wurde am nächsten Tag in neue $0.5 \mathrm{ml}$ Eppendorf Cups gegeben und die verbleibenden Peptide in mehreren Schritten aus den Gelstïcken extrahiert und ebenfalls in den neuen Cups gesammelt. Zunächst wurden die Peptide mit 0,1\% TFA für 30 Min. im Ultraschallwasserbad aus den Gelstücken gelöst. Dieser Vorgang wurde anschließend mit 30\% ACN in 0,1\% TFA, dann mit $60 \%$ ACN in $0,1 \%$ TFA und zuletzt mit $100 \%$ ACN wiederholt. Der in den neuen Eppendorf Cups gesammelte Überstand, der die Peptide enthielt, wurde mit dem Vakuumtrockner getrocknet und konnte bis zur massenspektrometrischen Untersuchung bei $-20^{\circ} \mathrm{C}$ eingefroren werden. Zur Analyse wurden die getrockneten Peptide in $0,1 \%$ Ameisensäure gelöst.

\subsection{Massenspektrometrische Proteinidentifikation}

Die massenspektrometrische Untersuchung der Peptidfragmente und die Proteinidentifikation wurden von Dr. A. R. Asif in der Abteilung für Klinische Chemie der Universitätsmedizin Göttingen durchgeführt.

Die Analyse der Peptidfragmente erfolgte über das Q-TOF Ultima Global Massenspektrometer (Micromass, Manchester, UK). Für die Datenerfassung wurde die MassLynx (Version 4.0) Software auf einem Windows NT PC verwendet und anschließend die Daten mittels des Protein-Lynx-Global-Servers (Version 2.1) (Micromass, Manchester, UK) weiterverarbeitet. Die Proteine wurden dann durch die MSDB und Swiss-Prot Datenbanken mittels Mascot Search Engine identifiziert.

\subsection{Vergleich und statistische Auswertung}

Der Vergleich der silbergefärbten 2-DE-Gele erfolgte mit der Software Delta 2D von Decodon (Greifswald, Deutschland). Es wurden pro Gruppe je vier 2-DE-Gele angefertigt und verglichen. Die quantitative Analyse der Westernblots erfolgte mit der Software LabImage (Version 2.52a). Die Ergebnisse wurden jeweils mit dem zweiseitigen $t$-Test für unverbundene Stichproben ausgewertet. Die Unterschiede in der Proteinexpression mit $p$-Werten $<0,05$ wurden als signifikant angesehen. Es wurden drei Signifikanzbereiche festgelegt: * $p<0,05$, ** $p<0,01$ und $* * * \mathrm{p}<$ 0,001 . 


\section{$4 \quad$ Ergebnisse}

In dieser Arbeit wurden die Proteinexpressionsmuster von nativen (nichttransfizierten) SH-SY5Y-Zellen, die nur endogenes $\operatorname{PrP}^{\mathrm{c}}$ exprimieren, mit stabil mit PRNP transfizierten und damit $\operatorname{PrP}^{\mathrm{c}}$-überexprimierenden SH-SY5Y-Zellen mittels 2-DE verglichen.

Die humane Neuroblastomzelllinie SH-SY5Y fand bereits mehrfach in der Prionforschung Verwendung. Neben Versuchen zu Prion-induziertem Nervenzelltod (Thellung et al. 2002, Dupiereux et al. 2006, Martinez und Pascual 2007) und der Untersuchung der biologischen Rolle des N-Terminus des $\operatorname{PrP}^{c}$ (Zeng et al. 2003), wurde auch schon die physiologische Funktion des $\operatorname{PrP}^{c}$ (Watt et al. 2007) anhand dieser Zelllinie untersucht.

Im Rahmen von Experimenten zur Erforschung der Alzheimererkrankung wurden diese Zellen von Kuzuya et al. verwendet. Dort wurden ebenfalls, wie in dieser Arbeit, die nativen SH-SY5Y-Zellen als Kontrollzellen herangezogen (Kuzuya et al. 2007). 


\subsection{Morphologie transfizierter und nicht-transfizierter SH-SY 5 Y-Zellen}

Zwischen den $\mathrm{PrP}^{\mathrm{c}}$-überexprimierenden und den nativen SH-SY5Y-Zellen konnten lichtmichtmikroskopisch keine morphologischen Unterschiede festgestellt werden.

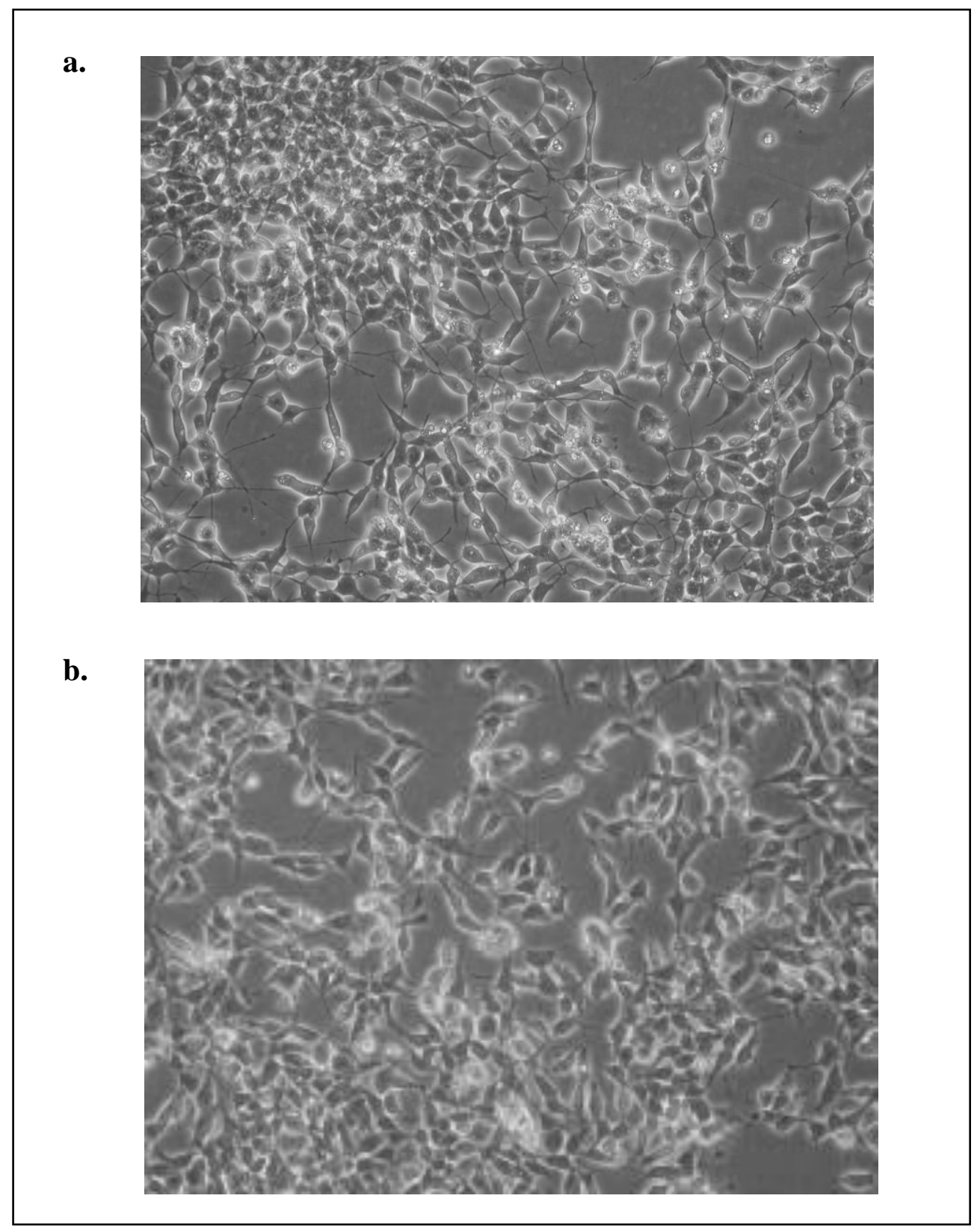

Abbildung 7 Morphologie der SH-SY5Y-Zellen. Lichtmikroskopische Aufnahme mit 10facher Vergrößerung von a. $\operatorname{PrP}^{c}$-überexprimierenden und b. nativen SH-SY5Y-Zellen. Es konnten keine morphologischen Unterschiede festgestellt werden. 


\subsection{Nachweis der $\operatorname{PrP}^{\mathrm{c}}$-Überexpression}

Um die Grundvoraussetzung für die folgenden 2-DE-Experimente zu sichern, musste zunächst der Nachweis erbracht werden, dass die stabil mit PRNP transfizierten SHSY5Y-Zellen im Vergleich $\mathrm{zu}$ den nicht-transfizierten Zellen das $\operatorname{PrP}^{\mathrm{c}}$ überexprimieren. Dazu wurden zwei Verfahren angewandt: der Nachweis der $\operatorname{PrP}^{\mathrm{c}}$ Expression mittels Westernblot und die quantitative Messung der $\operatorname{PrP}^{\mathrm{c}}$-Konzentration mittels ELISA.

\subsubsection{Prionprotein-Westernblot}

Im Westernblot konnte die Überexpression von $\operatorname{PrP}^{\mathrm{c}}$ in den transfizierten Zellen deutlich nachgewiesen werden. In allen angefertigten Blots zeigte sich bei den Lysaten der stabil mit $P R N P$ transfizierten Zellen im Vergleich zu den nur endogenes $\mathrm{PrP}^{\mathrm{c}}$ exprimierenden Kontrollzellen eine deutlich höhere Intensität der Banden im Bereich des für das $\operatorname{PrP}^{\mathrm{c}}$ typischen Molekulargewichts von 27 bis 36kDa. Das rekombinante Prionprotein liegt in unglykosylierter Form vor und wandert daher im elektrischen Feld am weitesten.

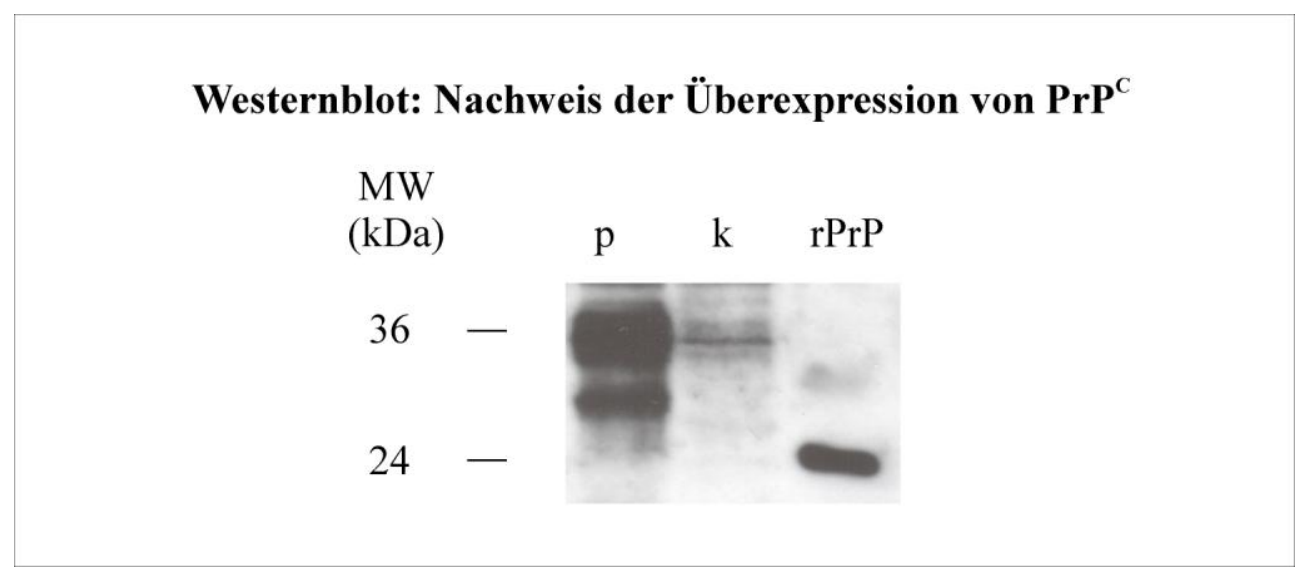

Abbildung 8 Nachweis der PrP ${ }^{\mathrm{c}}$-Expression von stabil mit PRNP transfizierten SH-SY5YZellen (p) und nativen SH-SY5Y-Zellen als Kontrollzellen (k) mittels Westernblot. Die Spuren

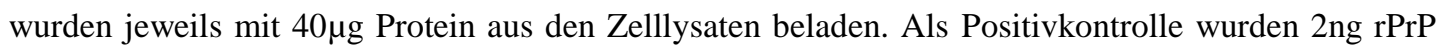
eingesetzt. Die Überexpression des $\operatorname{PrP}^{c}$ in den stabil transfizierten Zellen im Vergleich zu den Kontrollzellen ist deutlich nachweisbar. Der abgebildete Westernblot ist repräsentativ für alle vier durchgeführten Westernblots. 


\subsubsection{Prionprotein-Sandwich-ELISA}

Für die exakte Quantifizierung der $\operatorname{PrP}^{\mathrm{c}}$-Expression wurde ein Sandwich-ELISA mit dem BetaPrion ${ }^{\circledR}$ BSE EIA Test Kit (AJ Roboscreen, Leipzig) durchgeführt. Die $\mathrm{PrP}^{\mathrm{c}}$-Konzentration wurde in $50 \mu \mathrm{g}$ Gesamtprotein aus den Zelllysaten gemessen. In der Kontrollgruppe war die endogene $\operatorname{PrP}^{\mathrm{c}}$-Konzentration größtenteils unterhalb des durch den ELISA detektierbaren Bereichs. Somit konnte für die stabil mit PRNP transfizierten SH-SY5Y-Zellen die Überexpression von $\operatorname{PrP}^{\mathrm{c}}$ nachgewiesen werden. Die relativen Mittelwerte der $\operatorname{PrP}^{\mathrm{c}}$-Level in den $\mathrm{PrP}^{\mathrm{c}}$-überexprimierenden SH-SY5YZellen war knapp 16fach höher $(p<0,001)$ als die in den nativen SH-SY5Y Zellen.

\section{ELISA: PrP ${ }^{\mathrm{C}}$-Konzentration in humanen SH-SY5Y-Zellen}

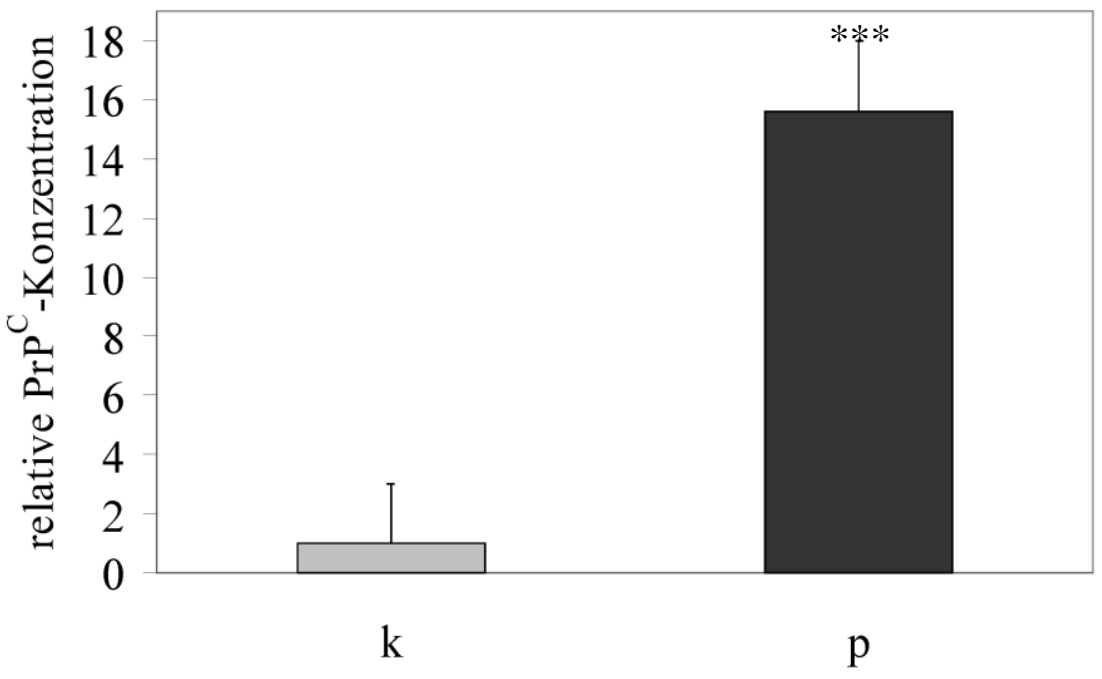

Abbildung 9 Quantitative Untersuchung der PrP $P^{\mathrm{c}}$-Expression von stabil mit PRNP transfizierten SH-SY5Y-Zellen (p) und Kontrollzellen (k) mittels Sandwich-ELISA. Die PrP ${ }^{\mathrm{c}}$ Konzentration in den Kontrollzellen lag weitestgehend unterhalb des für den ELISA detektierbaren Bereichs; daher erfolgt die Angabe der PrP ${ }^{\mathrm{c}}$-Konzentration hier in relativen Werten. Im Vergleich war die $\mathrm{PrP}^{\mathrm{c}}$-Konzentration in den stabil transfizierten Zellen signifikant höher. Signifikanzniveau ***, $p<0,001$. 


\subsection{Proteomanalyse}

Das Proteom von nicht-transfizierten SH-SY5Y-Zellen und stabil mit PRNP transfizierten SH-SY5Y-Zellen wurde verglichen, um Unterschiede in der Proteinexpression zwischen den beiden Gruppen herauszufiltern. Es wurden dabei jeweils vier silbergefärbte 2-DE-Gele verglichen. Die Auswertung mit der Software Delta 2D von Decodon (Greifswald, Deutschland) ergab 18 Proteine, deren Regulation sich zwischen den beiden Gruppen signifikant unterschied (siehe Tabelle 2). Abbildung 10 zeigt ein silbergefärbtes 2-DE-Gel und gibt die Lage der in Tabelle 2 aufgeführten Proteine im Gel wieder.

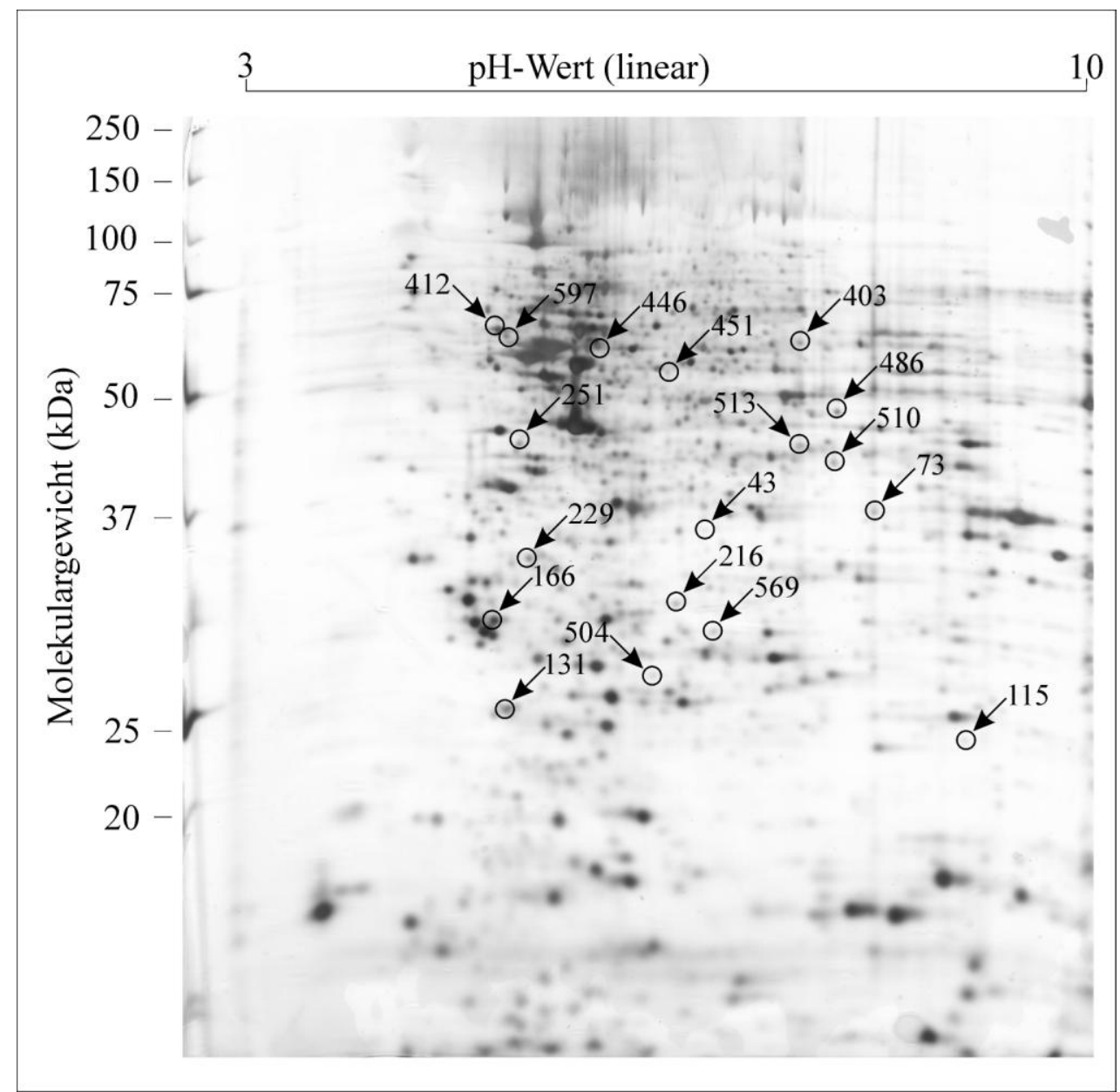

Abbildung 10 Silbergefärbtes 2-DE Gel aus Zelllysat von nicht-transfizierten SH-SY5Y-

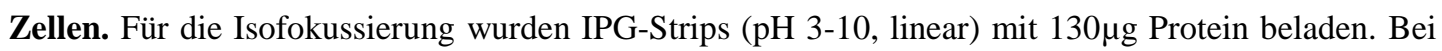
den mit Pfeilen markierten und nummerierten Spots konnte im Vergleich von Zelllysaten der mit PRNP transfizierten Zellen mit Lysaten nicht transfizierter SH-SY5Y-Zellen eine signifikante Regulation nachgewiesen werden. 
Tabelle 2

\begin{tabular}{|c|c|c|c|c|c|c|c|}
\hline $\begin{array}{l}\text { Spot } \\
\text { Nr. }\end{array}$ & Regu & ation & Protein & Datenbankeintrag & $\begin{array}{l}\text { Anzahl } \\
\text { Peptide }\end{array}$ & Score & $\begin{array}{c}p- \\
\text { Wert }\end{array}$ \\
\hline 43 & 4,23 & $\uparrow$ & $\begin{array}{l}\text { Polyglutamine-binding } \\
\text { protein } 1\end{array}$ & PQBP1_HUMAN & 6 & 95 & 0,049 \\
\hline 115 & 2,52 & $\uparrow$ & Transgelin-2 & TAGL2_HUMAN & 8 & 134 & 0,005 \\
\hline 131 & 1,69 & $\uparrow$ & $\begin{array}{l}\text { Translationally-controlled } \\
\text { tumor protein - human }\end{array}$ & TCTP_HUMAN & 15 & 259 & 0,007 \\
\hline 166 & 1,62 & $\uparrow$ & 14-3-3 protein gamma & 1433G_HUMAN & 4 & 81 & 0,02 \\
\hline 216 & 1,67 & $\uparrow$ & $\begin{array}{l}\text { Glutathione transferase } \\
\text { omega-1 }\end{array}$ & GSTO1_HUMAN & 14 & 185 & 0,03 \\
\hline 229 & 2,93 & $\uparrow$ & Annexin A5 & ANXA5_HUMAN & 11 & 165 & 0,002 \\
\hline 412 & 1,70 & $\uparrow$ & $\begin{array}{l}\text { Protein disulfide-isomerase } \\
\text { precursor }\end{array}$ & PDIA1_HUMAN & 6 & 150 & 0,03 \\
\hline 451 & 2,12 & $\uparrow$ & $\begin{array}{l}\text { Rho GTPase-activating } \\
\text { protein } 1\end{array}$ & RHG01_HUMAN & 8 & 112 & 0,002 \\
\hline 486 & 1,53 & $\uparrow$ & \begin{tabular}{|l|} 
Fumarate hydratase, \\
mitochondrial precursor
\end{tabular} & FUMH_HUMAN & 2 & 73 & 0,04 \\
\hline 504 & 2,16 & $\uparrow$ & $\begin{array}{l}\text { Growth factor receptor-bound } \\
\text { protein } 2\end{array}$ & GRB2_HUMAN & 15 & 127 & 0,034 \\
\hline 510 & 2,01 & $\uparrow$ & $\begin{array}{l}\text { Alcohol dehydrogenase class- } \\
3\end{array}$ & ADHX_HUMAN & 7 & 67 & 0,051 \\
\hline 569 & 1,73 & $\uparrow$ & $\begin{array}{l}\text { Platelet-activating factor } \\
\text { acetylhydrolase IB subunit } \\
\text { gamma }\end{array}$ & PA1B3_HUMAN & 3 & 36 & 0,02 \\
\hline 597 & 1,70 & $\uparrow$ & $\begin{array}{l}\text { UV excision repair protein } \\
\text { RAD23 homolog B }\end{array}$ & RD23B_HUMAN & 11 & 159 & 0,043 \\
\hline 73 & 0,52 & $\downarrow$ & $\begin{array}{l}\text { Bifunctional methylenetetra- } \\
\text { hydrofolate dehydrogenase/ } \\
\text { cyclohydrolase, } \\
\text { mitochondrial precursor }\end{array}$ & MTDC_HUMAN & 6 & 77 & 0,035 \\
\hline 251 & 0,55 & $\downarrow$ & Spermine synthase & SPSY_HUMAN & 6 & 54 & 0,012 \\
\hline 403 & 0,43 & $\downarrow$ & UPF0027 protein C22orf28 & CV028_HUMAN & 16 & 206 & 0,003 \\
\hline 446 & 0,45 & $\downarrow$ & FK506-binding protein 4 & FKBP4_HUMAN & 3 & 58 & 0,009 \\
\hline 513 & 0,40 & $\downarrow$ & $\begin{array}{l}40 \mathrm{kDa} \text { peptidyl-propyl cis- } \\
\text { trans isomerase }\end{array}$ & PPID_HUMAN & 14 & 151 & 0,018 \\
\hline
\end{tabular}

Übersicht über die in den 2-DE Gelen regulierten Proteine. Im Vergleich der 2-DE Gele nichttransfizierter SH-SY5Y-Zellen mit den stabil mit PRNP transfizierten, $\mathrm{PrP}^{\mathrm{c}}$-überexprimierenden $\mathrm{SH}$ SY5Y-Zellen konnten 18 in ihrer Expression regulierte Proteine nachgewiesen werden. Die Tabelle zeigt neben der genauen Proteinbezeichnung und entsprechendem Kürzel im Datenbankeintrag das Ausmaß der Regulation (x-fache Änderung) (gekennzeichnet durch die Pfeile $\uparrow$ und $\downarrow$ ), die Anzahl der gefundenen Peptide, Score und Signifikanz. Die Nummerierung der Proteine entspricht der in Abbildung 9 . 
Der Score, der die Homologie zwischen den sequenzierten Peptiden und ihren zugehörigen Proteinen angibt, war in dieser Arbeit bei allen Proteinen größer als 30 $(p<0,05)$. Dies bestätigt die komplette Übereinstimmung oder zumindestens eine hohe Homologie zwischen den bei der Sequenzierung gefundenen Peptiden und den ihnen zugeordneten Proteinen. Um keine wichtigen Informationen zu verlieren, wurde die Grenze für die Identifikation von hoch- bzw. herrunterregulierten Proteinen auf eine mindestens 1,5fache Änderung ihrer Expression festgesetzt. Auf diese weise konnten 18 regulierte Proteine nachgewiesen werden. Von den 18 Proteinen waren 13 durch die Überexpression von $\operatorname{PrP}^{\mathrm{c}}$ in ihrer Expression hoch- und fünf herunterreguliert. Neun der 18 gefundenen Proteine zeigten im Zuge der $\operatorname{PrP}^{\mathrm{c}}$ Überexpression eine mehr als zweifache Regulation. Zehn Proteine ließen sich unter funktionellen Kriterien drei Gruppen zuordnen: Proteine mit Einfluss auf Signalkaskaden, die Organisation des Zytoskeletts oder auf die Proteinfaltung. Alle weiteren Proteine, die keiner der drei funktionellen Gruppen zugeordnet werden konnten, wurden nach ihrer Regulation $(\uparrow / \downarrow)$ eingeteilt. Alle im Folgenden aufgeführten Proteine sind in Tabelle 2 aufgelistet.

Für drei der in den 2-DE-Gelen hochregulierten Proteine (1433G, ANXA5 und TAGL2) wurden zusätzlich Westernblots angefertigt. Die Auswahl dieser Proteine erfolgte aufgrund ihrer besonderen Assoziation zu neurodegenerativen Erkrankungen wie der CJK oder der Alzheimerschen Erkrankung. So dient 1433G als diagnostischer Marker für die CJK (siehe Kapitel 5.1), eine erhöhte Expression von ANXA5 wurde im Gehirn von sCJK Patienten (Xiang et al. 2005) und auch in transient mit $\operatorname{PrP}^{\mathrm{c}}$ transfizierten HEK293-Zellen (Ramljak et al. 2008) gefunden (siehe Kapitel 5.4.1). TAGL2 wird in der Großhirnrinde von Alzheimer Patienten signifikant höher exprimiert als in der Kontrollgruppe (Müller et al. 2007) (siehe Kapitel 5.2). 


\subsubsection{Proteine mit Einfluss auf Signalkaskaden}

Vier Proteine mit einer erhöhten Expression in den $\operatorname{PrP}^{\mathrm{c}}$-überexprimierenden Zellen sind direkt oder indirekt an Signalübertragungsketten beteiligt: das 14-3-3 Protein gamma (1433G), das Wachstumsfaktor-Rezeptor-Bindungsprotein 2 (GRB2), das Rho GTPase-Aktivierungsprotein (RHG01) und die Platelet-activating-FaktorAcetylhydrolase IB Subunit gamma (PA1B3).

Für das in der CJK Diagnostik bekannte Protein 1433G konnte im Vergleich der nativen mit den $\mathrm{PrP}^{\mathrm{c}}$-überexprimierenden $\mathrm{SH}-\mathrm{SY} 5 \mathrm{Y}-\mathrm{Zellen}$ eine durch $\mathrm{PrP}^{\mathrm{c}}$ induzierte Regulation nachgewiesen werden. Die in der densitometrischen Analyse der 2-DE-Gele gefundene Hochregulation um das 1,62fache in den mit PRNP transfizierten Zellen ist mit einem $p$-Wert von 0,02 signifikant $(p<0,05)$. Zusätzlich wurden Westernblots mit spezifischen Antikörpern gegen 1433G angefertigt. In der densitometrischen Auswertung der Westernblots bestätigte sich die Hochregulation von $1433 \mathrm{G}$ in der $\operatorname{PrP}^{\mathrm{c}}$-überexprimierenden Gruppe. Es ergab sich hierbei eine Hochregulation der 1433G-Expression um das 1,44fache der Expression in den Kontrollzellen. Dieser Wert ergibt sich nach Normalisierung durch die densitometrischen Werte von $\beta$-Actin zum Ausgleich kleiner Unterschiede in den beim Westernblot aufgetragenen Proteinmengen. 


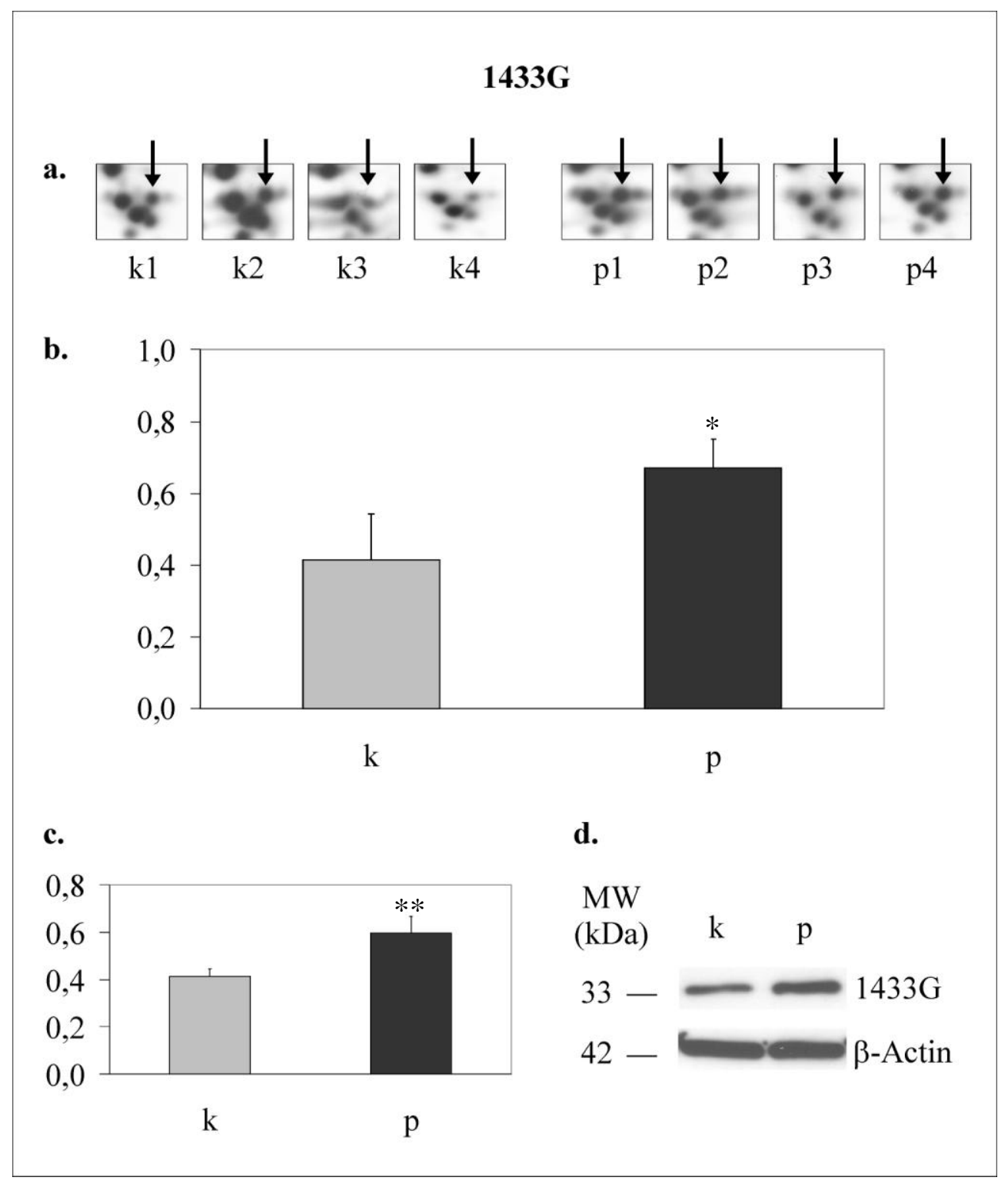

Abbildung 11 PrP $^{\mathrm{c}}$-induzierte Regulation von 1433G im Vergleich von nicht-transfizierten (k) mit PRNP transfizierten SH-SY5Y-Zellen (p). Das Protein 1433G ist durch die $\operatorname{PrP}^{\mathrm{c}}$ Überexpression in den transfizierten Zellen im Vergleich zu den Kontrollzellen signifikant hochreguliert. a. Ausschnitte aus den verglichenen 2-DE-Gelen; mit Pfeilen markiert ist 1433G (Spot Nr. 166 in Abb. 10). b. Densitometrische Analyse der 2-DE-Gele. Vertikale Achse: Densitometrische Werte von 1433G. Die Expression in den transfizierten Zellen im Vergleich zu den nicht-transfizierten Zellen zeigte eine Hochregulation von 1433G um das 1,62fache. Mittelwerte und Standardabweichungen wurden aus vier unabhängigen Experimenten berechnet, zweiseitiger $t$-Test für unverbundene Stichproben mit Signifikanzbereich $*, p<0,05$. c. Densitometrische Analyse der $1433 \mathrm{G}-$ Westernblots. Vertikale Achse: Densitometrische Werte von $1433 \mathrm{G}$ relativ zu den $\beta$-ActinWerten. Hier ergab sich eine Hochregulation um das 1,44fache, Signifikanzbereich **, p<0,01 d. Westernblot von $1433 \mathrm{G}$, bei $33 \mathrm{kDa}$ in der transfizierten Gruppe im Vergleich zu den Kontrollen deutlichere Bande nachweisbar, keine signifikanten Unterschiede der $\beta$-Actin-Werte. 


\subsubsection{Proteine mit Einfluss auf die Organisation des Zytoskeletts}

RHG01 kann durch seine funktionelle Variabilität zusätzlich einer weiteren Gruppe zugeteilt werden. Hierzu gehören Proteine, die an der Organisation und Stabilität des Zytoskeletts beteiligt sind. Außer RHG01 gehören noch Transgelin 2 (TAGL2), das translationell kontrollierete Tumorprotein (TCTP) und vermutlich auch das UPF0027-Protein C22orf28 (CV028) in diese Kategorie. Die drei erstgenannten Proteine weisen in den $\mathrm{PrP}^{\mathrm{c}}$-überexprimierenden Zellen im Vergleich $\mathrm{zu}$ den Kontrollzellen eine signifikante Erhöhung ihrer Expression auf, wohingegen CV028 durch die $\operatorname{PrP}^{\mathrm{c}}$-Überexpression herunterreguliert wird (siehe Tabelle 2).

TAGL2 ist ein Protein mit Aktinbindungsfähigkeit. Die in der densitometrischen Analyse der 2-DE-Gele gefundene Hochregulation der TAGL2-Expression um das 2,52fache in den mit PRNP transfizierten Zellen ist mit einem $p$-Wert von 0,005 hochsignifikant $(p<0,01)$. Zusätzlich wurden Westernblots mit spezifischen Antikörpern gegen TAGL2 angefertigt. In der densitometrischen Auswertung der Westernblots bestätigte sich die Hochregulation von TAGL2 in der $\operatorname{PrP}^{\mathrm{c}}$ überexprimierenden Gruppe. Hier ergab sich eine Erhöhung der TAGL2-Expression um das 266 fache der Expression in den nativen SH-SY5Y-Zellen. Dieser Wert ergibt sich nach Normalisierung durch die densitometrischen Werte von $\beta$-Actin. Kleine Unterschiede in der beim Westernblot aufgetragenen Proteinmenge sind somit ausgeglichen. 


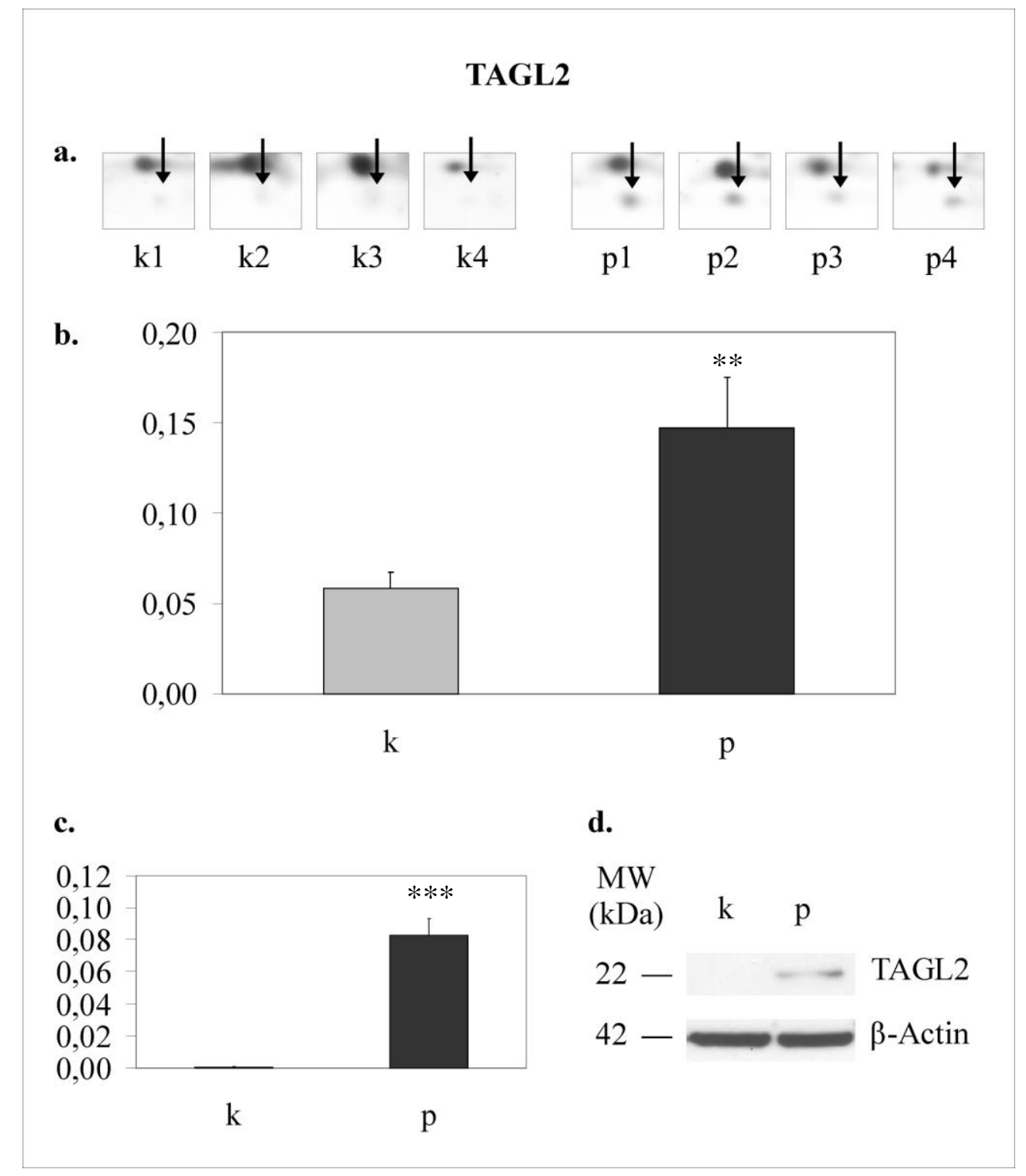

Abbildung $12 \quad$ PrP $^{\mathrm{c}}$-induzierte Regulation von TAGL2 im Vergleich von nicht-transfizierten (k) mit PRNP transfizierten SH-SY5Y-Zellen (p). Das Protein TAGL2 ist durch die PrP' Überexpression in den transfizierten Zellen im Vergleich zu den Kontrollzellen hochsignifikant hochreguliert. a. Ausschnitte aus den verglichenen 2-DE-Gelen, mit Pfeilen markiert ist TAGL2 (Spot Nr. 115 in Abb. 10). b. Densitometrische Analyse der 2-DE-Gele. Vertikale Achse: Densitometrische Werte von TAGL2. Die Expression in den transfizierten Zellen im Vergleich zu den nichttransfizierten Zellen zeigte eine Hochregulation von TAGL2 um das 2,52fache. Mittelwerte und Standardabweichungen wurden aus vier unabhängigen Experimenten berechnet, zweiseitiger $t$-Test für unverbundene Stichproben mit Signifikanzbereich **, $p<0,01$. c. Densitometrische Analyse der TAGL2-Westernblots. Vertikale Achse: Densitometrische Werte von TAGL2 relativ zu den $\beta$-ActinWerten. Hier ergab sich eine Hochregulation um das $~ 266 f$ fache, Signifikanzbereich ***, p < 0,001. d. Westernblot von TAGL2; bei 22kDa ist in der transfizierten Gruppe im Vergleich zu den Kontrollen deutliche Bande nachweisbar, während sich keine signifikanten Unterschiede der $\beta$-Actin-Werte finden. 


\subsubsection{Proteine mit Einfluss auf die Proteinfaltung}

In die Gruppe der Proteine mit Einfluss auf die Proteinfaltung fallen drei Proteine unterschiedlicher Regulation. Das Proteindisulfidisomerase-Vorläuferprotein (PDIA1) ist in dieser Kategorie als einziges hochreguliert. Das FK506Bindungsprotein 4 (FKBP4) und die 40kDa-Peptidylpropyl-cis/trans-Isomerase (PPID) werden hingegen durch die $\operatorname{PrP}^{\mathrm{c}}$-Überexpression in ihrer Expression herrunterreguliert.

\subsubsection{Weitere durch die $\operatorname{PrP}^{\mathrm{c}}$-Überexpression regulierte Proteine}

Einige Proteine konnten den drei Funktionsbereichen nicht zugeordnet werden. Darunter fallen fünf durch die $\mathrm{PrP}^{\mathrm{c}}$-Überexpression hoch- und zwei herunterregulierte Proteine.

\subsubsection{Hochregulierte Proteine}

Das Protein mit der deutlichsten $\mathrm{PrP}^{\mathrm{c}}$-induzierten Hochregulation in den SH-SY5YZellen ist das Polyglutamin-bindende Protein 1 (PQBP1). Das vor allem in Neuronen vorkommende Protein PQBP1 weist in den $\mathrm{PrP}^{\mathrm{c}}$-überexprimierenden Zellen nach der densitometrischen Analyse der 2-DE-Gele eine mehr als vierfache Hochregulation im Vergleich zu den Kontrollzellen auf. Dieser Unterschied ist signifikant $(p=$ 0,049).

$\mathrm{Zu}$ den hochregulierten Proteinen zählt ebenfalls das Kalzium- und Phospholipidbindende Protein Annexin A5 (ANXA5), dessen Regulation durch die Überexpression von $\mathrm{PrP}^{\mathrm{c}}$ bereits in HEK293-Zellen gezeigt werden konnte (Ramljak et al. 2008). Die in der densitometrischen Analyse der 2-DE-Gele gefundene Hochregulation der ANXA5-Expression um das 2,93fache in den mit PRNP transfizierten Zellen ist mit einem $p$-Wert von 0,005 höchst signifikant $(p<0,01)$. Zusätzlich wurden Westernblots mit spezifischen Antikörpern gegen ANXA5 angefertigt. In der densitometrischen Auswertung der Westernblots bestätigte sich die Hochregulation von ANXA5 in der $\operatorname{PrP}^{\mathrm{c}}$-überexprimierenden Gruppe. Hier ergab sich eine Erhöhung der ANXA5-Expression um das 3,97fache der Expression in den nicht-transfizierten Kontrollzellen. Dieser Wert ergibt sich nach Normalisierung durch die densitometrischen Werte von $\beta$-Actin. Kleine Unterschiede in der beim Westernblot aufgetragenen Proteinmenge sind somit wiederum ausgeglichen. 


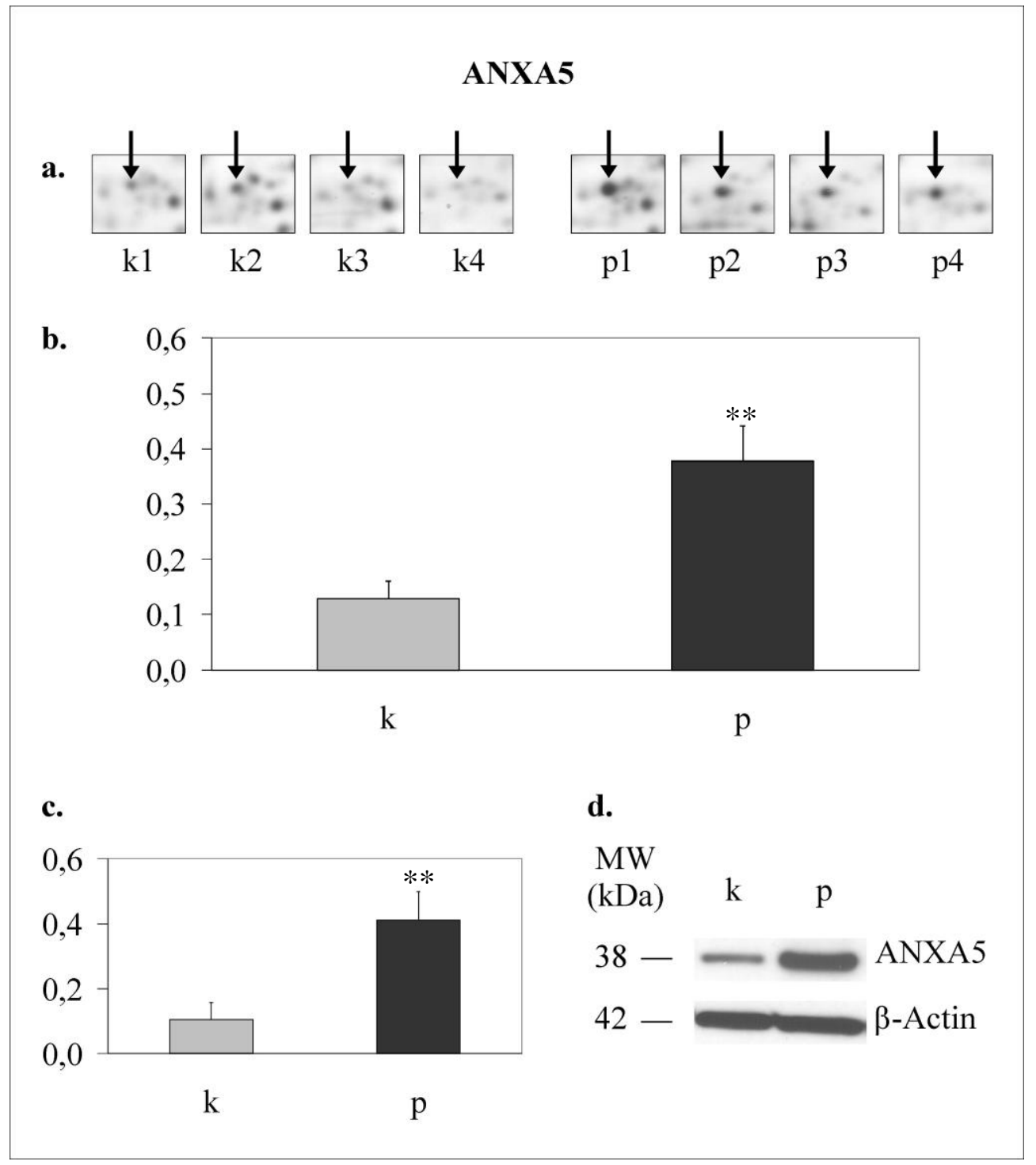

Abbildung $13 \quad$ PrP $^{\mathrm{c}}$-induzierte Regulation von ANXA5 im Vergleich von nicht-transfizierten (k) mit PRNP transfizierten SH-SY5Y-Zellen (p). Das Protein ANXA5 ist durch die PrP ${ }^{\text {c }}$ Überexpression in den transfizierten Zellen im Vergleich zu den Kontrollzellen signifikant hochreguliert. a. Ausschnitte aus den verglichenen 2-DE-Gelen; mit Pfeilen markiert ist ANXA5 (Spot Nr. 229 in Abb. 10). b. Densitometrische Analyse der 2-DE-Gele. Vertikale Achse: Densitometrische Werte von ANXA5. Die Expression in den transfizierten Zellen im Vergleich zu den nicht-transfizierten Zellen zeigte eine Hochregulation von ANXA5 um das 2,93fache. Mittelwerte und Standardabweichungen wurden aus vier unabhängigen Experimenten berechnet, zweiseitiger $t$ Test für unverbundene Stichproben mit Signifikanzbereich **, $p<0,01$. c. Densitometrische Analyse der ANXA5-Westernblots. Vertikale Achse: Densitometrische Werte von ANXA5 relativ zu den $\beta$ Actin-Werten. Hier ergab sich eine Hochregulation um das 3,97fache, Signifikanzbereich **, p < 0,01. d. Westernblot von ANXA5, bei 38kDa in der transfizierten Gruppe im Vergleich zu den Kontrollen stärkere Bande nachweisbar, keine signifikanten Unterschiede der $\beta$-Actin-Werte. 
Eine erhöhte Expression zeigten in der mit PRNP transfizierten und $\operatorname{PrP}^{\mathrm{c}}$ überexprimierenden Gruppe ebenfalls die Glutathiontransferase omega-1 (GSTO1), ein Protein, welches an detoxifizierenden Prozessen beteiligt ist, die Fumarathydratase (FUMH), ein Enzym des Energiestoffwechsels und die Alkoholdehydrogenase Klasse 3 (ADHX), die auch als Glutathion-abhängige Formaldehyddehydrogenase bekannt ist. Des Weiteren wurde durch die $\operatorname{PrP}^{\mathrm{c}}$ Überexpression die Expression das UV-Exzisions-Reparaturprotein RAD23Homolog-B (RD23B) signifikant hochreguliert.

\subsubsection{Herunterregulierte Proteine}

Durch die Überexpression des $\operatorname{PrP}^{c}$ wurden fünf Proteine signifikant in ihrer Expression vermindert. In diese Gruppe gehören zusätzlich zu den bereits genannten Proteinen das mitochondriale Enzym bifunktionelle MethylentetrahydrofolatDehydrogenase/Cyclohydrolase (MTDC) und die Sperminsynthase (SPSY), die für Zellwachstum und -differenzierung wesentlich ist. 


\section{4 p53-Westernblot}

Im Hinblick darauf, dass durch die alleinige $\operatorname{PrP}^{\mathrm{c}}$-Überexpression in verschiedenen Zelllinien eine erhöhte endogene p53-Expression im Westernblot nachgewiesen werden konnte (Paitel et al. 2003) (siehe dazu auch Kapitel 5.5), wurden in der vorliegenden Arbeit zusätzlich Westernblots mit spezifisch an p53 bindenden Antikörpern durchgeführt. Zur Kontrolle gleicher Proteinmengen wurden $\beta$-ActinAntikörper verwendet. Zwischen den $\operatorname{PrP}^{\mathrm{c}}$-überexprimierenden und den Lysaten nativer SH-SY5Y-Zellen ergab sich in der qualitativen Untersuchung der Westernblots keine Unterschiede in der Expression von p53 oder der $\beta$-Actin-Level (siehe Abbildung 14).

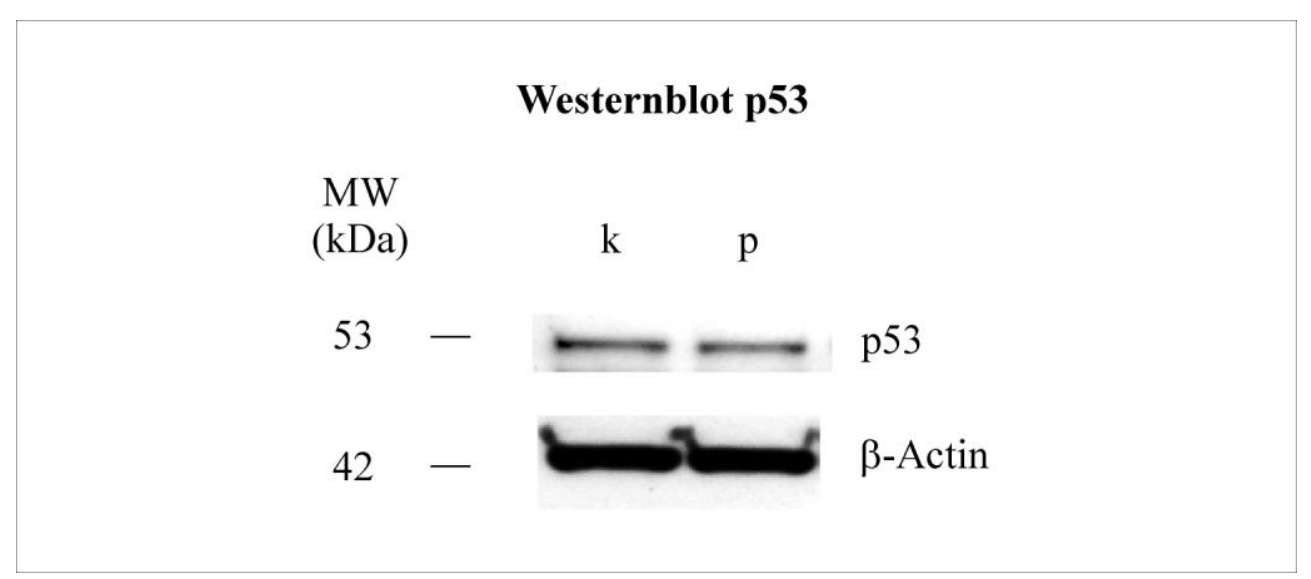

Abbildung 14 Nachweis der Expression von p53 in Lysaten stabil mit PRNP transfizierter SH-SY5Y-Zellen (p) und nativer SH-SY5Y-Zellen als Kontrollzellen (k) mittels Westernblot.

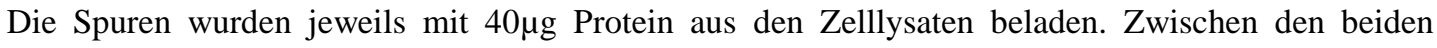
Gruppen sind keine Unterschiede in der p53-Expression nachweisbar, ebenfalls zeigen sich keine Unterschiede in den $\beta$-Actin-Leveln. Der Westernblot wurde vier Mal wiederholt. 


\section{$5 \quad$ Diskussion}

Die humane Neuroblastomzelllinie SH-SY5Y ist gut charakterisiert und wurde häufig entweder als Modell zur Erforschung der physiologischen Funktion des $\operatorname{PrP}^{\mathrm{c}}$ (Watt et al. 2007), der biologischen Rolle des N-Terminus des $\operatorname{PrP}^{\mathrm{c}}$ (Zeng et al. 2003) oder des Prion-induzierten Nervenzelltodes (Thellung et al. 2002, Dupiereux et al. 2006, Martinez und Pascual 2007) verwendet. In der dieser Studie wurde ein Proteom-basierter Ansatz gewählt, um biologische Prozesse zu beschreiben, die durch die stabile Überexpression des humanen $\operatorname{PrP}^{\mathrm{c}}$ in der Neuroblastomzellinie SHSY5Y beeinflusst werden.

Verschiedenen unabhängigen Berichten zufolge entwickeln transgene Mäuse durch eine Überexpression von Wildtyp- $\operatorname{PrP}^{c}$ neurodegenerative Veränderungen (Huang et al. 2007, Westaway et al. 1994, Chiesa et al. 2008). Im Einklang hiermit zeigte eine andere Studie, dass die Akkumulation cytosolischen $\operatorname{PrP}^{\mathrm{c}} \mathrm{s}$ in vitro und in vivo neurotoxisch wirkt (Ma et al. 2002). Schließlich wurde vor kurzem nachgewiesen, dass eine transiente Transfektion von HEK293-Zellen mit menschlichem PRNP die Expression von Proteinen deregulieren kann, die für den Energiestoffwechsel und das zelluläre Gleichgewicht von entscheidender Bedeutung sind (Ramljak et al. 2008).

Der in der hier vorliegenden Studie durchgeführte Proteomvergleich neuronaler Zellen mit endogenem $\mathrm{PrP}^{\mathrm{c}}$-Level und den deutlich $\operatorname{PrP}^{\mathrm{c}}$-überexprimierenden stabil transfizierten SH-SY5Y-Zellen ergab ebenfalls die Deregulation mehrerer Proteine. Die Mehrzahl der in ihrer Regulation veränderten Proteine steht entweder in Verbindung mit Signalübertragunsketten, der Organisation des Zytoskeletts oder der Proteinfaltung. Daraus lässt sich ableiten, dass die Überexpression von $\operatorname{PrP}^{c}$ das zelluläre Gleichgewicht unabhängig von Zelltyp oder Transfektionsmethode beeinflusst. 


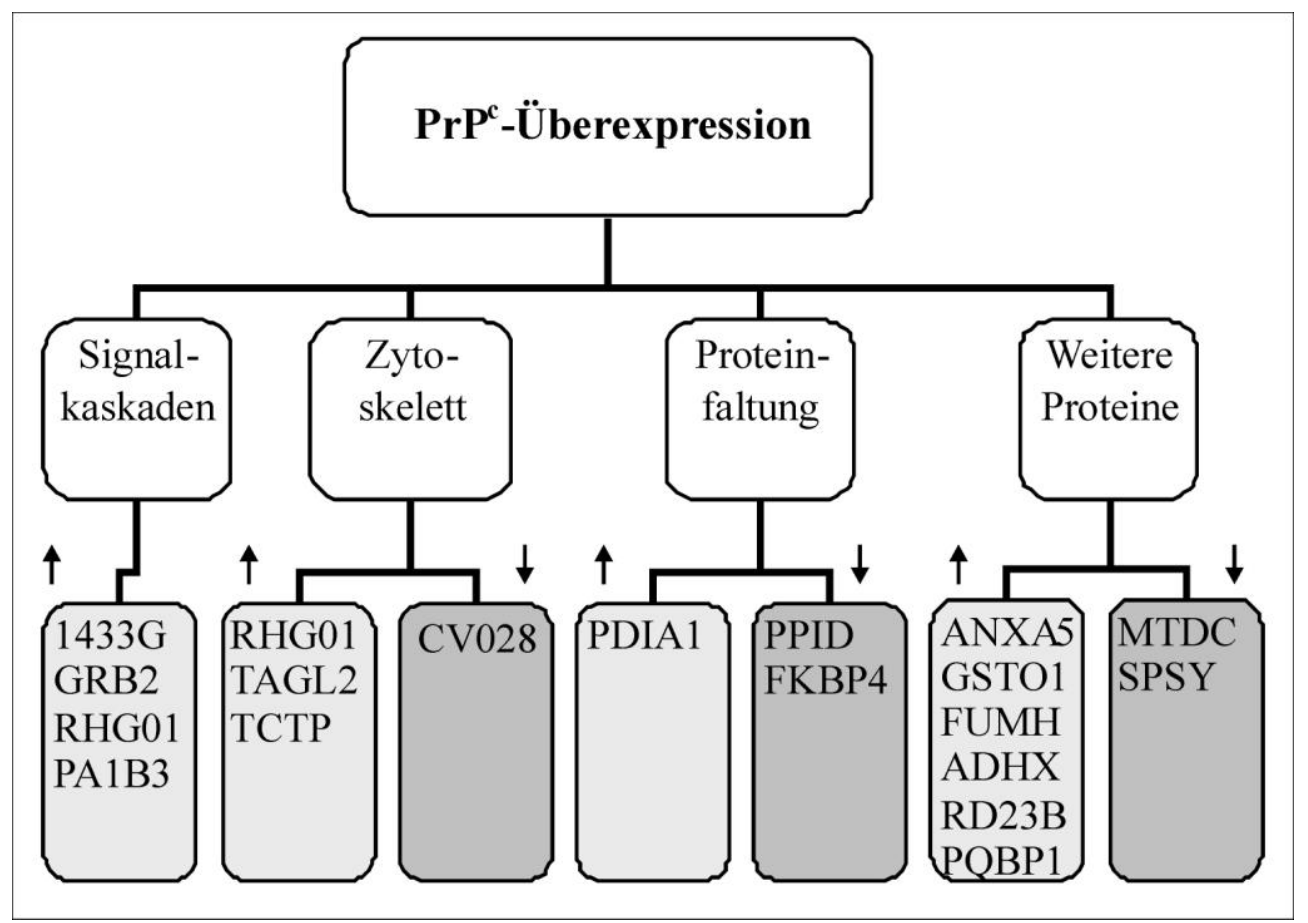

Abbildung 15 Übersicht über die 18 regulierten Proteine und ihre Einteilung. Drei funktionelle Gruppen: Proteine mit Einfluss auf Signalkaskaden, das Zytoskelett und die Proteinfaltung. Vierte Gruppe alle weiteren nicht nach ihrer Funktion klassifizierbaren regulierten Proteine. Einteilung nach Regulation: $\square$ und $\uparrow$ : hochregulierte Proteine, $\square$ und $\downarrow:$ herunterregulierte Proteine.

\subsection{Proteine mit Einfluss auf Signalkaskaden}

Die Steuerung bestimmter Signalübertragungsketten durch $\operatorname{PrP}^{c}$ ist gewiss. Daher ist die Feststellung nicht verwunderlich, dass $\operatorname{PrP}^{\mathrm{c}}$ die Regulation von Proteinen, die in Verbindung mit Signalkaskaden stehen, beeinflussen kann. Drei Proteine, die im Zusammenhang mit Signalübertragungswegen stehen, wurden durch die stabile $\operatorname{PrP}^{\mathrm{c}}$ Überexpression hochreguliert. Dazu zählen das 14-3-3 Protein Gamma (1433G), das Wachstumsfaktor-Rezeptor-Bindungsprotein 2 (GRB2) und das Rho GTPaseAktivierungsprotein (RHG01). Diese Funde stützen einmal mehr die Tatsache, dass $\operatorname{PrP}^{\mathrm{c}}$ eine wichtige Rolle in der Übertragung zellulärer Signale spielt.

Das Protein 1433G ist ein gut bekannter Marker zur Unterscheidung zwischen der sCJK und anderen Demezerkrankungen (Van Everbroeck et al. 2005). Proteine der 14-3-3 Familie haben einen wesentlichen Einfluss auf diverse Signalübertragungsketten, die Regulation des Zellzyklus und der Apoptose (Fu et al. 2000). Die Hochregulation von $1433 \mathrm{G}$ scheint während ischämischen Ereignissen einen schützenden Effekt auf Astrozyten auszuüben und somit das Zellüberleben zu fördern (Chen XQ et al. 2005), während eine Abnahme von 1433G zu einer erhöhten 
Apoptoserate führt. Ob oder inwieweit 1433G über seine Funktion als Biomarker hinaus einen Einfluss auf die CJK hat ist bisher jedoch unklar.

Ein weiteres Signalprotein, dessen Hochregulation nach $\operatorname{PrP}^{\mathrm{c}}$-Überexpression gezeigt werden konnte, ist GRB2. Eine frühere Studie wies in einem Hefe-Zwei-HybridSystem die Interaktion von GRB2 und $\mathrm{PrP}^{\mathrm{c}}$ nach (Spielhaupter und Schatzl 2001). GRB2 ist ein Adapterprotein, welches hauptsächlich die Signale von extrazellulären bzw. transmembranen Rezeptoren, wie neuronalen oder epidermalen Wachstumsfaktorrezeptoren, mit intrazellulären Signalmolekülen verbindet. Als solches ist es wesentlich für die Ausbildung von Signalkomplexen (Cheng et al. 1998).

Zusätzlich wies RHG01 in den transfizierten Zellen durch die $\operatorname{PrP}^{\mathrm{c}}$-Überexpression im Vergleich zu den Kontrollzellen eine erhöhte Expression auf. Es gehört zu einer kleinen Gruppe an GTPasen der Ras-Superfamilie, die an zahlreichen zellulären Aktivitäten wie beispielsweise der Kontrolle von Signalkaskaden der c-Jun Nterminalen Kinase und der p38 mitogen-aktivierten Proteinkinase beteiligt sind (Coso et al. 1995, Minden et al. 1995). Ebenfalls wirken Rho GTPasen an Regulation und Aufbau des Aktinzytoskeletts mit (Hall 1998) (siehe dazu Kapitel 5.2). Abgesehen davon wurde vor kurzem in Microarray-Experimenten das Rho GTPaseAktivierungsprotein 15 als eines der Interaktionspartner von $\operatorname{PrP}^{\mathrm{c}}$ ausgemacht (Satoh et al. 2009).

Die Platelet-activating-Faktor-Acetylhydrolasen (PAF-AH) sind eine kleine Proteinfamilie, die der Superfamilie der Phospholipasen A2 angehört. Der PAF-AH IB Subunit gamma (PA1B3) war in dieser Studie durch die erhöhte $\operatorname{PrP}^{\mathrm{c}}$ Konzentration ebenso in ihrer Expression hochreguliert. Der Platelet-activatingFaktor (PAF) ist einer der effektivsten Lipidmessenger, der von PAF-AH durch Spaltung der Acyl-Gruppe an der sn-2 Position inaktiviert werden kann (Prescott et al. 2000). Die Identifikation von spezifischen PAF-Bindungsstellen im Gehirn von Wüstenrennmäusen und Ratten deutet darauf hin, dass PAF eine physiologische Rolle im Gehirn spielt (Domingo et al. 1988, Marcheselli et al. 1990). PAF-AH könnte dafür zuständig sein die Menge an PAF im Gehirn zu regulieren, indem es die Ansammlung von PAF in den Zellen vermindert (Hattori et al. 1993). Intrazelluläre PAF-AH kann des Weiteren oxidativ modifizierte Phospholipide hydrolysieren und bei ihrer Entfernung mithelfen. Oxidierte Phospholipide wurden in normalem Gehirn gefunden und es ist bekannt, dass sie nach Lipidperoxidation auf Grund der Bildung 
von freien Radikalen oder oxidativem Stress vermehrt vorliegen (Hattori et al. 1993). Intrazelluläre PAF-AH, welches konstitutiv aktiv ist und selektiv oxidierte Phospholipide hydrolysiert, könnte somit an der Entfernung dieser oxidierten Phospholipide beteiligt sein. Eine $\operatorname{PrP}^{\mathrm{c}}$-induzierte Hochregulation von PAF-AH könnte somit außerdem auf eine erhöhte Rate von oxidierten Phospholipiden in $\operatorname{PrP}^{\mathrm{c}}$ überexprimierenden SH-SY5Y-Zellen hinweisen.

\subsection{Proteine mit Einfluss auf die Organisation des Zytoskeletts}

Dass $\operatorname{PrP}^{\mathrm{c}}$ die Fähigkeit hat, die Dynamik von Mikrotubuli zu regulieren und das Aktinzytoskelett zu reorganisieren, ist gut dokumentiert (Dong et al. 2008, MalagaTrillo et al. 2009). So konnten in dieser Arbeit vier Proteine gefunden werden, die an der Organisation des Zytoskeletts beteiligt sind. Drei dieser Proteine wurden durch $\operatorname{PrP}^{\mathrm{c}}$ hochreguliert, eines hingegen herunterreguliert.

Wie in Kapitel 5.1 erwähnt, gehört RHG01 nicht nur zu den Proteinen, die an Signalübertragungen beteiligt sind, sondern des Weiteren zu der Gruppe, die Einfluss auf das Zytoskelett hat. Mitglieder der Proteinfamilie der Rho GTPasen können durch ihre Interaktion mit zahlreichen Zielproteinen das Aktinzytoskelett regulieren und sorgen für die Kontrolle anderer zelluärer Aktivitäten wie beispielsweise der Gentranskription oder Zelladhäsion (Hall 1998).

Ein weiteres Protein, dessen Expression durch die $\operatorname{PrP}^{\mathrm{c}}$-Überexpression in den transfizierten Zellen signifikant hochreguliert wurde, ist Transgelin 2 (TAGL2). TAGL2 gehört in die Aktin-bindende Proteinfamilie der Calponine. Transgelin ist somit ein Protein, welches durch seine Aktinbindungsfähigkeit an der Organisation und Stabilität des Aktinzytoskeletts beteiligt ist (Goodman et al. 2003). Darüberhinaus wirkt Transgelin möglicherweise durch die Ausbildung von Podosomen an der Zellbeweglichkeit mit (Kaverina et al. 2003). Außerdem scheint es als Tumorsupressor zu fungieren (Assinder et al. 2009). Es supprimiert dabei die Expression der Metallo-Matrix Proteinase 9 (MMP-9) (Nair et al. 2006). MMPs spielen eine entscheidende physiologische Rolle für die synaptische Plastizität und axonale Migration und wirken üblicherweise an der Pathophysiologie neuronaler Zellen mit (Dzwonek et al. 2004). Kürzlich konnte die $\operatorname{PrP}^{\mathrm{c}}$-abhängige Herunterregulation der MMP-9-Transkription nachgewiesen werden (Pradines et al. 
2008). $\operatorname{PrP}^{\mathrm{c}}$ hat die Fähigkeit das cAMP responisve element binding protein (CREB) zu aktivieren, welches über die Transkription verschiedener Gene Zellüberleben, -proliferation und Neuroplastizität positiv beeinflusst. Durch die $\operatorname{PrP}^{\mathrm{c}}$-abhängige Aktivierung von CREB zeigte sich, dass MMP-9 vermindert, ihr Inhibitor TIMP-1 hingegen vermehrt transkribiert wurde. Insgesamt könnte für die Herunterregulation der MMP-9 neben der vermehrten Transkription ihres Inhibitors TIMP-1 auch die Hochregulation von dem die MMP-9-supprimierenden Protein TAGL2 eine Rolle spielen. Es scheint möglich, dass TAGL2 in dieser Kette das Bindeglied ist, über welches die $\operatorname{PrP}^{\mathrm{c}}$-induzierte Herunterregulation der MMP-9-Transkription vermittelt wird. Möglicherweise werden somit die oben genannten, durch die CREBAktivierung ausgelösten positiven Effekte des $\operatorname{PrP}^{\mathrm{c}}$ auf Zellüberleben, -proliferation und Neuroplastizität durch die Herunterregulation der MMP-9 verursacht. Zusätzlich zeigte sich, dass MMP-9-knockout-Mäuse für ischämische Ereignisse weniger suszeptibel sind als Wildtyp-Mäuse (Svedin et al. 2007), was ebenfalls für einen protektiven Einfluss der MMP-9 spricht. Ein weiterer Aspekt der Funktion von Transgelin ist der Zusammenhang zwischen seiner Aktinbindungsfähigkeit und der Zellalterung. Das Ausschalten des SCP1-Gens (kodierend für das Aktin-bindende Protein Scp1p; homolog in Säugetieren kodierend für SM22/Transgelin) in Hefekulturen führt zur verringerten Produktion von hochreaktiven Sauerstoffmetaboliten und einem signifikanten Anstieg der Lebensdauer (Gourlay et al. 2004). Dies weist darauf hin, dass Transgelin in Prozesse involviert ist, die an der Regulation der Zellalterung beteiligt sind. Außerdem ist Transgelin im Zusammenhang mit der Alzheimerschen Erkrankung bekannt. Die nach Induktion der Expression der intrazellulären Domäne des Amyloidvorläuferproteins durchgeführte Transkriptomanalyse in einem menschlichen Nervenzellkultursystem brachte eine erhöhte Expression des Transgelingens zum Vorschein. Darüberhinaus war Transgelin in der frontalen Großhirnrinde von Alzheimer-Patienten signifikant höher exprimiert als in der altersentsprechenden Kontrollgruppe (Müller et al. 2007). Als drittes durch die $\operatorname{PrP}^{\mathrm{c}}$-Überexpression hochreguliertes Protein gehört das translationell kontrollierete Tumorprotein (TCTP) in die Gruppe der Proteine, die im Zusammenhang mit dem Zytoskelett stehen. Die primäre physiologische Funktion von TCTP ist weitestgehend unklar. Lediglich bekannt ist, dass TCTP Eigenschaften eines Tubulin-bindenden Proteins besitzt. Es verbindet sich während des Zellzyklus mit Mikrotubuli und vorübergehend auch mit der Mitosespindel (Gachet et al. 1999). 
Weiterhin führen erhöhte TCTP-Level zur Reorganisation von Mikrotubuli und zur Zunahme von Mikrotubulimenge und -stabilität (Gachet et al. 1999). Außerdem interagiert TCTP in einem Hefe-Zwei-Hybrid-System mit der dritten zytoplasmatischen Domäne der $\mathrm{Na}^{+} / \mathrm{K}^{+}$-ATPase-alpha-subunit und inhibiert sie dosisabhängig (Jung et al. 2004). Interessanterweise führt eine TCTPÜberexpression in vivo zur Hemmung der Aktivität der $\mathrm{Na}^{+} / \mathrm{K}^{+}$-ATPase und der intrazellulären $\mathrm{Ca}^{2+}$-Mobilisation (Kim et al. 2008). Schließlich konnte vor kurzem die $\alpha 2 / \beta 2-\mathrm{Na}^{+} / \mathrm{K}^{+}$-ATPase als neuer $\operatorname{PrP}^{\mathrm{c}}$-Bindungspartner identifiziert werden, wobei $\operatorname{PrP}^{\mathrm{c}}$ die Aktivität der $\mathrm{Na}^{+} / \mathrm{K}^{+}$-ATPase zu modulieren scheint (Kleene et al. 2007).

Das UPF0027-Protein C22orf28 (CV028), ein Protein der uncharakterisierten Proteinfamilie (UPF) UPF0027 wird im Gegensatz zu den drei vorhergehenden Proteinen dieser Gruppe durch $\operatorname{PrP}^{\mathrm{c}}$ mehr als zweifach herunterrguliert. Die Funktion dieses Proteins ist praktisch unbekannt. Aus physikalischer Sicht kann lediglich abgeleitet werden, dass CV028 mit Vinculin interagiert (UniProt 01. April 2009). Vinculin ist ein Actinfilament bindendes Protein, welches in Haftplatten lokalisiert ist (Le Clainche und Carlier 2008) und möglicherweise eine Rolle für die Wachstumsregulation in neuroendokrinen Tumoren spielt (Liu M et al. 2007). Daher kann eine direkte oder indirekte Beteiligung von CV028 an der Regulation des Zytoskeletts in Betracht gezogen werden.

\subsection{Proteine mit Einfluss auf die Proteinfaltung}

Die Möglichkeit, dass die $\operatorname{PrP}^{\mathrm{c}}$-Überexpression die Regulation von Proteinen, die an der Proteinfaltung beteiligt sind, verursachen könnte ist in der Prionforschung von besonderem Interesse, da Prionerkrankungen durch die Akkumulation des $\mathrm{PrP}^{\mathrm{Sc}}$ ausgelöst werden. In dieser Studie konnten drei Proteine gefunden werden, die die Proteinfaltung beeinflussen. Zwei davon sind durch die $\operatorname{PrP}^{\mathrm{c}}$-Überexpression in den mit PRNP transfizierten Zellen jeweils verglichen mit den Kontrollzellen in ihrer Expression herunterreguliert. Ein Protein ist hochreguliert.

Das einzige hochregulierte Protein in dieser Gruppe ist das Proteindisulfidisomerase (PDI) -Vorläuferprotein (PDIA1), ein Enzym, welches die Proteinfaltung unterstützt. Es ist ein Protein, welches im endoplasmatischen Retikulum (ER) lokalisiert ist und die Isomerisierung von intra- und intermolekularen Disulfidbindungen katalysiert. 
Dabei kann es einerseits, in geringen Konzentrationen vorliegend, als Chaperon die Aggregation von Proteinen fördern, andererseits als sogenanntes Anti-Chaperon, wenn es in hohen Konzentrationen vorliegt, die Aggregation von Proteinen vermindern (Gilbert 1997). Funktion und Aktivität von PDIA1 deckt sich mit derjenigen von GRP58, ebenfalls ein Mitglied der Proteindisulfidisomerase Proteinfamilie. In einem Scrapie-Modell an Mäusen konnte gezeigt werden, dass die Scrapieinfektion in der präsymptomatischen Krankheitsphase $\mathrm{zu}$ einer Hochregulation der GRP58-Expression führt (Hetz et al. 2005). Ebenfalls konnte gezeigt werden, dass die Überexpression von GRP58 in N2a-Zellen mit einer geringeren Empfänglichkeit für $\mathrm{PrP}^{\mathrm{Sc}}$-induzierten Stress einhergeht (Hetz et al. 2005). Veränderungen der ER-Homöostase können durch verschiedene Formen von Stress ausgelöst werden und spezifische zellprotektive Mechanismen aktivieren. Diese können dann beispielsweise zu einer Hochregulation von ER-Chaperonen wie PDIA1 führen (Liu H et al. 1997, Ferri und Kroemer 2001, Rao et al. 2002). Eine Überexpression von PDIA1 könnte somit als Reaktion auf die durch die $\operatorname{PrP}^{\mathrm{c}}$ Überexpression gestörte ER-Homöostase angesehen werden. Eine weitere Studie zeigte die Überexpression von PDI im Gehirn von sCJK-Patienten (Yoo et al. 2002). Umgekehrt wurde die Expression der 40kDa-Peptidypropyl-cis/trans-Isomerase (PPID) (auch Cyclophilin 40 genannt), ein weiteres Protein mit Chaperonaktivität, unter $\operatorname{PrP}^{\mathrm{c}}$-Überexpression herunterreguliert. Die Ergebnisse von Cohen und Taraboulos (2003) deuten darauf hin, dass Cyclophiline im normalen Stoffwechsel von $\operatorname{PrP}^{c}$ eine Rolle spielen. Sie fanden heraus, dass die Zugabe des Immunsuppressivums Cyclosporin $\mathrm{A}$ zu zwei Zelllinien von Maus und Hamster Peptidylpropyl Isomerasen (PPI) der Cyclophilin Familie hemmen und zur Akkumulation einer Proteasom-resistenten PrP-Form führen. Sie vermuten weiterhin, dass die Schwächung der PPIase-Aktivität während des Alterns Ablagerungen von PrP im Gehirn verursachen und damit einen Beitrag zur Entwicklung von sporadischen Prionerkrankungen leisten könnte (Cohen und Taraboulos 2003).

Ebenso zeigte das FK506-Bindungsprotein 4 (FKBP4 oder FKBP52) in dieser Arbeit eine mehr als zweifache Heunterregulation durch PrP ${ }^{c}$ FKBP52 gehört zur Immunophillin-Familie, ebenfalls eine Gruppe von Chaperonproteinen, die immunsuppressive Medikamente binden und PPI-Aktivität besitzen. Immunophiline sind in hohen Konzentrationen im zentralen und peripheren Nervensystem zu finden (Steiner et al. 1992). FKBP52 ist ein Teil des Steroidrezeptorkomplexes und wird 
über das 90kDa Hitzeschockprotein (HSP) mit dem Rezeptorkomplex verbunden (Sanchez 1990, Tai et al. 1992, Perdew und Whitelaw 1991). Darüberhinaus scheint FKBP52 die das Neuritenwachstum fördernde Eigenschaft des Immunsuppressivums FK506 zu vermitteln (Gold et al. 1999). Für ein anderes Mitglied der ImmunophillinFamilie, das FK506 bindende Protein 1B, konnte interessanterweise in Mikroarrayversuchen eine mehr als zweifache Herunterregulation im frontalen Cortex von sCJK-Patienten nachgewiesen werden (Xiang et al. 2005).

\subsection{Weitere durch die $\operatorname{PrP}^{\mathrm{c}}$ - Überexpression regulierte Proteine}

Neben den bisher beschriebenen Proteinen wurden durch die $\operatorname{PrP}^{\mathrm{c}}$-Überexpression acht weitere Proteine reguliert, die an anderen biologischen Prozessen beteiligt sind. Die Mehrzahl dieser Proteine, deren Aufgaben und mögliche Zusammenhänge zur physiologischen Funktion von $\operatorname{PrP}^{c}$ im Folgenden beschrieben werden, wies in den $\operatorname{PrP}^{\mathrm{c}}$-überexprimierenden Zellen eine erhöhte Expression auf.

\subsubsection{Hochregulierte Proteine}

Das Protein, welches in der densitometrischen Analyse der 2-DE-Gele in der $\operatorname{PrP}^{\mathrm{c}}$ überexprimierenden Gruppe verglichen mit nativen SH-SY5Y-Zellen die deutlichste Hochregulation zeigte war das Polyglutamin-bindende Protein 1 (PQBP1). Dieses Protein ist im Zellkern lokalisiert und wird ubiquitär exprimiert. Hauptsächlich kommt es in Neuronen des ZNS vor, dabei wurden hohe Konzentrationen dieses Proteins in der Kleinhirnrinde, dem Hippokampus und dem Bulbus olfactorius nachgewiesen (Waragai et al. 1999). In vitro konnte gezeigt werden, dass die Überexpression von PQBP1 das Zellwachstum hemmt und die Empfänglichkeit der Zellen für verschiedene Arten von Stress ansteigt (Waragai et al. 1999). In Einklang mit diesen Erkenntnissen führt die PQBP1-Überexpression in vivo zu einem spät einsetzenden Abbau von Nervenzellen im ZNS (Okuda et al. 2003). Des Weiteren kann durch PQBP1 Nervenzelltod ausgelöst werden. Dieser Vorgang scheint über mitochondrialen Stress, einem Schlüsselelement, das bei vielen neurodegenerativen Störungen beteiligt ist, vermittelt $\mathrm{zu}$ werden (Marubuchi et al. 2005). Die Hochregulation von PQBP1 führt daher zu der Annahme, dass die Überexpression von $\operatorname{PrP}^{c}$ das zelluläre Gleichgewicht stört. 
Ein sehr wichtiges Protein, das durch die PrP ${ }^{\mathrm{c}}$-Überexpression in den SH-SY5YZellen in seiner Expression hochreguliert wurde, scheint Annexin A5 (ANXA5) zu sein. Die PrP ${ }^{\mathrm{c}}$-induzierte Deregulation von ANXA5 konnte bereits in der Studie von Ramljak et al. (2008) nach transienter Transfektion von HEK293-Zellen mit PRNP gezeigt werden (Ramljak et al. 2008). ANXA5 war das einzige Protein, welches sowohl in der hier vorliegenden Studie durch die stabile $\operatorname{PrP}^{\mathrm{c}}$-Überexpression, als auch durch die transiente Überexpression des $\operatorname{PrP}^{\mathrm{c}}$ als hochreguliert nachgewiesen werden konnte (Ramljak et al. 2008). Ebenfalls konnte eine Hochregulation von ANXA5 in Westernblots aus Lysaten zweier weiterer transient mit $\operatorname{PrP}^{\mathrm{c}}$ transfizierter Zellinien nachgewiesen werden. In N2a Neuroblastomzellen der Maus ergab sich in mit $\operatorname{PrP}^{\mathrm{c}}$ transfizierten Zellen im Vergleich $\mathrm{zu}$ mit einem leeren Kontrollvektor transfizierten Zellen eine 2 fache Hochregulation von ANXA5, in menschlichen SKN-LO Neuroblastomzellen war eine 1,8 fache Hochregulation nachweisbar (Weiss et. al. 2010). Daher scheint die $\operatorname{PrP}^{\mathrm{c}}$-vermittelte Regulation von ANXA5 weder zelltypspezifisch noch abhängig von der Art der Transfektion zu sein. ANXA5 gehört zu der Annexin-Familie der Kalzium- und Phospholipid-bindenden Proteine, deren physiologische Rolle nur wenig bekannt ist. Im Einklang mit den bereits bekannten Funktionen des $\operatorname{PrP}^{\mathrm{c}}$ scheint ANXA5 für das Überleben und Neuritenwachstum sich entwickelnder kortikaler Neuronen wichtig zu sein. Auch schützt ANXA5 Neuronen vor durch Peroxid oder Hypoxie verursachten Schäden (Han et al. 2004). Ein weiterer interessanter Zusammenhang von ANXA5 zu Prionerkrankungen ist die in einer Genexpressionsstudie an sCJK-Patienten gefundene Hochregulation von ANXA5 im frontalen Cortex (Xiang et al. 2005). Dies verdeutlicht die mögliche Rolle von ANXA5 für die Pathophysiologie der CJK. In ANXA5-Knockout-DT-40-Zellen zeigte sich eine Resistenz gegenüber verschiedener apoptose-induzierender Mittel wie Staurosporin, die über einen $\mathrm{Ca}^{2+}$ abhängigen Weg den programmierten Zelltod vermitteln (Hawkins et al. 2002). Umgekehrt stimuliert die Überexpression von ANXA5 apoptotische Ereignisse, unabhängig von der Zugabe apoptose-induzierender Agenzien wie Staurosporin (Wang und Kirsch 2006). Interessanterweise zeigten einige frühere Experimente, dass die $\operatorname{PrP}^{c}$-Überexpression in verschiedenen Zelllinien einen Anstieg des durch Staurosporin hervorgerufenen Zelltods via p53 hervorruft (Paitel et al. 2002, Paitel et al. 2003, Paitel et al. 2004). In dieser Studie konnte keine Hochregulation von p53 gezeigt werden. Über eine funktionelle Beziehung zwischen der schon früher 
beschriebenen erhöhten Empfänglichkeit von $\operatorname{PrP}^{\mathrm{c}}$-überexprimierenden Zellen gegenüber Staurosporin und der Hochregulation von ANXA5 kann jedoch trotzdem spekuliert werden (siehe Kapitel 5.5).

Ein weiteres Protein, welches durch die $\mathrm{PrP}^{\mathrm{c}}$-Überexpression in SH-SY5Y-Zellen hochreguliert wurde ist die Glutathiontransferase Omega-1 (GSTO1). GSTO1 ist ein Enzym der Glutathion-S-Transferase-Familie, welches durch die Konjugation von Fremdstoffen mit reduziertem Glutathion eine wichtige Rolle in Entgiftungsprozessen spielt. In der Studie von Ramljak et al. (2008) wurde die Glutathion-S-Transferase $\mathrm{P}$ durch eine moderate $\operatorname{PrP}^{\mathrm{c}}$-Überexpression in HEK293Zellen hochreguliert (Ramljak et al. 2008). Bemerkenswert ist außerdem, dass genetische Studien zum Alter bei Erkrankungsbeginn der Alzheimer- und Parkinsonerkrankung unter anderem das GSTO1-Gen hervorbrachten. GSTO1 wird als wichtig für die Kontrolle des Alters bei Erkrankungsbeginn angesehen (Li et al. 2003).

$\mathrm{Zu}$ den durch die $\mathrm{PrP}^{\mathrm{c}}$-Überexpression deregulierten Proteinen gehören zwei mitochondriale Proteine, die Fumarathydratase (FUMH) und die bifunktionelle Methylentetrahydrofolat-Dehydrogenase/Cyclohydrolase (MTDC). FUMH konnte in den transfizierten Zellen gegenüber den Kontrollzellen als hochreguliert nachgewiesen werden. Dagegen war MTDC herunterreguliert (für MTDC siehe Kapitel 5.4.2) nachgewiesen werden. FUMH ist ein Enzym der Atmungskette, genauer gesagt des Zitratzyklus', welches Fumarat in Malat umwandelt. Damit ist es ein Protein, welches in den zellulären Energiestoffwechsel involviert ist.

Die Alkoholdehydrogenase Klasse III (ADHX), ein unter $\mathrm{PrP}^{\mathrm{c}}$-Überexpression zweifach hochreguliertes Protein, ist die einzige Alkoholdehydrogenase, die im erwachsenen menschlichen Gehirn exprimiert wird und dessen primäre Funktion nicht die Oxidation von Ethanol darstellt, wohl aber die Oxidation von langkettigen primären Alkoholen (Giri et al. 1989). ADHX ist auch bekannt als Glutathionabhängige Formaldehyddehydrogenase (Holmquist und Vallee 1991), die eine wichtige Rolle in der Formaldehydentgiftung und Reduktion des Stickstoffmonoxidmetaboliten S-Nitroglutathion spielt (Sanghani et al. 2003). Abgesehen von einer möglicherweise entgiftenden Funktion bleibt die Ursache für die Hochregulation dieses Proteins unklar.

Das in den mit PRNP transfizierten Zellen im Vergleich zu den nativen Zellen knapp zweifach hochregulierte UV-Exzisions-Reparaturprotein RAD23-Homolog-B 
(RD23B) spielt wie alle RAD23-Proteine sowohl eine Rolle für die DNA-Reparatur als auch für die Regulation der Proteinstabilität (Glockzin et al. 2003, Brignone et al. 2004). Es wird außerdem angenommen, dass RD23B an der Nukleotidexzisionsreparatur beteiligt ist, einem der wichtigsten DNA-Reparatur-Mechanismen, welcher eine Vielzahl an Basenläsionen beseitigen kann (Sugasawa et al. 1996).

\subsubsection{Herunterregulierte Proteine}

Das zweite mitochondriale Protein ist, wie oben erwähnt, die bifunktionelle Methylentetrahydrofolat-Dehydrogenase/Cyclohydrolase (MTDC). In dieser Arbeit wurde es durch die $\operatorname{PrP}^{\mathrm{c}}$-Überexpression vermindert ausgebildet. Die physiologische Funktion dieses Proteins ist bisher unbekannt. Man weiß jedoch, dass MTDCknockout-Mäuse in utero sterben. Daher wird davon ausgegangen, dass MTDC eine wesentliche Rolle während der embyonalen Entwicklung spielt und möglicherweise mit dem mitochondrialen Folsäuremetabolismus zusammenhängt (Di Pietro et al. 2002).

Ein weiteres durch die stabile Überexpression von $\operatorname{PrP}^{\mathrm{c}}$ herunterreguliertes Protein ist die Sperminsynthase (SPSY). SPSY ist ein Protein, das der Familie der Aminopropyltransferasen angehört und die Synthese von Spermin katalysiert, indem es den Anbau einer Aminopropylgruppe an das Polyamin Spermidine bewirkt. Polyamine wie Spermin kommen in Säugetiergeweben ubiquitär vor und sind für Zellwachstum und -differenzierung entscheidend (Pegg und McCann 1982). Spermin kann außerdem direkt als Fänger freier Radikaler fungieren und die DNA vor den dadurch induzierten oxidativen Schäden bewahren (Ha et al. 1998). Darüberhinaus konnte nachgewiesen werden, dass Spermin die nukleinsäureinduzierte Polymerisierung des Prionproteins vermindern kann (Bera und Nandi 2007) und sogar in der Lage ist die Vermehrung von $\operatorname{PrP}^{\mathrm{Sc}} \mathrm{zu}$ hemmen. Insbesondere zeigte sich, dass ein Polyamin, welches in der Kopfgruppe Spermin enthält, die Fähigkeit besitzt bereits gebildetes $\operatorname{PrP}^{\mathrm{Sc}}$ abzubauen (Winkelhofer und Tatzelt 2000). Insgesamt könnte somit eine Herunterregulation der SPSY und damit verbunden eine niedrigere Konzentration an Spermin diese Prozesse negativ beeinflussen und möglicherweise für einen verzögerten $\mathrm{Abbau}$ von $\operatorname{PrP}^{\mathrm{c}}$ und $\operatorname{PrP}^{\mathrm{Sc}}$ verantwortlich sein. Interessanterweise zeigt das in dieser Studie ebenfalls als dereguliert nachgewiesene DNA-Reparaturprotein RD23B, wie in Kapitel 5.4.1 beschrieben, eine $\operatorname{PrP}^{\mathrm{c}}$ induzierte Hochregulation seiner Expression. 


\subsection{Zusammenhang: $\quad \operatorname{PrP}^{\mathrm{c}}$-Überexpression und Apoptose}

Zahlreiche frühere Studien beschäftigten sich mit dem Einfluss des Prionproteins auf den programmierten Zelltod. Wie bereits in Kapitel 1.6 erläutert konnten für $\mathrm{PrP}^{\mathrm{c}}$ sowohl anti- (Kuwahara et al. 1999, Sakudo et al. 2003) als auch proapoptotische Eigenschaften nachgewiesen werden. Letztere werden möglicherweise über das C1Fragment vermittelt, welches über die Aktivierung des p53-abhängigen Apoptoseweges die Sensibilität für apoptotische Reize steigert (Sunyach et al. 2007). Vor allem interessant scheint dabei der mögliche Zusammenhang zwischen dem in dieser Studie in den $\mathrm{PrP}^{\mathrm{c}}$-überexprimierenden Zellen hochregulierten Protein ANXA5 und der proapoptotischen Funktion des Prionproteins zu sein. Dass ANXA5 unterschiedlich Einfluss auf Apoptoseereignisse nimmt ist in mehreren Studien belegt. So zeigen ANXA5-Knockout-DT-40-Zellen eine Resistenz gegenüber verschiedenen apoptose-induzierenden Mitteln wie Staurosporin (Hawkins et al. 2002). Andererseits vermag die Überexpression von ANXA5 apoptotische Ereignisse sogar ohne Zugabe apoptose-induzierender Mittel wie Staurosprin zu fördern (Wang und Kirsch 2006). Die $\operatorname{PrP}^{\mathrm{c}}$-Überexpression wiederum kann einen Anstieg der durch Staurosporin hervorgerufenen Zelltodrate via p53 hervorrufen (Paitel et al. 2002, Paitel et al. 2003, Paitel et al. 2004).

In der hier vorliegenden Studie konnte allerdings durch die alleinige $\operatorname{PrP}^{\mathrm{c}}$ Überexpression in den 2-DE-Gelen keine p53-Regulation nachgewiesen werden. Ebenfalls bestätigten die zusätzlich zu den 2-DE-Gelen angefertigten Westernblots, dass die p53-Expression durch die reine $\mathrm{PrP}^{\mathrm{c}}$-Überexpression in $\mathrm{SH}-\mathrm{S} Y 5 Y-Z e l l e n$ unter unveränderten Bedingungen, d.h. ohne Zugabe apoptose-induzierender Substanzen, in der Tat unverändert bleibt. Die alleinige $\mathrm{PrP}^{\mathrm{c}}$-Überexpression in $\mathrm{SH}-$ SY5Y-Zellen reicht somit nicht aus, um den p53-abhängigen Apoptoseweg zu aktivieren. Trotzallem scheint es plausibel, dass die erhöhte Empfänglichkeit von $\operatorname{PrP}^{\mathrm{c}}$-überexprimierenden Zellen für Staurosporin im Zusammenhang mit der Hochregulation von ANXA5 steht.

Ein weiteres hochreguliertes Protein, welches einen Zusammenhang zwischen der $\operatorname{PrP}^{\mathrm{c}}$-Überexpression und dem Zelltod, speziell dem Nervenzelltod, herstellt, ist PQBP1 (siehe Kapitel 5.4.1). Durch seine Fähigkeit das Membranpotential von Mitochondrien zu zerstören, führt es zur Aktivierung von Caspasen und somit zum Zelltod. Die Aktivierung von Caspase 3 und Cytochrom $c$ und zusätzlich 
Veränderungen der mitochondrialen Morphologie konnten nach vehrmehrter Expression von PQBP1 nachgewiesen werden (Marubuchi et al. 2005). Mitochondriale Veränderungen konnten in zahlreichen neurodegenerativen Erkrankungen nachgewiesen werden (Friedlander 2003) und sind vermutlich ein wesentlicher Bestandteil der Neurodegeneration. Die Hochregulation von PQBP1 deutet darauf hin, dass $\mathrm{PrP}^{\mathrm{c}}$ in den SH-SY5Y-Zellen die Apoptosebereitschaft erhöht und sie möglicherweise für neurodegenerative Prozesse empfänglicher macht. Auch hier muss jedoch die exakte Rolle von PQBP1 für die Pathogenese von Prionerkrankungen in weiteren Experimenten untersucht werden. 


\section{$6 \quad$ Zusammenfassung}

Bis heute sind zahlreiche Studien zur physiologischen Funktion des zellulären Prionproteins $\left(\operatorname{PrP}^{c}\right)$ durchgeführt worden, wodurch die Erkenntnisse über dieses Protein ein weites Spektrum verschiedener, teilweise gegensätzlicher Funktionen abdecken. Nachdem in-vivo-Experimente gezeigt haben, dass die $\operatorname{PrP}^{\mathrm{c}}$ Überexpression zu Neurodegeneration führen kann (Westaway et al. 1994, Huang et al. 2007), sind besonders die molekularen Mechanismen von Interesse, die dazu beigetragen haben könnten. Die hier vorliegende Studie gewährt über einen Proteomvergleich mittels stabiler Überexpression von $\operatorname{PrP}^{\mathrm{c}}$ in humanen Neuroblastomzellen weitere Einblicke, an welchen zellulären Prozessen das Prionprotein beteiligt ist und filtert Proteine heraus, die einen wesentlichen Einfluss auf die physiologische Funktion von $\operatorname{PrP}^{\mathrm{c}}$ haben könnten.

Hierbei scheint ANXA5, dessen Hochregulation sowohl in SH-SY5Y-Zellen als auch in HEK293- (Ramljak et al. 2008), N2a- und SK-N-LO-Zellen (Weiss et al. 2010) oder nach Untersuchungen der Genexpression im frontalen Kortex von CJKPatienten gezeigt werden konnte (Xiang et al. 2005), eine wesentliche Rolle zu spielen. Insgesamt weisen die Ergebnisse dieser Studie darauf hin, dass die PrP ${ }^{\mathrm{c}}$ Überexpression das zelluläre Gleichgewicht stört. So ist die Mehrzahl der Proteine, die durch die $\operatorname{PrP}^{\mathrm{c}}$-Überexpression reguliert worden sind, an wichtigen Prozessen wie Zellkommunikation, Zytoskelettorganisation und Proteinfaltung beteiligt. Einige sind aber auch für den Energiestoffwechsel, das zelluläre Gleichgewicht oder die DNAReparatur wichtig. Alleine, dass die reine $\operatorname{PrP}^{\mathrm{c}}$-Überexpression zur Deregulation zahlreicher wichtiger Proteine führt, bestätigt deutlich, dass $\operatorname{PrP}^{\mathfrak{c}}$ für verschiedenste physiologische Prozesse relevant sein könnte.

Besonders interessant ist, dass die Expression von Proteinen verändert wurde, die im Zusammenhang mit der Alzheimer-Krankheit oder der sCJK stehen. Diese Feststellung könnte für das Verständnis der molekularen Mechanismen, die der Pathogenese von Prion- und anderen neurodegenerativen Erkrankungen zu Grunde liegen, nützlich sein.

In Bezug auf Apoptose deutet die Hochregulation von ANXA5 und PQBP1 darauf hin, dass die Überexpression von $\operatorname{PrP}^{\mathrm{c}}$ apoptotische Prozesse erleichtert. Ein Zusammenhang zwischen $\operatorname{PrP}^{c}$ und dem p53-abhängigen Zelltod konnte in den SH- 
SY5Y-Zellen jedoch nicht nachgewiesen werden. Somit genügt die Überexpression von $\mathrm{PrP}^{\mathrm{c}}$ in $\mathrm{SH}-\mathrm{SY} 5 \mathrm{Y}-Z$ ellen scheinbar, um die zelluläre Homöostase zu stören, reicht jedoch für die Aktivierung der Apoptosekaskade nicht aus. Die in anderen Experimenten schon mehrfach nachgewiesene gesteigerte Empfänglichkeit von $\operatorname{PrP}^{\mathrm{c}}$ überexprimierenden Zellen für Apoptose-induzierende Mittel wie Staurosporin wird über einen p53-abhängigen Weg vermittelt. Andere Proteine, die an diesem Prozess beteiligt sind, oder ihre Phosphorylierungsmuster sind jedoch größtenteils unbekannt. Ihre Untersuchung könnte zukünftigen Experimenten zugrunde liegen. 


\section{$7 \quad$ Literaturverzeichnis}

Aguzzi A (2003): Prions and the immune system: a journey through gut, spleen, and nerves. Adv Immunol $\underline{81}, 123-71$

Alper T, Haig DA, Clarke MC (1966): The exceptionally small size of the scrapie agent. Biochem Biophys Res Commun 22, 278-84

Alper T, Cramp WA, Haig DA, Clarke MC (1967): Does the agent of scrapie replicate without nucleic acid? Nature $\underline{214}, 764-6$

Assinder SJ, Stanton JA, Prasad PD (2009): Transgelin: an actin-binding protein and tumour suppressor. Int J Biochem Cell Biol 41, 482-6

Beekes M, McBride PA, Baldauf E (1998): Cerebral targeting indicates vagal spread of infection in hamsters fed with scrapie. J Gen Virol 79 ( Pt 3), 601-7

Bendheim PE, Brown HR, Rudelli RD, Scala LJ, Goller NL, Wen GY, Kascsak RJ, Cashman NR, Bolton DC (1992): Nearly ubiquitous tissue distribution of the scrapie agent precursor protein. Neurology $\underline{42}, 149-56$

Bera A und Nandi PK (2007): Biological polyamines inhibit nucleic-acid-induced polymerisation of prion protein. Arch Virol 152, 655-68

Blum H, Beier H, Gross HJ (1987): Improved silver staining of plants proteins, RNA and DNA in polyacrylamide gels. Electrophoresis $\underline{8}, 93-99$

Bolton DC, McKinley MP, Prusiner SB (1982): Identification of a protein that purifies with the scrapie prion. Science 218, 1309-11

Borchelt DR, Scott M, Taraboulos A, Stahl N, Prusiner SB (1990): Scrapie and cellular prion proteins differ in their kinetics of synthesis and topology in cultured cells. J Cell Biol 110, 743-52

Bounhar Y, Zhang Y, Goodyer CG, LeBlanc A (2001): Prion protein protects human neurons against Bax-mediated apoptosis. J Biol Chem 276, 39145-9

Bradford MM (1976): A rapid and sensitive method for the quantitation of microgram quantities of protein utilizing the principle of protein-dye binding. Anal Biochem $\underline{72}, 248-54$

Brandner S, Raeber A, Sailer A, Blattler T, Fischer M, Weissmann C und Aguzzi A (1996): Normal host prion protein (PrPc) is required for scrapie spread within the

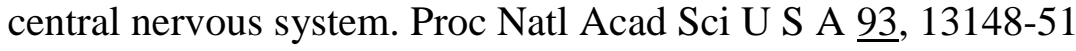

Brignone C, Bradley KE, Kisselev AF, Grossman SR (2004): A post-ubiquitination role for MDM2 and hHR23A in the p53 degradation pathway. Oncogene $\underline{23}$, 4121-9 
Brown DR und Besinger A (1998): Prion protein expression and superoxide dismutase activity. Biochem. J. 334, 423-9

Brown DR, Schmidt B und Kretzschmar HA (1996): Role of microglia and host prion protein in neurotoxicity of a prion protein fragment. Nature $\underline{380}, 345-7$

Budka H: Portrait der Creutzfeldt-Jakob-Krankheit (CJD); in: Prionen und Prionkrankheiten, hrsg. v. Hörnlimann B, Riesner D and Kretzschmar H; Walter de Gruyter, Berlin 2001a, 147-151

Budka H: Portrait des Gerstmann-Sträussler-Scheinker-Syndroms (GSS); in: Prionen und Prionkrankheiten, 1. Auflage; hrsg. v. Hörnlimann B, Riesner D and Kretzschmar H; Walter de Gruyter, Berlin 2001b, 159

Büeler HR, Aguzzi A, Sailer A, Greiner RA, Autenried P, Aquet M und Weissmann C (1993): Mice devoid of PrP are resistant to scrapie. Cell $\underline{73}, 1339-47$

Chen S, Mange A, Dong L, Lehmann S und Schachner M (2003): Prion protein as trans-interacting partner for neurons is involved in neurite outgrowth and neuronal survival. Mol Cell Neurosci 22, 227-33

Chen XQ, Fung YW, Yu AC (2005): Association of 14-3-3gamma and phosphorylated bad attenuates injury in ischemic astrocytes. J Cereb Blood Flow Metab 25, 338-47

Cheng AM, Saxton TM, Sakai R, Kulkarni S, Mbamalu G, Vogel W, Tortorice CG, Cardiff RD, Cross JC, Muller WJ, Pawson T (1998): Mammalian Grb2 Regulates Multiple Steps in Embryonic Development and Malignant Transformation. Cell $\underline{95}$, 793-803

Chiarini LB, Freitas AR, Zanata SM, Brentani RR, Martins VR und Linden R (2002): Cellular prion protein transduces neuroprotective signals. EMBO J 21, 331726

Chiesa R, Piccardo P, Biasini E, Ghetti B, Harris DA (2008): Aggregated, wild-type prion protein causes neurological dysfunction and synaptic abnormalities. J Neurosci $\underline{28}, 13258-67$

Cohen E, Taraboulos A (2003): Scrapie-like prion protein accumulates in aggresomes of cyclosporin A-treated cells. EMBO J 22, 404-17

Cohen FE, Pan KM, Huang Z, Baldwin M, Fletterick RJ und Prusiner SB (1994): Structural clues to prion replication. Science 264, 530-1

Collinge J (2005): Molecular neurology of prion disease. J Neurol Neurosurg Psychiatry $\underline{76}, 906-19$

Come JH, Fraser PE, Lansbury PT, Jr. (1993): A kinetic model for amyloid formation in the prion diseases: importance of seeding. Proc Natl Acad Sci U S A $\underline{90}$, 5959-63 
Coso OA, Chiariello M, Yu JC, Teramoto H, Crespo P, Xu N, Miki T, Gutkind JS (1995): The small GTP-binding proteins Rac1 and Cdc42 regulate the activity of the JNK/SAPK signaling pathway. Cell $\underline{81}, 1137-46$

Cuillé J, Chelle PL (1939): Experimental transmission of trembling to the goat. CR Seances Acad. Sci. 208, 1058-1060

De Gioia L, Selvaggini C, Ghibaudi E, Diomede L, Bugiani O, Forloni G, Tagliavini F und Salmona M (1994): Conformational polymorphism of the amyloidogenic and neurotoxic peptide homologous to residues 106-126 of the prion protein. J Biol Chem. 269, 7859-62

Di Pietro E, Sirois J, Tremblay ML, MacKenzie RE (2002): Mitochondrial NADdependent methylenetetrahydrofolate dehydrogenase-methenyltetrahydrofolate cyclohydrolase is essential for embryonic development. Mol Cell Biol 22, 4158-66

Domingo MT, Spinnewyn B, Chabrier PE, Braquet P (1988): Presence of specific binding sites for platelet-activating factor (PAF) in brain. Biochem Biophys Res Commun 151, 730-6

Dong CF, Shi S, Wang XF, An R, Li P, Chen JM, Wang X, Wang GR, Shan B, Zhang BY (2008): The N-terminus of PrP is responsible for interacting with tubulin and fCJD related PrP mutants possess stronger inhibitive effect on microtubule assembly in vitro. Arch Biochem Biophys $\underline{470}$, 83-92

Dupiereux I, Zorzi W, Rachidi W, Zorzi D, Pierard O, Lhereux B, Heinen E, Elmoualij B (2006): Study on the toxic mechanism of prion protein peptide 106-126 in neuronal and non neuronal cells. J Neurosci Res $\underline{84}$, 637-46

Dzwonek J, Rylski M, Kaczmarek L (2004): Matrix metalloproteinases and their endogenous inhibitors in neuronal physiology of the adult brain. FEBS Lett $\underline{567}$, $129-35$

Ferri KF, Kroemer G (2001): Organelle-specific initiation of cell death pathways. Nat Cell Biol $\underline{3}$, E255-63

Forloni G, Angeretti N, Chiesa R, Monzani E, Salmona M, Bugiani O und Tagliavini F (1993): Neurotoxicity of a prion protein fragment. Nature $\underline{362}, 543-6$

Friedlander RM (2003): Apoptosis and caspases in neurodegenerative diseases. N Engl J Med 348, 1365-75

Fu H, Subramanian RR, Masters SC (2000): 14-3-3 proteins: structure, function, and regulation. Annu Rev Pharmacol Toxicol 40, 617-47

Gachet Y, Tournier S, Lee M, Lazaris-Karatzas A, Poulton T, Bommer UA (1999): The growth-related, translationally controlled protein $\mathrm{P} 23$ has properties of a tubulin binding protein and associates transiently with microtubules during the cell cycle. $\mathrm{J}$ Cell Sci 112, 1257-71 
Gilbert HF (1997): Protein disulfide isomerase and assisted protein folding. J Biol Chem 272, 29399-402

Giri PR, Linnoila M, O'Neill JB, Goldman D (1989): Distribution and possible metabolic role of class III alcohol dehydrogenase in the human brain. Brain Res $\underline{481}$, $131-41$

Glockzin S, Ogi FX, Hengstermann A, Scheffner M, Blattner C (2003): Involvement of the DNA repair protein hHR23 in p53 degradation. Mol Cell Biol 23, 8960-9

Gold BG, Densmore V, Shou W, Matzuk MM, Gordon HS (1999): Immunophilin FK506-binding protein 52 (not FK506-binding protein 12) mediates the neurotrophic action of FK506. J Pharmacol Exp Ther 289, 1202-10

Goodman A, Goode BL, Matsudaira P und Fink GR (2003): The Saccharomyces cerevisiae calponin/transgelin homolog Scp1 functions with fimbrin to regulate stability and organization of the actin cytoskeleton. Mol Biol Cell 14, 2617-29

Gorodinsky A, Harris DA (1995): Glycolipid-anchored proteins in neuroblastoma cells form detergent-resistant complexes without caveolin. J Cell Biol 129, 619-27

Gourlay CW, Carpp LN, Timpson P, Winder SJ und Ayscough KR (2004): A role for the actin cytoskeleton in cell death and aging in yeast. J Cell Biol 164, 803-9

Graner E, Mercadante AF, Zanata SM, Forlenza OV, Cabral AL, Veiga SS, Juliano MA, Roesler R, Walz R, Minetti A (2000): Cellular prion protein binds laminin and mediates neuritogenesis. Brain Res Mol Brain Res $\underline{76}, 85-92$

Griffith JS (1967): Self-replication and scrapie. Nature 215, 1043-4

Ha HC, Sirisoma NS, Kuppusamy P, Zweier JL, Woster PM, Casero RA, Jr. (1998): The natural polyamine spermine functions directly as a free radical scavenger. Proc Natl Acad Sci U S A $\underline{95}, 11140-5$

Hall A (1998): Rho GTPases and the actin cytoskeleton. Science 279, 509-14

Han S, Zhang KH, Lu PH, Xu XM (2004): Effects of annexins II and V on survival of neurons and astrocytes in vitro. Acta Pharmacol Sin $\underline{25}, 602-10$

Haraguchi T, Fisher S, Olofsson S, Endo T, Groth D, Tarentino A, Borchelt DR, Teplow D, Hood L, Burlingame A (1989): Asparagine-linked glycosylation of the scrapie and cellular prion proteins. Arch Biochem Biophys 274, 1-13

Harris DA (2003): Trafficking, turnover and membrane topology of PrP. Br Med Bull $\underline{66}, 71-85$

Hattori M, Arai H, Inoue K (1993): Purification and characterization of bovine brain platelet-activating factor acetylhydrolase. J Biol Chem $\underline{268}$, 18748-53 
Hawkins TE, Das D, Young B, Moss SE (2002): DT40 cells lacking the Ca2+binding protein annexin 5 are resistant to $\mathrm{Ca} 2+-$ dependent apoptosis. Proc Natl Acad Sci U S A $\underline{99}, 8054-9$

Hetz C, Russelakis-Carneiro M, Walchli S, Carboni S, Vial-Knecht E, Maundrell K, Castilla J, Soto C (2005): The disulfide isomerase Grp58 is a protective factor against prion neurotoxicity. J Neurosci $25,2793-802$

Hill AF, Zeidler M, Ironside J, Collinge J (1997): Diagnosis of new variant Creutzfeldt-Jakob disease by tonsil biopsy. Lancet $\underline{349}$, 99-100

Holmquist B, Vallee BL (1991): Human liver class III alcohol and glutathione dependent formaldehyde dehydrogenase are the same enzyme. Biochem Biophys Res Commun $\underline{178}$, 1371-7

Hörnlimann B: Portrait der Kuru; in: Prionen und Prionkrankheiten, 1. Auflage; hrsg. v. Hörnlimann B, Riesner D and Kretzschmar H; Walter de Gruyter, Berlin 2001, $141-146$

Hornshaw MP, McDermott JR, Candy JM (1995): Copper binding to the N-terminal tandem repeat regions of mammalian and avian prion protein. Biochem Biophys Res Commun 207, 621-9

Hsiao K, Baker HF, Crow TJ, Poulter M, Owen F, Terwilliger JD, Westaway D, Ott J, Prusiner SB (1989): Linkage of a prion protein missense variant to GerstmannStraussler syndrome. Nature $\underline{338}, 342-5$

Huang S, Liang J, Zheng M, Li X, Wang M, Wang P, Vanegas D, Wu D, Chakraborty B, Hays AP (2007): Inducible overexpression of wild-type prion protein in the muscles leads to a primary myopathy in transgenic mice. Proc Natl Acad Sci U S A $\underline{104}, 6800-5$

Johnson CJ, Phillips KE, Schramm PT, McKenzie D, Aiken JM und Pedersen JA (2006): Prions adhere to soil minerals and remain infectious. PloS Pathog. 2, e32

Jung J, Kim M, Kim MJ, Kim J, Moon J, Lim JS, Lee K (2004): Translationally controlled tumor protein interacts with the third cytoplasmic domain of $\mathrm{Na}, \mathrm{K}$ ATPase alpha subunit and inhibits the pump activity in HeLa cells. J Biol Chem $\underline{279}$, 49868-75

Kaverina I, Stradal TEB und Gimona M (2003): Podosome formation in cultured A7r5 vascular smooth muscle cells requires Arp2/3-dependent denovo actin polymerization at discrete microdomains. J Cell Sci $\underline{116}, 4915-24$

Kim MJ, Kwon JS, Suh SH, Suh JK, Jung J, Lee SN, Kim YH, Cho MC, Oh GT, Lee K (2008): Transgenic overexpression of translationally controlled tumor protein induces systemic hypertension via repression of $\mathrm{Na}+, \mathrm{K}+-\mathrm{ATPase}$. J Mol Cell Cardiol 44, 151-9 
Kleene R, Loers G, Langer J, Frobert Y, Buck F, Schachner M (2007): Prion protein regulates glutamate-dependent lactate transport of astrocytes. J Neurosci $\underline{27}$, 1233140

Krasemann S, Jurgens T, Bodemer W (1999): Generation of monoclonal antibodies against prion proteins with an unconventional nucleic acid-based immunization strategy. J Biotechnol 73, 119-29

Kretzschmar HA (1999): Molecular pathogenesis of prion diseases. Eur Arch Psychiatry Clin Neurosci 249 Suppl 3, 56-63

Kretzschmar HA, Stowring LE, Westaway D, Stubblebine WH, Prusiner SB, Dearmond SJ (1986): Molecular cloning of a human prion protein cDNA. DNA $\underline{5}$, $315-24$

Kuwahara C, Takeuchi AM, Nishimura T, Haraguchi K, Kubosaki A, Matsumoto Y, Saeki K, Yokoyama T, Itohara S, Onodera T (1999): Prions prevent neuronal cellline death. Nature $\underline{400}, 225-6$

Kuzuya A, Uemura K, Kitagawa N, Aoyagi N, Kihara T, Ninomiya H, Ishiura S, Takahashi R, Shimohama S (2007): Presenilin 1 is involved in the maturation of beta-site amyloid precursor protein-cleaving enzyme 1 (BACE1). J Neurosci Res $\underline{85}$, $153-65$

Ladogana A, Puopolo M, Croes EA, Budka H, Jarius C, Collins S, Klug GM, Sutcliffe T, Giulivi A, Alperovitch A (2005): Mortality from Creutzfeldt-Jakob disease and related disorders in Europe, Australia, and Canada. Neurology 64, 158691

Lansbury PT, Jr., Caughey B (1995): The chemistry of scrapie infection: implications of the 'ice 9' metaphor. Chem Biol $\underline{2}, 1-5$

Lasmezas CI, Deslys JP, Robain O, Jaegly A, Beringue V, Peyrin JM, Fournier JG, Hauw JJ, Rossier J, Dormont D (1997): Transmission of the BSE agent to mice in the absence of detectable abnormal prion protein. Science $\underline{275}, 402-5$

LeBlanc A: Unravelling the controversy of prion diseases; in: Handbook of the aging brain, hrsg. v. Wang E and Snyder S; Academic Press, New York 1998, 202-214

Le Clainche C, Carlier MF (2008): Regulation of actin assembly associated with protrusion and adhesion in cell migration. Physiol Rev $\underline{88}, 489-513$

Legname G, Baskakov IV, Nguyen HOB, Riesner D, Cohen FE, DeArmond SJ und Prusiner SB (2004): Synthetic mammmalian prions. Science 305, 673-6

Lewis PA, Tattum MH, Jones S, Bhelt D, Batchelor M, Clarke AR, Collinge J, Jackson GS (2006): Codon 129 polymorphism of the human prion protein influences the kinetics of amyloid formation. J Gen Virol 87, 2443-9

Li YJ, Oliveira SA, Xu P, Martin ER, Stenger JE, Scherzer CR, Hauser MA, Scott WK, Small GW, Nance MA (2003): Glutathione S-transferase omega-1 modifies 
age-at-onset of Alzheimer disease and Parkinson disease. Hum Mol Genet 12, 325967

Liu H, Bowes RC, 3rd, van de Water B, Sillence C, Nagelkerke JF, Stevens JL (1997): Endoplasmic reticulum chaperones GRP78 and calreticulin prevent oxidative stress, Ca2+ disturbances, and cell death in renal epithelial cells. J Biol Chem $\underline{272}$, 21751-9

Liu M, Oberg K, Zhou Y (2007): Expression and function of vinculin in neuroendocrine tumors. Tumour Biol $\underline{28}, 196-204$

Lupi O (2003): Could ectoparasites act as vectors for prion diseases? Int J Dermatol $\underline{42}, 425-9$

Ma J, Wollmann R, Lindquist S (2002): Neurotoxicity and neurodegeneration when PrP accumulates in the cytosol. Science $\underline{298}, 1781-5$

Makarava N, Kovacs GG, Bocharova O, Savtchenko R, Alexeeva I, Budka H, Rohwer RG, Baskakov IV (2009): Recombinant prion protein induces a new transmissible prion disease in wild-type animals. Acta Neuropathol $\underline{199}, 177-87$

Malaga-Trillo E, Solis GP, Schrock Y, Geiss C, Luncz L, Thomanetz V, Stuermer CA (2009): Regulation of embryonic cell adhesion by the prion protein. PLoS Biol $\underline{7}$, $\mathrm{e} 55$

Mallucci GR, Ratté S, Asante EA, Linehan J, Gowland I, Jefferys JGR und Collinge J (2002): Post-natal knockout of prion protein alters hippocampal CA1 properties, but does not result in neurodegeneration. EMBO J $\underline{21}, 202-10$

Mallucci GR, Dickinson A, Linehan J, Klohn PC, Brandner S, Collinge J (2003): Depleting neuronal PrP in prion infection prevents disease and reverses spongiosis. Science $\underline{302}, 871-4$

Manuelidis L, Yu ZX, Barquero N, Mullins B (2007): Cells infected with scrapie and Creutzfeldt-Jakob disease agents produce intracellular $25-\mathrm{nm}$ virus-like particles. Proc Natl Acad Sci U S A $\underline{104}$, 1965-70

Marcheselli VL, Rossowska MJ, Domingo MT, Braquet P, Bazan NG (1990): Distinct platelet-activating factor binding sites in synaptic endings and in intracellular membranes of rat cerebral cortex. J Biol Chem $\underline{265}$, 9140-5

Marciano PG, Brettschneider J, Manduchi E, Davis JE, Eastman S, Raghupathi R, Saatman KE, Speed TP, Stoeckert CJ, Jr., Eberwine JH (2004): Neuron-specific mRNA complexity responses during hippocampal apoptosis after traumatic brain injury. J Neurosci $\underline{24}$, 2866-76

Martinez T, Pascual A (2007): Identification of genes differentially expressed in SHSY5Y neuroblastoma cells exposed to the prion peptide 106-126. Eur J Neurosci 26, $51-9$ 
Marubuchi S, Wada Y, Okuda T, Hara Y, Qi ML, Hoshino M, Nakagawa M, Kanazawa I, Okazawa H (2005): Polyglutamine tract-binding protein-1 dysfunction induces cell death of neurons through mitochondrial stress. J Neurochem $\underline{95}, 858-70$

McLennan NF, Brennan PM, McNeill A, Davies I, Fotheringham A, Rennison KA, Ritchie D, Brannan F, Head MW, Ironside JW (2004): Prion protein accumulation and neuroprotection in hypoxic brain damage. Am J Pathol 165, 227-35

Medori R, Tritschler HJ, LeBlanc A, Villare F, Manetto V, Chen HY, Xue R, Leal S, Montagna P, Cortelli P (1992): Fatal familial insomnia, a prion disease with a mutation at codon 178 of the prion protein gene. N Engl J Med $\underline{326}, 444-9$

Meyer RK, McKinley MP, Bowman KA, Braunfeld MB, Barry RA und Prusiner SB (1986): Separation and properties of cellular and scrapie prion proteins. Proc. Natl. Acad. Sci. USA $\underline{83}$, 2310-4

Minden A, Lin A, Claret FX, Abo A, Karin M (1995): Selective activation of the JNK signaling cascade and c-Jun transcriptional activity by the small GTPases Rac and Cdc42Hs. Cell $\underline{81}, 1147-57$

Mitteregger G, Vosko M, Krebs B, Xiang W, Kohlmannsperger V, Nolting S, Hamann GF, Kretzschmar HA (2007): The role of the octarepeat region in neuroprotective function of the cellular prion protein. Brain Pathol 17, 174-83

Moore RC, Lee IY, Silverman GL, Harrison PM, Strome R, Heinrich C, Karunaratne A, Pasternak SH, Chishti MA, Liang Y (1999): Ataxia in prion protein (PrP)deficient mice is associated with upregulation of the novel PrP-like protein doppel. $\mathrm{J}$ Mol Biol 292, 797-817

Mouillet-Richard S, Ermonval M, Chebassier C, Laplanche JL, Lehmann S, Launay JM, Kellermann O (2000): Signal transduction through prion protein. Science 289, $1925-8$

Müller T, Concannon CG, Ward MW, Walsh CM, Tirniceriu AL, Tribl F, Kögel D, Prehn JH und Egensperger R (2007): Modulation of gene expression and cytoskeletal dynamics by the amyloid precursor protein intracellular domain (AICD). Mol Biol Cell $\underline{18}, 201-10$

Nair RR, Solway J, Boyd DD (2006): Expression cloning identifies transgelin (SM22) as a novel repressor of 92-kDa type IV collagenase (MMP-9) expression. J Biol Chem 281, 26424-36

Naslavsky N, Stein R, Yanai A, Friedlander G, Taraboulos A (1997): Characterization of detergent-insoluble complexes containing the cellular prion protein and its scrapie isoform. J Biol Chem $\underline{272}$, 6324-31

NCJDSU (Dezember 2007): veröffentlicht auf der Website der "National Creutzfeldt-Jakob-Disease Surveillance Unit" (NCJDSU), Edinburgh. http://www.cjd.ed.ac.uk/report16.pdf 
NCJDSU (Februar 2009): veröffentlicht auf der Website der "National CreutzfeldtJakob-Disease Surveillance Unit" (NCJDSU), Edinburgh. http://www.cjd.ed.ac.uk/vcjdworld.htm

Nishida N, Tremblay P, Sugimoto T, Shigematsu K, Shirabe S, Petromilli C, Erpel SP, Nakaoke R, Atarashi R, Houtani T (1999): A mouse prion protein transgene rescues mice deficient for the prion protein gene from purkinje cell degeneration and demyelination. Lab Invest $\underline{79}, 689-97$

Oesch B, Westaway D, Walchli M, McKinley MP, Kent SB, Aebersold R, Barry RA, Tempst P, Teplow DB, Hood LE (1985): A cellular gene encodes scrapie PrP 27-30 protein. Cell $\underline{40}, 735-46$

Okuda T, Hattori H, Takeuchi S, Shimizu J, Ueda H, Palvimo JJ, Kanazawa I, Kawano H, Nakagawa M, Okazawa H (2003): PQBP-1 transgenic mice show a lateonset motor neuron disease-like phenotype. Hum Mol Genet $\underline{12}$, 711-25

Paitel E, Alves da Costa C, Vilette D, Grassi J, Checler F (2002): Overexpression of PrPc triggers caspase 3 activation: potentiation by proteasome inhibitors and blockade by anti-PrP antibodies. J Neurochem $\underline{83}, 1208-14$

Paitel E, Fahraeus R, Checler F (2003): Cellular prion protein sensitizes neurons to apoptotic stimuli through Mdm2-regulated and p53-dependent caspase 3-like activation. J Biol Chem $\underline{278}$, 10061-6

Paitel E, Sunyach C, Alves da Costa C, Bourdon JC, Vincent B, Checler F (2004): Primary cultured neurons devoid of cellular prion display lower responsiveness to staurosporine through the control of p53 at both transcriptional and posttranscriptional levels. J Biol Chem $\underline{279}, 612-8$

Palmer MS, Dryden AJ, Hughes JT, Collinge J (1991): Homozygous prion protein genotype predisposes to sporadic Creutzfeldt-Jakob disease. Nature $\underline{352}$, 340-2

Pan KM, Baldwin M, Nguyen J, Gasset M, Serban A, Groth D, Mehlhorn I, Huang Z, Fletterick RJ, Cohen FE (1993): Conversion of alpha-helices into beta-sheets features in the formation of the scrapie prion proteins. Proc Natl Acad Sci U S A $\underline{90}$, 10962-6

Pegg AE, McCann PP (1982): Polyamine metabolism and function. Am J Physiol $\underline{243}, \mathrm{C} 212-21$

Perdew GH, Whitelaw ML (1991): Evidence that the 90-kDa heat shock protein (HSP90) exists in cytosol in heteromeric complexes containing HSP70 and three other proteins with Mr of 63,000, 56,000, and 50,000. J Biol Chem 266, 6708-13

Peters PJ, Mironov A, Jr., Peretz D, van Donselaar E, Leclerc E, Erpel S, DeArmond SJ, Burton DR, Williamson RA, Vey M (2003): Trafficking of prion proteins through a caveolae-mediated endosomal pathway. J Cell Biol 162, 703-17

Poeck K, Hacke W: Neurologie. 11. Auflage; Springer-Verlag, Berlin 2001 
Post K, Riesner D, Walldorf V, Mehlhorn H (1999): Fly larvae and pupae as vectors for scrapie. Lancet $\underline{354}$, 1969-70

Pradines E, Loubet D, Schneider B, Launay JM, Kellermann O, Mouillet-Richard S (2008): CREB-dependent gene regulation by prion protein: impact on MMP-9 and beta-dystroglycan. Cell Signal 20, 2050-8

Prescott SM, Zimmerman GA, Stafforini DM, McIntyre TM (2000): Plateletactivating factor and related lipid mediators. Annu Rev Biochem $\underline{69}$, 419-45

Prusiner SB (1982): Novel proteinaceous infectious particles cause scrapie. Science $\underline{216}, 136-44$

Prusiner SB (1982): Novel proteinaceous infectious particles cause scrapie. Science 216, $136-44$

Prusiner SB (1998): Prions. Proc Natl Acad Sci U S A $\underline{95}$, 13363-83

Prusiner SB: Prions Prions Prions, Springer Verlag, Berlin Heidelberg New 1996, Einband

Prusiner SB, Scott M, Foster D, Pan KM, Groth D, Mirenda C, Torchia M, Yang SL, Serban D, Carlson GA (1990): Transgenetic studies implicate interactions between homologous PrP isoforms in scrapie prion replication. Cell $\underline{63}, 673-86$

Puckett C, Concannon P, Casey C, Hood L (1991): Genomic structure of the human prion protein gene. Am J Hum Genet $\underline{49}$, 320-9

Rachidi W, Vilette D, Guiraud P, Arlotto M, Riondel J, Laude H, Lehmann S und Favier A (2003): Expression of prion protein increases cellular copper binding and antioxidant enzyme activities but not copper delivery. J Biol Chem $\underline{278}$, 9064-72

Ramljak S, Asif AR, Armstrong VW, Wrede A, Groschup MH, Buschmann A, Schulz-Schaeffer W, Bodemer W, Zerr I (2008): Physiological role of the cellular prion protein $(\mathrm{PrPc})$ : protein profiling study in two cell culture systems. J Proteome Res $\underline{7}, 2681-95$

Rao RV, Peel A, Logvinova A, del Rio G, Hermel E, Yokota T, Goldsmith PC, Ellerby LM, Ellerby HM, Bredesen DE (2002): Coupling endoplasmic reticulum stress to the cell death program: role of the ER chaperone GRP78. FEBS Lett $\underline{514}$, $122-8$

Ricketts MN: Public Health and the BSE Epidemic; in: Current Topics in Microbiology and Immnunology, Band 284: Mad Cow Disease and Related Spongiform Encephalopathies; hrsg. v. Harris DA; Springer Verlag, Berlin 2004, 112

Riek R, Hornemann S, Wider G, Billeter M, Glockshuber R, Wuthrich K (1996): NMR structure of the mouse prion protein domain $\operatorname{PrP}(121-321)$. Nature $\underline{382}, 180-2$

Rossi D, Cozzio A, Flechsig E, Klein MA, Rulicke T, Aguzzi A, Weissmann C (2001): Onset of ataxia and Purkinje cell loss in PrP null mice inversely correlated with Dpl level in brain. EMBO J 20, 694-702 
Sakaguchi S, Katamine S, Nishida N, Moriuchi R, Shigematsu K, Sugimoto T, Nakatani A, Kataoka Y, Houtani T, Shirabe S (1996): Loss of cerebellar Purkinje cells in aged mice homozygous for a disrupted PrP gene. Nature $\underline{380}, 528-31$

Sakudo A, Lee DC, Saeki K, Nakamura Y, Inoue K, Matsumoto Y, Itohara S, Onodera T (2003): Impairment of superoxide dismutase activation by $\mathrm{N}$-terminally truncated prion protein (PrP) in PrP-deficient neuronal cell line. Biochem Biophys Res Commun $\underline{308}, 660-7$

Sanchez ER (1990): Hsp56: a novel heat shock protein associated with untransformed steroid receptor complexes. J Biol Chem 265, 22067-70

Sanghani PC, Robinson H, Bennett-Lovsey R, Hurley TD, Bosron WF (2003): Structure-function relationships in human Class III alcohol dehydrogenase (formaldehyde dehydrogenase). Chem Biol Interact 143-144, 195-200

Satoh J und Yamamura T (2004): Gene expression profile following stable expression of the cellular prion protein. Cell Mol Neurobiol 24, 793-814

Satoh J, Obayashi S, Misawa T, Sumiyoshi K, Oosumi K, Tabunoki H (2009): Protein microarray analysis identifies human cellular prion protein interactors. Neuropathol Appl Neurobiol 35, 16-35

Schmitt-Ulms G, Legname G, Baldwin MA, Ball HL, Bradon N, Bosque PJ, Crossin KL, Edelman GM, DeArmond SJ, Cohen FE (2001): Binding of Neural Cell Adhesion Molecules (N-CAMs) to the Cellular Prion Protein. J. Mol. Biol. $\underline{314}$, $1209-25$

Seidel B, Thomzig A, Buschmann A, Groschup MH, Peters R, Beekes M, Terytze K (2007): Scrapie Agent (Strain 263K) Can Transmit Disease via the Oral Route after Persistence in Soil over Years. PloS One 2, e435

Shevchenko A, Wilm M, Vorm O, Mann M (1996): Mass spectrometric sequencing of proteins silver-stained polyacrylamide gels. Anal Chem $\underline{68}, 850-8$

Shyng SL, Huber MT, Harris DA (1993): A prion protein cycles between the cell surface and an endocytic compartment in cultured neuroblastoma cells. J Biol Chem $\underline{268}, 15922-8$

Soto C (2004): Diagnosing prion diseases: needs, challenges and hopes. Nat Rev Microbiol 2, 809-19

Spielhaupter C und Schätzl HM (2001): PrPC Directly Interacts with Proteins Involved in Signaling Pathways. J Biol Chem 276, 44604-12

Stahl N, Borchelt DR, Hsiao K, Prusiner SB (1987): Scrapie prion protein contains a phosphatidylinositol glycolipid. Cell $\underline{51}, 229-40$ 
Stahl N, Baldwin MA, Teplow DB, Hood L, Gibson BW, Burlingame AL, Prusiner SB (1993): Structural studies of the scrapie prion protein using mass spectrometry and amino acid sequencing. Biochemistry $\underline{32}$, 1991-2002

Steiner JP, Dawson TM, Fotuhi M, Glatt CE, Snowman AM, Cohen N, Snyder SH (1992): High brain densities of the immunophilin FKBP colocalized with calcineurin. Nature $\underline{358}, 584-7$

Strom A, Diecke S, Hunsmann G und Stuke AW (2006): Identification of prion protein binding proteins by combined use of far-Western immunoblotting, two dimensional gel electrophoresis and mass spectrometry. Proteomics $\underline{6}, 26-34$

Sturzenegger M: Die Klinik der Prionkrankheiten des Menschen; in: Prionen und Prionkrankheiten, hrsg. v. Hörnlimann B, Riesner D and Kretzschmar H; Walter de Gruyter, Berlin 2001, 250-251

Sugasawa K, Masutani C, Uchida A, Maekawa T, van der Spek PJ, Bootsma D, Hoeijmakers JH, Hanaoka F (1996): HHR23B, a human Rad23 homolog, stimulates XPC protein in nucleotide excision repair in vitro. Mol Cell Biol 16, 4852-61

Sunyach C, Cisse MA, da Costa CA, Vincent B und Checler F (2007): The Cterminal products of cellular prion protein processing, $\mathrm{C} 1$ and $\mathrm{C} 2$, exert distinct influence on p53-dependent staurosporine-induced caspase-3 activation. J Biol Chem $\underline{282}$, 195663

Svedin P, Hagberg H, Sävman K, Zhu C und Mallard C (2007): Matrix Metalloproteinase-9 Gene Knock-out Protects the Immature Brain after Cerebral Hypoxia-Ischemia. J Neurosci 27, 1511-8

Tagliavini F, Prelli F, Verga L, Giaccone G, Sarma R, Gorevic P, Ghetti B, Passerini F, Ghibaudi E und Forloni G (1993): Synthetic peptides homologues to prion protein residues 106-147 form amyloid-like fibrils in vitro. Proc Natl Acad Sci U S A $\underline{90}$, 9678-82

Tai PK, Albers MW, Chang H, Faber LE, Schreiber SL (1992): Association of a 59kilodalton immunophilin with the glucocorticoid receptor complex. Science 256 , $1315-8$

Telling GC, Scott M, Mastrianni J, Gabizon R, Torchia M, Cohen FE, DeArmond SJ, Prusiner SB (1995): Prion propagation in mice expressing human and chimeric PrP transgenes implicates the interaction of cellular PrP with another protein. Cell $\underline{83}$, 7990

Thellung S, Villa V, Corsaro A, Arena S, Millo E, Damonte G, Benatti U, Tagliavini F, Florio T, Schettini G (2002): p38 MAP kinase mediates the cell death induced by PrP106-126 in the SH-SY5Y neuroblastoma cells. Neurobiol Dis $\underline{9}, 69-81$

Turk E, Teplow DB, Hood LE, Prusiner SB (1988): Purification and properties of the cellular and scrapie hamster prion proteins. Eur J Biochem 176, 21-30 
UniProt (01. April 2009): veröffentlicht auf der Website der Universal Protein Resource (UniProt) Datenbank. http://www.uniprot.org/uniprot/Q9Y3I0

Van Everbroeck BR, Boons J, Cras P (2005): 14-3-3 \{gamma\}-isoform detection distinguishes sporadic Creutzfeldt-Jakob disease from other dementias. J Neurol Neurosurg Psychiatry $\underline{76}, 100-2$

Vassallo N, Herms J (2003): Cellular prion protein function in copper homeostasis and redox signalling at the synapse. $\mathrm{J}$ Neurochem $\underline{86}, 538-44$

Vassallo N, Herms J, Behrens C, Krebs B, Saeki K, Onodera T, Windl O, Kretzschmar HA (2005): Activation of phosphatidylinositol 3-kinase by cellular prion protein and its role in cell survival. Biochem Biophys Res Commun 332, 75-82

Wang W und Kirsch T (2006): Annexin V/_5 Integrin Interactions Regulate Apoptosis of Growth Plate Chondrocytes. J Biol Chem 281, 30848-56

Waragai M, Lammers $\mathrm{CH}$, Takeuchi S, Imafuku I, Udagawa Y, Kanazawa I, Kawabata M, Mouradian MM, Okazawa H (1999): PQBP-1, a novel polyglutamine tract-binding protein, inhibits transcription activation by Brn-2 and affects cell survival. Hum Mol Genet $\underline{8}$, 977-87

Watt NT, Routledge MN, Wild CP, Hooper NM (2007): Cellular prion protein protects against reactive-oxygen-species-induced DNA damage. Free Radic Biol Med 43, 959-67

Weise J, Crome O, Sandau R, Schulz-Schaeffer W, Bahr M, Zerr I (2004): Upregulation of cellular prion protein $(\mathrm{PrPc})$ after focal cerebral ischemia and influence of lesion severity. Neurosci Lett $\underline{372}, 146-50$

Weise J, Sandau R, Schwarting S, Crome O, Wrede A, Schulz-Schaeffer W, Zerr I, Bahr M (2006): Deletion of cellular prion protein results in reduced Akt activation, enhanced postischemic caspase-3 activation, and exacerbation of ischemic brain injury. Stroke $\underline{37}, 1296-300$

Weiss E, Ramljak S, Asif AR, Ciesielczyk B, Schmitz M, Gawinecka J, SchulzSchaeffer W, Behrens C, Zerr I (2010): Cellular prion protein overexpression disturbs cellular homeostasis in SH-SY5Y neuroblastoma cells but does not alter p53 expression: a proteomic study. Neuroscience 12.06.2010 [Epub ahead of print]

Westaway D, DeArmond SJ, Cayetano-Canlas J, Groth D, Foster D, Yang SL, Torchia M, Carlson GA, Prusiner SB (1994): Degeneration of skeletal muscle, peripheral nerves, and the central nervous system in transgenic mice overexpressing wild-type prion proteins. Cell $\underline{76}, 117-29$

Westergard L, Christensen HM, Harris DA (2007): The cellular prion protein $(\operatorname{PrP}(\mathrm{C}))$ : its physiological function and role in disease. Biochim Biophys Acta $\underline{1772}$, $629-44$

Winkelhofer KF und Tatzelt J (2000): Cationic lipopolyamines induce degradation of PrPSc in scrapie-infected mouse neuroblastoma cells. Biol Chem $\underline{381}$, 463-9 
Wisniewski HM, Sigurdarson S, Rubenstein R, Kascsak RJ, Carp RI (1996): Mites as vectors for scrapie. Lancet $\underline{347}, 1114$

Xiang W, Windl O, Westner IM, Neumann M, Zerr I, Lederer RM, Kretzschmar HA (2005): Cerebral gene expression profiles in sporadic Creutzfeldt-Jakob disease. Ann Neurol $\underline{58}, 242-57$

Yoo BC, Krapfenbauer K, Cairns N, Belay G, Bajo M, Lubec G (2002): Overexpressed protein disulfide isomerase in brains of patients with sporadic Creutzfeldt-Jakob disease. Neurosci Lett $\underline{334}$, 196-200

Zanata SM, Lopes MH, Mercadante AF, Hajj GNM, Chiarini LB, Nomizo R, Freitas ARO, Cabral ALB, Lee KS, Juliano MA (2002): Stress-inducible protein 1 is a cell surface ligand for cellular prion that triggers neuroprotection. EMBO J 21, 3307-16

Zeng F, Watt NT, Walmsley AR, Hooper NM (2003): Tethering the N-terminus of the prion protein compromises the cellular response to oxidative stress. J Neurochem $\underline{84}, 480-90$

Zerr I, Janzen RWC, Schulz, Steinhoff BJ, Urbach H: Creutzfeldt-Jakob-Krankheit; in: Leitlinien für Diagnostik und Therapie in der Neurologie, 2. Auflage; hrsg. v. Diener HC; Georg Thieme Verlag, Stuttgart 2003, 216-219

Zomosa-Signoret V, Arnaud JD, Fontes P, Alvarez-Martinez MT, Liautard JP (2008): Physiological role of the cellular prion protein. Vet Res $\underline{39}, 9$ 


\section{Abbildungsverzeichnis}

Abbildung 1 Glykosylierung des zellulären Prionproteins ................................. 8

Abbildung 2 Schematische Darstellung des zellulären Prionproteins .................. 8

Abbildung 3 Trafficking und proteolytische Spaltung von $\operatorname{PrP}^{\mathrm{c}}$........................ 9

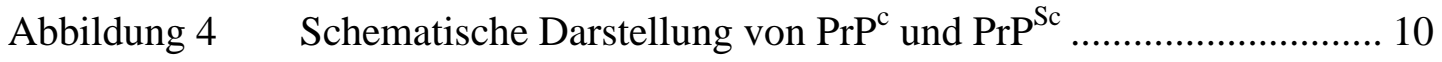

Abbildung 5 Modelle für die Konversion von $\operatorname{PrP}^{\mathrm{c}} \mathrm{zu} \operatorname{PrP}^{\mathrm{Sc}}$............................ 11

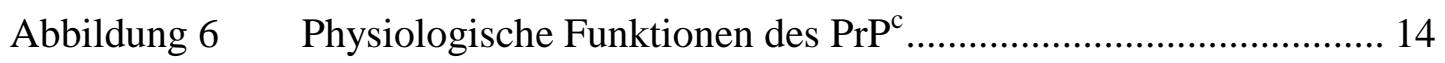

Abbildung $7 \quad$ Morphologie der SH-SY5Y-Zellen ............................................... 34

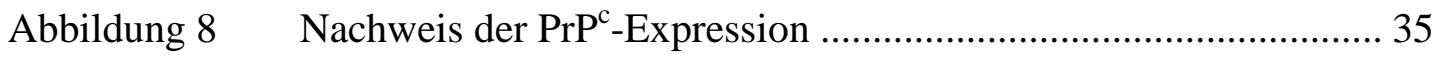

Abbildung 9 Quantitative Untersuchung der $\operatorname{PrP}^{\mathrm{c}}$-Expression ........................... 36

Abbildung 10 Silbergefärbtes 2-DE Gel aus Zelllysat von nicht-transfizierten SH-

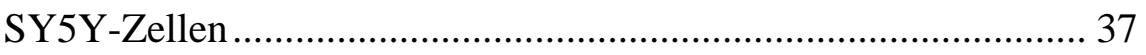

Abbildung $11 \quad \mathrm{PrP}^{\mathrm{c}}$-induzierte Regulation von 1433G...................................... 41

Abbildung $12 \quad \mathrm{PrP}^{\mathrm{c}}$-induzierte Regulation von TAGL2 .................................... 43

Abbildung $13 \quad \mathrm{PrP}^{\mathrm{c}}$-induzierte Regulation von ANXA5 …................................ 45

Abbildung $14 \quad$ Nachweis der Expression von p53 ............................................. 47

Abbildung 15 Übersicht über die 18 regulierten Proteine und ihre Einteilung .... 49 


\section{Danksagung}

Zum Abschluss meiner Doktorarbeit möchte ich mich bei vielen Menschen herzlich bedanken, ohne die die Entstehung der Arbeit nicht ermöglicht worden wäre.

Zunächsteinmal gilt mein besonderer Dank meiner Doktormutter Prof. Inga Zerr. Sie hat mir dieses interessante Thema zur Verfügung gestellt und mir die Möglichkeiten und Freiheiten gegeben, in ihrem Labor wissenschaftlich zu arbeiten. Ich danke ihr für ihre wertvollen Anregungen und ihre Unterstützung, die maßgeblich zum Gelingen meiner Arbeit beigetragen haben.

Ganz besonders bedanke ich mich bei meiner Betreuerin Dr. Sanja Ramljak, die mich gewissenhaft in die Durchführung aller Methoden einarbeitete, mich an ihrem fundierten Fachwissen teilhaben ließ und für ihre Mühen beim Korrigieren meiner Arbeit. Sie ist mir durch ihre fröhliche und offene Art nicht nur als Betreuerin sehr ans Herz gewachsen. Auch Holger Herlin danke ich für das Korrekturlesen der ersten Versionen.

Ohne Barbara Ciesielczyk, die gute Seele des Prionforschungslabors, die mir immer weiterhalf und mich ermunterte, wäre der Laboralltag sicherlich nicht so reibungslos abgelaufen. Ich danke ihr sehr.

Herzlicher Dank gilt der Abteilung für Neuropathologie, deren Zellkulturlabor ich freundlicherweise nutzen durfte und insbesondere Dr. Christina Behrens für ihre Bereitstellung der transfizierten und nicht-transfizierten SH-SY5Y Zellen.

Bei Dr. A. R. Asif und seinen technischen Assistentinnen möchte ich mich für die Durchführung der massenspektrometrischen Analysen bedanken und ihre freundliche Hilfe, wenn beim Gießen der 2D-Gele zum wiederholten Male der Wasserspiegel absank. Auch bei Darinka Petrova bedanke ich mich für die Zeit, die sie sich genommen hat, um mir die Auswertung mit der Decodon Software zu erklären.

Ich danke Joanna Gawinecka und Matthias Schmitz für ihre Unterstützung in kleinen, aber doch entscheidenden Laborfragen, wo sie mir jedererzeit hilfsbereit zur Seite standen und mir mit interessanten Gesprächen manche Wartezeit versüßten. 